\title{
SILMARA MENEGUIN
}

Avaliação de como os sujeitos da pesquisa entendem a sua participação em ensaios clínicos num hospital terciário

Tese apresentada à Faculdade de Medicina da Universidade de São Paulo para obtenção do título de Doutor em Ciências

Área de concentração: Cardiologia

Orientador: Prof. Dr. Luiz Antônio Machado César

\section{SÃO PAULO}

2009 


\section{DEDICATÓRIA}

Aos meus pais

Por terem me dado a vida e pelo que sou hoje. Por me ensinarem a vivê-la com dignidade e honestidade. Que se doaram por inteiro e renunciaram muitas vezes dos seus sonhos para que os meus fossem realizados. Por confiarem nas minhas escolhas e compartilharem dos meus sonhos. Pela compreensão do meu distanciamento durante esses anos. Pelo carinho, meu mais profundo respeito e amor. 


\section{AGRADECIMENTOS}

Ao meu orientador, Prof. Dr. Luiz Antônio Machado César, por ter aceitado o desafio de conduzir esta tese, pela confiança, disponibilidade, amizade, respeito, por todos os recursos viabilizados para que este trabalho pudesse ser realizado, e por ter me incentivado e apoiado a buscar, no exterior, uma experiência nesta área que ainda não temos no país.

Ao Prof. Dr. Diego Gracia, da Universidade Complutense de Madri, com que tive o prazer de conviver durante alguns meses, pelos ensinamentos e oportunidade de crescimento.

À D. Jurema da Silva Herbas Palomo, pelo exemplo de competência e profissionalismo, pela credibilidade e concessão do afastamento que viabilizou meu estágio na Espanha.

À Prof. Dra. Elma Lourdes Campos Pavone Zoboli, pela atenção dispensada desde o início deste trabalho e pelas sugestões na banca de qualificação.

Ao Prof. Dr. Moacyr Roberto Cuce Nobre, pelas inúmeras contribuições ao longo da realização deste estudo.

À Prof. Dra. Maria de Lourdes da Silva M. Ferreira, da UNESP de Botucatu, pela amizade e inestimável auxílio na análise dos dados qualitativos.

À querida amiga Dra. Claudia Stella, por me apoiar e dividir comigo as incertezas dessa caminhada e também pelas 
valiosas contribuições durante a metodologia de análise qualitativa.

À Rachel Zanetta de Lima Domingues pela realização do grupo focal, pelas sugestões e atenção dispensada a este trabalho.

À Equipe da Coordenação de Enfermagem e do Serviço de Educação, pela convivência diária e por todo auxílio durante este período.

Ao casal de amigos Sérgio e Antônia, pelo apoio irrestrito durante estes anos de convivência e por todo auxílio dispensado.

Ao meu irmão Eduardo, pela colaboração na realização dos gráficos.

À minha irmã Silvia Helena, pela paciência e compreensão nos momentos de dificuldade .

Às colegas da pós graduação $\mathcal{N} e u s a$ Rodrigues Dini, Juliana Lattari Sobrinho e Eva Guiss de Oliveira pelo apoio, estímulo e amizade.

À Elisabete Forte, pela inestimável colaboração, disponibilidade e apoio ao longo deste trabalho, principalmente nos momentos mais difíceis.

À Júlia Tizue Fuķushima, pela eficiente consultoria estatística e interesse pelo trabalho.

À Silvia Regina Garrub6o, pelo profissionalismo, amizade e cooperação. 
À Meyrielli Alves Vieira Rodrigues de Almeida, pelo carinho, amizade, cooperação e boa vontade.

Ao casal de amigos Solange e Roberto, pelo carinho durante o período que estive na Espanha e por já fazerem parte da nossa família.

Aos amigos não mencionados, mas muito presentes que compartilharam as dificuldades, alegrias e me auxiliaram nos momentos que mais críticos.

Aos pacientes, que compartilharam comigo suas experiências e representam o elemento primordial para realização do estudo, os meus mais sinceros agradecimentos.

A Deus, que esteve todos os momentos ao meu lado me confortando e me sustentando diante de tantas dificuldades enfrentadas durante a realização desta tese.

Ao Banco Santander, pelo apoio financeiro dispensado ao Programa de Mobilidade Internacional Santander/USP viabilizando a realização do estágio na Espanha.

A todos aqueles que, de forma direta ou indireta, contribuíram para realização deste estudo.

A todos, Muito Obrigada! 


\section{SUMÁRIO}

LISTA DE QUADROS

LISTA DE TABELAS

LISTA DE FIGURAS

RESUMO

SUMMARY

1. INTRODUÇÃO.............................................................................. 1

1.1. Ética da Investigação Clínica..................................................... 6

1.2. Termo de Consentimento Livre e Esclarecido.............................. 13

1.3. Problemas éticos em investigação clínica................................. 16

2. OBJETIVOS ........................................................................................... 21

2.1. Objetivo Primário.................................................................... 22

2.2. Objetivo Secundário........................................................ 22

3. MÉTODOS............................................................................... 23

31. Ética da Investigação Clínica.................................................. 24

3.2. Local do estudo............................................................... 24

3.3. Casuística.............................................................................. 25

3.4. Coleta de dados......................................................... 28

3.4.1. Instrumento para coleta de dados...................................... 28

3.4.2. Procedimento para coleta de dados..................................... 29

3.5. Análise estatística........................................................... 34

3.6. Análise qualitativa........................................................... 35

3.7. Grupo Focal.................................................................. 37

3.7.1. Procedimentos operacionais no uso da técnica de grupo focal. 37

3.7.2. Procedimentos para coleta dos dados................................ 40

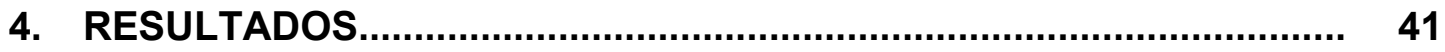

4.1. Diagrama dos pacientes selecionados para o estudo.................. 43

4.2. Perfil sócio-demográfico da amostra..................................... 44

4.3. Informações acerca da participação no ensaio clínico.................... 49

4.4. Dados relacionados ao Termo de Consentimento Livre e Esclarecido como documento em si 
4.5. Dados sobre o impacto da participação na pesquisa

4.6. Associação entre as questões e as variáveis quantitativas e classificatórias

4.7. Descrição das respostas que ancoraram as unidades temáticas.... 83

4.7.1. Entendimento do significado do termo placebo...................... 83

4.7.2. Importância atribuída à participação na pesquisa.................... 84

4.7.3. Informação a respeito do convite a um amigo ou parente para participar de uma pesquisa.

4.7.4. Pontos negativos identificados na análise das respostas.

4.8. Descrição do grupo focal.

90

4.8.1. Diagrama dos pacientes que participaram do grupo focal........ 90

4.8.2. Perfil da amostra do grupo focal.................................... 90

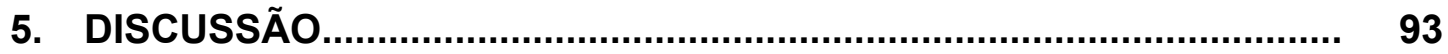

5.1. As características da população estudada................................ 94

5.2. Informações acerca da participação na pesquisa......................... 99

5.3. Dados relacionados ao Termo de Consentimento Livre e Esclarecido como documento em si

5.4. Considerações a respeito do termo placebo.

5.5. Dados sobre o impacto da participação na pesquisa.

5.6. Grupo focal.

5.6.1. Percepção na pesquisa.

5.6.2. Compreensão do Termo de Consentimento Livre e Esclarecido.

5.6.3. Entendimento do significado do placebo.

6. COMENTÁRIOS E PERSPECTIVAS.

7 CONCLUSÕES.

8. ANEXOS

8.1. Instrumento para Coleta de dados.

8.2. Aprovação do projeto de pesquisa pela Comissão de Ética para Análise de Projetos de Pesquisa - CAPPesq.

8.3. Termo de Consentimento Livre e Esclarecido. 
8.4. Transcrição da Gravação do Grupo Focal - Grupo I..................... 142

8.5. Transcrição da Gravação do Grupo Focal - Grupo II................... 157

9. REFERÊNCIAS BIBLIOGRÁFICAS................................................ 169 


\section{LISTA DE QUADROS}

Pág.

Quadro 1. Perfil de desenvolvimento dos ensaios clínicos utilizados no grupo I e II............................................................... 32

Quadro 2. Roteiro das questões norteadoras para o grupo focal........... 39

Quadro 3. Descrição das temáticas, categorias e sub-categorias identificadas na análise das transcrições do grupo focal, segundo os grupos I e II 


\section{LISTA DE TABELAS}

Pág.

Tabela 1. Distribuição da amostra quanto à idade e tempo de seguimento na instituição

Tabela 2. Distribuição da amostra segundo as características sócio demográficas dos sujeitos da pesquisa nos grupos I e II......

Tabela 3. Distribuição das ocupações dos sujeitos de pesquisa dos grupos I e II

Tabela 4. Distribuição da amostra estudada segundo o motivo que determinou a participação do paciente na pesquisa.

Tabela 5. Freqüência absoluta e percentual dos esclarecimentos realizados pelo pesquisador a respeito das informações contidas no TCLE, segundo resposta dos sujeitos.

Tabela 6. Distribuição dos dados a respeito de se os pacientes leram e assinaram o Termo de Consentimento Livre e Esclarecido, antes de participar da pesquisa

Tabela 7. Distribuição dos entrevistados, segundo menção de discutir o TCLE com o pesquisador.

Tabela 8. Distribuição dos entrevistados, quanto a ter entendido o conteúdo do TCLE quando o assinou.

Tabela 9. Menção de como procederam aqueles que não entenderam o conteúdo do TCLE.

Tabela 10. Distribuição da amostra estudada segundo informação se recebeu uma cópia do TCLE.

Tabela 11. Entendimento dos entrevistados a respeito do significado do termo placebo.

Tabela 12. Distribuição das categorias à pergunta temática a respeito do entendimento do termo placebo, em ambos os grupos.....

Tabela 13. Distribuição das categorias à pergunta temática relacionada ao entendimento do significado do termo placebo, segundo os grupos

Tabela 14. Distribuição das categorias à pergunta temática relacionada ao significado do termo placebo, segundo as respostas afirmativas em ambos os grupos 
Tabela 15. Distribuição das categorias à pergunta temática relacionada ao significado do termo placebo, segundo as respostas negativas.

Tabela 16. Freqüência dos entrevistados que afirmaram ter conhecimento de que poderiam tomar um comprimido sem nenhum efeito durante alguns meses

Tabela 17. Relato dos entrevistados a respeito da participação em uma pesquisa semelhante, caso fosse convidado.

Tabela 18. Distribuição dos sujeitos, quanto a se pensou em abandonar a pesquisa

Tabela 19. Motivos que levaram os entrevistados a pensar em abandonar a pesquisa.

Tabela 20. Distribuição da amostra estudada segundo o motivo pelo qual não informou que gostaria de desistir da pesquisa.

Tabela 21. Distribuição dos entrevistados, segundo a importância atribuída em participar de uma pesquisa

Tabela 22. Distribuição das categorias à pergunta temática relacionadas à importância em participar de uma pesquisa.

Tabela 23. Distribuição das categorias mais freqüentes relacionadas à importância em participar de uma pesquisa clínica, segundo os grupos

Tabela 24. Distribuição das categorias à pergunta temática relacionada à importância na participação em uma pesquisa, segundo as respostas afirmativas e negativas em ambos os grupos.

Tabela 25. Posição a respeito de convidar um amigou ou parente para participar de uma pesquisa

Tabela 26. Distribuição das categorias à pergunta temática no que se refere à indicação de um amigo ou parente para participar de uma pesquisa.

Tabela 27. Distribuição das categorias à pergunta temática no que se refere à indicação de um amigo ou parente para participar de uma pesquisa, segundo os grupos 
Tabela 28. Distribuição das categorias à pergunta temática no que se refere à indicação de um amigo ou parente para participar de uma pesquisa, segundo as respostas afirmativas e negativas em ambos os grupos...

Tabela 29. Distribuição da idade, sexo, escolaridade, companheiro e atividade profissional segundo leitura do TCLE antes da assinatura.

Tabela 30. Descrição da idade, sexo, escolaridade, companheiro, atividade profissional e participação até o final do estudo, segundo informação a respeito de conversa sobre o TCLE.

Tabela 31. Distribuição da idade, sexo, escolaridade, companheiro, atividade profissional e participação até o final do estudo segundo entendimento do TCLE quando assinou.

Tabela 32. Entendimento do significado do termo placebo, segundo idade, sexo, escolaridade, ocupação e informação de quem o convidou para participar da pesquisa.

Tabela 33. Distribuição da idade, sexo, escolaridade, companheiro, atividade profissional e informação de que poderia tomar um comprimido sem nenhum efeito durante alguns meses.

Tabela 34. Distribuição da amostra do grupo focal quanto à idade e tempo de seguimento na instituição.

Tabela 35. Distribuição da amostra do grupo focal quanto ao sexo e escolaridade. 


\section{LISTA DE FIGURAS}

Pág.

Figura 1. Distribuição da amostra segundo estudo no qual participou.. 45

Figura 2. Distribuição dos sujeitos de pesquisa, segundo ano de inclusão nos ensaios clínicos.

Figura 3. Distribuição dos entrevistados sobre se sua participação no ensaio clínico foi até o final.

Figura 4. Distribuição dos entrevistados, segundo informação de quem os convidou para participar da pesquisa

Figura 5. Modo de contato utilizado para convidar o paciente para participar da pesquisa

Figura 6. Menção feita pelos pacientes, quanto a se foi informado no momento do contato que o objetivo era a participação em uma pesquisa.

Figura 7. Associação entre companheiro dos sujeitos da pesquisa e leitura do termo de consentimento antes de assinar.

Figura 8. Associação entre o nível de escolaridade dos sujeitos da pesquisa e conversar sobre o termo com pesquisador.

Figura 9. Associação entre o nível de escolaridade dos sujeitos da pesquisa e o entendimento do significado do placebo

Figura 10. Associação entre o nível de escolaridade dos sujeitos da pesquisa e se sabiam que poderiam tomar um comprimido sem nenhum efeito durante três meses 


\section{RESUMO}

Meneguin S. Avaliação de como os sujeitos da pesquisa entendem a sua participação em ensaios clínicos num hospital terciário [tese]. São Paulo: Faculdade de Medicina, Universidade de São Paulo; 2009. 189p.

INTRODUÇÃO: Em ensaios clínicos o termo de consentimento livre e esclarecido é fundamental para a preservação da ética na pesquisa clínica e precisa ser lido e assinado pelos pacientes. No entanto, dada a sua complexidade este documento pode não ser entendido pelos mesmos. Para avaliar o entendimento destes sobre a pesquisa realizamos esta investigação. MÉTODOS: Convidamos os sujeitos participantes de ensaios clínicos de hipertensão arterial sistêmica e doença arterial coronária, fase II, III ou IV ambulatoriais e com fármacos, de jan/2002 a dez/2006, para responder questionário estruturado com 29 questões. Estes foram divididos em dois grupos, com uso (grupo I) ou não (grupo II) de placebo, após a randomização. Ao final, 80 pacientes compareceram de 106. Doutros 26 sujeitos, sete se recusaram, nove não foram localizados, oito foram excluídos e dois faleceram. As variáveis de cada questão foram consideradas por freqüência de ocorrência. A comparação entre as médias dos grupos foi realizada pelos testes $t$ de Student ou Wilcoxon. Para avaliar associações utilizou-se o Qui-Quadrado, o teste de Razão de Verossimilhança ou Fisher. Para confirmar as informações, realizou-se também o grupo focal, tendo participado 8 do grupo I e 11 do grupo II. RESULTADOS: Avaliamos 80 sujeitos (grupo I- 47, grupo II- 33). As características sócio demográficas foram similares em ambos. Quanto à motivação para participar da pesquisa, 66,2\% atribuíram-na ao benefício próprio, $42,5 \%$ pelo bem da ciência, e atendendo ao pedido médico $25,0 \%$, em ambos os grupos. Quanto ao termo de consentimento livre e esclarecido, $50 \%$ não entenderam o seu conteúdo e $32,9 \%$ sequer o leram, mas o assinaram. No grupo I, 66,7\% dos sujeitos não entenderam o significado de placebo e dos que afirmaram ter entendido $(n=23)$ somente doze de fato comprovam o entendimento correto. Foram realizadas associações entre o não entender o significado do termo placebo com as variáveis de interesse para o estudo, e encontramos forte correlação com a escolaridade $(p=0,022)$, evidenciando que quanto menor o nível de instrução menor também $O$ entendimento. Houve também tendência entre ter um companheiro e ler o termo de consentimento livre e esclarecido antes de 
assinar ( $p=0,052)$, e o nível de escolaridade dos sujeitos e conversar sobre o termo de consentimento livre e esclarecido com o pesquisador $(p=0,053)$. No que tange ao grupo focal, este corroborou os resultados e evidenciou que $o$ termo de consentimento livre e esclarecido é considerado difícil pelos pacientes, porém a compreensão é favorecida pela equipe que complementa as informações de maneira clara e dispensa a leitura em virtude do vínculo de confiança estabelecido com esta. CONCLUSÕES: O termo de consentimento livre e esclarecido é pouco compreendido pelos sujeitos e para alguns a confiança no seu médico é crucial para a sua decisão em participar de um ensaio clínico com fármaco; evidenciou-se também influência do nível de instrução dos sujeitos no entendimento do termo placebo. Por outro lado, não houve repercussão na vida dos sujeitos em participar de ensaios clínicos com ou sem placebo, uma vez que a maior motivação para participar é pela expectativa do benefício terapêutico.

Descritores: 1.Ensaio clínico 2.Consentimento esclarecido 3.Compreensão 4.Bioética. 


\section{SUMMARY}

Meneguin S. Assessment of how the subjects understand their participation in clinical trials in a tertiary care hospital [thesis]. São Paulo: "Faculdade de Medicina, Universidade de São Paulo"; 2009.189p.

INTRODUCTION: To participate in a clinical trial patients have to sign an informed consent, often with misinterpretation words. Herein we addressed the issue of what do patients understand about the informed consent. METHODS: Patients that have participated in clinical trials in our institution were invited to an interview. From a data bank, between 2002 to 2006, patients were contacted by phone call. The questionnaire patients were submitted to was composed of 29 questions. To confirm some data, we did a second interview using the focal technique. Patients were allocated in two groups: Group 1- those that could have taken placebo for the treatment of their illness after a randomization, Group 2- those that did not take placebo during the treatment period but could have taken during the wash-out period. Statistics: were done with the $t$-Student test, or the Wilcoxon test. To evaluate associations we used the Qui-Square, Similarity test or the Fisher test and we considered a $p$ value of 0,05 . RESULTS: 80 patients, $60(75 \%)$ males, age (average in years \pm SD) of $58.8 \pm 9.2 ; 47$ in group $1(58.3 \pm 9.0)$ and 33 in group $2(59.4 \pm 9.8)$. Except for the job situation, both groups were similar. Of notice is the number of patients that were illiterate or have not completed the primary school. The most quoted motivation to participate was in their own benefit $(66.2 \%)$, and second to the interest of science $(42.5 \%)$. It is noteworthy that $50 \%$ of patients did not understand the informed consent but even in this case they did sign it. $66 \%$ did not understand the meaning of placebo that was correlated to the patients' level of education $(p=0.02)$. Also, $36.2 \%$ of patients in group-I were not aware they could have taken tablets with no effect. In 19 patients (eight in group I and 11 in group II) submitted to the focal technique interview, what came out as the more important to their decision making to participate or not in a clinical trial, was the opinion of their assistant doctor. This was stood by almost all (90\%) patients in this second interview. CONCLUSION: The informed consent was poorly understood, and for some patients the trust in their assistant doctors is crucial for their agreement to participate in a trial. This raised concerns about long and boring informed consent, and also how important are doctors' words in the decision making of patients, probably due to their education level. 
Descriptors: 1.Clinical trials 2.Informed consent 3.Comprehension 4.Bioethics 


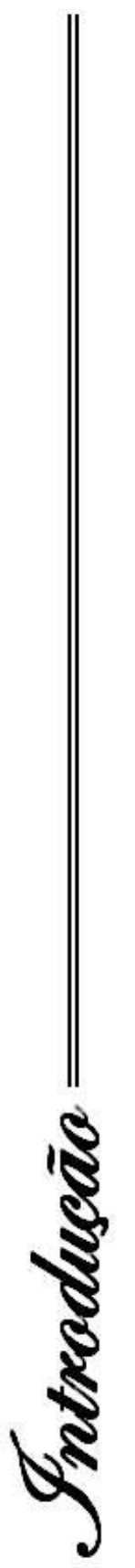




\section{INTRODUÇÃO}

As pesquisas clínicas utilizando a participação de seres humanos na avaliação de novos fármacos e procedimentos continuam sendo indispensáveis antes que os mesmos sejam disponibilizados para comercialização.

Apesar dos avanços científicos e tecnológicos ocorridos nas últimas décadas, os experimentos obtidos a partir dos testes em animais de laboratório não podem ser considerados seguros para a espécie humana, dado seu escasso valor preditivo ${ }^{1}$.

Tal fato justifica a investigação sistemática por meio de ensaios clínicos, que atendem à necessidade de oferecer maior transparência para alcançar a valorização de novas e estabelecidas terapias ${ }^{2}$.

De acordo com a International Conference on Harmonisation of Technical Requirements for Registration of Pharmaceutical for Human Use $(\mathrm{ICH})^{3}$, ensaio clínico é qualquer investigação experimental em seres humanos voltada para a descoberta dos efeitos clínicos, farmacológicos e/ou farmacodinâmicos de um produto sob investigação, e/ou identificar suas 
reações adversas e efeitos secundários com o objetivo de determinar sua segurança e eficácia.

Não obstante, quando um fármaco supera com êxito a investigação em animais, o que implica fundamentalmente em provas de farmacocinética e de toxicidade adequadas ao tipo de fármaco e via de administração, é que se inicia a investigação em seres humanos ${ }^{4}$.

Por convenção internacional, divide-se o desenvolvimento clínico de um novo fármaco em quatro fases seqüenciais, sendo que as três primeiras são prévias à comercialização do produto.

De acordo com a resolução CNS/MS $251 / 97^{5}$, nos estudos de fase I busca-se avaliar a tolerância/segurança do fármaco em um número restrito de voluntários sadios.

Já os estudos de fase II procuram demonstrar a atividade e estabelecer a segurança, a curto prazo, do fármaco, em pacientes afetados por uma determinada condição patológica ${ }^{5}$.

No que concerne aos estudos de fase III, são ensaios randomizados e realizados em grandes e variados grupos de pacientes, para testar a hipótese de que o tratamento melhora a condição-alvo ou reduz o risco do indivíduo desenvolver uma doença ou um evento relacionado à doença, com nível aceitável de segurança. Explora-se nessa fase o tipo e perfil das reações adversas mais freqüentes ${ }^{6}$.

Os estudos de fase IV são pesquisas realizadas após a comercialização do produto, empreendidas para análise do surgimento de novas reações adversas e/ou confirmação da freqüência das reações já 
conhecidas, bem como para as novas estratégias de tratamento. Esses estudos, na sua grande maioria, são conduzidos e patrocinados pela indústria farmacêutica com o objetivo de avaliar a incidência de efeitos colaterais graves em uma população maior ${ }^{5,6}$.

No que tange à resposta de um paciente, uma intervenção farmacológica é o resultado da intervenção de quatro componentes: efeito farmacodinâmico, efeito inespecífico devido ao medicamento, efeito inespecífico devido ao médico, efeito de regressão à média ${ }^{7}$. Este último efeito consiste na evolução natural da própria enfermidade, pois qualquer parâmetro que apresente variações em seus valores com o tempo tende a regressar a um valor médio ${ }^{8,9}$.

No entanto, é difícil precisar em que proporção cada um participa, inclusive porque o efeito de alguns deles poderá ser nulo. Cabe salientar que os últimos três efeitos constituem o chamado efeito placebo, que de alguma maneira proporciona algum benefício aparente, permitindo avaliar a resposta a uma intervenção farmacológica, discriminando o efeito farmacodinâmico do efeito placebo ${ }^{7,10}$. De uma maneira mais direta o efeito placebo pode ser considerado uma alteração favorável que ocorre no curso da doença de um paciente e é atribuída ao caráter simbólico da intervenção curativa ${ }^{8}$.

Já o efeito nocebo, considerado efeito oposto ao placebo ${ }^{11,12}$, representa um dano percebido pelo paciente ${ }^{10}$ e abarca as reações adversas associadas com substâncias inertes, inclusive os efeitos psicológicos negativos que podem acompanhar tratamentos medicamentosos ${ }^{8}$. 
A utilização do placebo no delineamento de um ensaio clínico pode ser atribuída ao fato de que quando um estudo compara o novo fármaco em estudo com placebo acaba possuindo uma característica especial que o torna metodologicamente superior aos outros delineamentos ${ }^{13}$.

Os ensaios clínicos constituem atualmente uma atividade totalmente globalizada e em sua a maioria financiada pela indústria farmacêutica ${ }^{14,15}$. Segundo a ANVISA, no período de 2003 a março de 2006 foram aprovados 564 estudos, sendo $64 \%$ patrocinados diretamente pela indústria farmacêutica, 31\% por CROs (Organizações Representativas de Pesquisa Clínica - ORPC's para a ANVISA) e $5 \%$ pelas Universidades/Fundações ${ }^{16}$. Dos estudos patrocinados pela indústria farmacêutica, 95\% foram por multinacionais, refletindo o caráter majoritário dos ensaios clínicos patrocinados por estas empresas no âmbito nacional ${ }^{17}$.

Estas pesquisas multicêntricas e internacionais suscitam muitas questões éticas, pois os investigadores ou patrocinadores são de um país desenvolvido ou de uma grande companhia farmacêutica e o ensaio clínico é conduzido em um país em desenvolvimento, o que torna os sujeitos mais vulneráveis à exploração ${ }^{18,19,20}$.

Para Macklin ${ }^{18}$ há duas preocupações éticas importantes neste tipo de pesquisa. A primeira remete ao fato de que os sujeitos são vulneráveis em virtude do baixo nível de escolaridade ou falta de familiaridade com termos científicos. Além disso, há a condição de pobreza e fragilidade que os tornam suscetíveis a alguma forma de exploração. Já a segunda 
preocupação é que um grande número de pessoas nestes países não possui acesso a bons serviços de saúde e, eventualmente, acesso a nenhum.

Partindo-se desta premissa há que se considerar que em todas as pesquisas envolvendo seres humanos, ética e ciência são inseparáveis. $O$ uso de um bom delineamento da pesquisa e aderência a princípios éticos deve resultar na condução de uma pesquisa que é valida, confiável e eticamente aceitável em qualquer país ${ }^{21}$.

O principio fundamental que deve nortear a realização de todo ensaio clínico é a necessidade de uma investigação que beneficie o paciente e a comunidade, e a condição de que toda investigação será humanitária, cientificamente útil e eticamente aceitável ${ }^{1}$.

Apesar das diferenças, qualquer ensaio clínico deve seguir uma série de normas éticas e a uma legislação específica, que é diferente em cada país, ainda que em termos gerais sejam similares.

\section{1. Ética da Investigação Clínica}

Para Gracia, clinica é toda ação realizada sobre o corpo humano com o objetivo de melhorar o conhecimento e o manejo das enfermidades. No entanto, quando o propósito desta ação é diagnosticar e tratar fala-se em prática clinica; quando o objetivo é o conhecimento de um meio diagnóstico ou terapêutico estamos frente a uma ação que corresponde a uma investigação clinica ${ }^{22}$. 
Embora grande parte do progresso da medicina se apóie na investigação clínica, os limites éticos na realização e condução destas pesquisas são tênues ${ }^{23}$ e os experimentos clássicos com seres humanos pautados em três condições: marginalização dos afetados, falta de consentimento e ausência de critérios objetivos de ponderação de riscos e benefícios $^{22}$.

Frente a estas condições tem-se elaborado um novo tipo de atitude denominada ética da investigação clínica; podemos dividi-la em três grandes períodos $^{22}$.

O primeiro, que abarca desde a antiguidade até o ano de 1900, foi marcado por uma ética guiada pelo principio da beneficência, ou seja, a intervenção sobre o corpo humano somente era justificada se houvesse um benefício. A intervenção com o propósito de conhecer somente era permitida em animais, cadáveres e, durante algumas épocas e sob certas condições, em condenados à morte. Outra tese marcante neste período foi uma lógica para aquisição do conhecimento médico que primava pelas experiências pessoais e se fiava plenamente no princípio da analogia, ou seja, resultados observados em animais eram aplicados a seres humanos. Nesta época, o conhecimento resultante das experiências era subjetivo e baseado em opiniões, especialmente autorizadas. ${ }^{22,24}$.

O segundo período se inicia em 1900 e vai até 1947. É considerado o período do experimento moderno e nele se opera uma mudança radical na concepção lógica e ética da investigação clínica, que tem como princípio o respeito à autonomia dos sujeitos da pesquisa ${ }^{22,24}$. 
Pouco a pouco os dados objetivos começam a ganhar confiança através de observações sistemáticas e se toma consciência de que as observações individuais estão expostas a numerosos erros; propõem-se então o desenho experimental. As observações passam a ser controladas e sistematizadas e surgem os diferentes desenhos de investigação com a intenção de aproximá-los ao máximo possível das melhores condições de comparabilidade. Por fim, alcança-se o refinamento de todo este processo da origem ao ensaio clínico controlado e aleatorizado, justamente conhecido como o paradigma da investigação clínica ${ }^{22}$.

Prática clínica e investigação clínica começam a caminhar muito unidas e o princípio da analogia entra em crise. Na tentativa de conter os abusos da experimentação humana, o Ministério do Interior Alemão promulga, em 1931, um protocolo de comportamento ético dos investigadores e o primeiro código de ética de investigação do mundo, que exigia dos sujeitos da pesquisa seu consentimento ${ }^{25}$.

Apesar da importância atribuída à autonomia dos sujeitos da pesquisa nesta fase da investigação clínica, os experimentos realizados nos campos de concentração na Alemanha foram, como seria de se imaginar, sem consentimento e sem conhecimento das verdadeiras vítimas que foram seus participantes.

A partir do julgamento dos abusos cometidos neste período por oficiais nazistas e médicos que tinham desrespeitado cruelmente os direitos humanos de prisioneiros de guerra, foi promulgado, em 1947/48, o Código de Nuremberg, com dez itens que regulamentam a pesquisa com seres 
humanos e insere o consentimento voluntário, como expressão de autonomia do sujeito de pesquisa $a^{22,26,27,28}$.

Efetivamente, com o Código de Nuremberg tem início o terceiro período, iniciado em 1947 e presente até os nossos dias ${ }^{22,24}$.

Cabe salientar que, embora Nuremberg tenha sido o primeiro código de ética internacional, em nenhum momento pensou-se em traduzi-lo em legislações nacionais mais específicas ${ }^{22}$. No seu início, a idéia de que os conflitos científicos se autorregulariam, tendo como pressuposto os abusos ocorridos dos campos de concentração, foi equivocada. Embora amplamente difundido em todo o mundo, os seus requisitos eram considerados exagerados pelos investigadores, principalmente sua exigência tão contundente do consentimento informado. $\mathrm{Na}$ verdade, era visto como uma referência direta às condições de realização dos experimentos nazistas e não aplicável aos países "democráticos"26.

Outro fator a ser considerado no período pós-guerra diz respeito ao aumento dos orçamentos destinados à pesquisa, contribuindo para que os setores de ponta, como o agroalimentar, informática e a biomédica tivessem um desenvolvimento considerável. As descobertas científicas provenientes da biomédica foram rapidamente aplicáveis aos humanos, permitindo prolongar e manter a vida de um modo que jamais havia sido possível anteriormente $^{29}$. No entanto, algumas dessas pesquisas deram origem a vários escândalos que indignaram o meio científico e a opinião pública.

Um dos primeiros relatos ocorreu em 1962, com o nascimento de várias crianças afetadas por má-formações congênitas, como a falta de 
membros decorrente da ingestão da talidomida pela mãe, durante a gestação. Cabe esclarecer que esse medicamento foi testado em pessoas que não sabiam que estavam participando de uma pesquisa clínica e sem aprovação pelo FDA ${ }^{30}$.

A crise da talidomida foi um sinal de alerta quanto aos abusos que estavam ocorrendo e iniciou o processo de desenvolvimento da atual ética de investigação ${ }^{26}$.

Outros escândalos surgiram - desde o Projeto Tuskegee de 1972, patrocinado pelo Serviço de Saúde Pública Norte-americano, deixando morrer indivíduos com evolução natural de sífilis mesmo quando já havia se comprovado a cura com penicilina, ao estudo do Jewish Chronic Disease Hospital, que consistiu na injeção subcutânea de células cancerosas em idosos sem consentimento, e o Willowbrook State School, que, com o intuito de descobrir uma vacina, fez injeções de vírus de um tipo de hepatite em crianças com deficiência mental, com consentimento por escrito dos pais $^{22,27,31,32}$

Mais recentemente, destacam-se na literatura as pesquisas realizadas na África do Sul e outros países em desenvolvimento, utilizando placebo para tratamento de mulheres grávidas infectadas pelo HIV e a morte trágica de duas jovens voluntárias que participavam de um estudo de asma e de transferência genética nos Estados Unidos ${ }^{27,33,34,35,36}$.

Face aos abusos ocorridos na investigação com seres humanos, a Associação Médica Mundial começou a considerar imprescindível um novo código de ética internacional desvinculado do contexto nazista e situado no 
âmbito da investigação médica contemporânea ${ }^{26}$. Após longos debates, na XVIII Assembléia Mundial de Médicos em Helsinque, em 1964, aprovou-se a “Declaração de Helsinque”, com sua última versão aprovada e revisada em $2000^{37,38,39}$.

Dentre as exigências contempladas por Helsinque, duas tiveram grande importância histórica no controle de experiências em seres humanos: a exigência do consentimento informado dos sujeitos e a avaliação ética do protocolo de pesquisa por um comitê de ética independente do pesquisador $^{40}$. Esta declaração também contribuiu para instituir os postulados éticos da integridade moral e responsabilidade do médico, além de ser um ponto de apoio para as legislações nacionais que começaram a ser desenvolvidas a respeito do tema ${ }^{26}$.

No entanto, apesar de todos os esforços para assegurar a qualidade de padrões éticos na pesquisa com seres humanos, a discussão retorna à evidência em 1974, quando o governo americano institui a comissão nacional para a proteção dos seres humanos em pesquisa biomédica e de comportamento, com o propósito principal de identificar os princípios éticos básicos que deveriam nortear a investigação em seres humanos e desenvolver diretrizes que assegurassem a condução de pesquisas pautadas nestes princípios. Esta comissão publica em 1978 o Relatório Belmont, o qual incorporava três princípios básicos que passaram a ser o tripé da pesquisa com seres humanos: autonomia, beneficência e justiça ${ }^{41}$.

No ano seguinte, Beauchamp \& Childress introduzem uma posterior modificação, acrescentando-se aos três princípios já estabelecidos o de não 
maleficiência, e que passaram a nortear as condutas inerentes à ética biomédica $^{42}$.

Estes princípios também foram incorporados às diretrizes da resolução CNS/MS 196/96, que regulamenta a pesquisa com seres humanos (em âmbito nacional) nas várias áreas do conhecimento e, em seu ítem III, são destacados explicitamente os princípios de respeito à autonomia, beneficência, não-maleficência e justiça ao sujeito de pesquisa ${ }^{43}$.

Estes princípios também passaram a nortear a elaboração do Termo de Consentimento Livre e Esclarecido (TCLE), que deve ser um processo compartilhado de troca de informações, que se amalgama ao trabalho da assistência à saúde e se insere no bojo da relação vincular entre os profissionais e usuários dos serviços ${ }^{44}$.

Embora o consentimento informado seja um item necessário à pesquisa, não é suficiente para assegurar sua dimensão ética ${ }^{45}$. Na ótica de Emanuel et al. ${ }^{45}$, a avaliação ética de um ensaio clinico é mais abrangente e deve ser realizada levando-se em consideração os seguintes requisitos: valor da pesquisa, validade científica, seleção justa dos sujeitos, proporção favorável de risco-benefício, revisão por um comitê de ética independente, consentimento informado e respeito aos sujeitos incluídos na pesquisa. Estes itens, além de elucidarem padrões éticos específicos para condução da pesquisa clínica, assumem outras obrigações éticas como a honestidade e responsabilidade intelectual do pesquisador.

Neste particular, a contribuição do Council for International Organizations of Medical Sciences (CIOMS), em parceria com a 
Organização Mundial de Saúde (WHO), e do National Institutes of Health (NIH), tem se constituído na elaboração de "guidelines" para assegurar a ética na realização de pesquisas biomédicas com seres humanos ${ }^{46,47}$.

\subsection{Termo de Consentimento Livre e Esclarecido}

O TCLE é um conceito que evolui com o tempo até tornar-se o elemento fundamental da relação medico-paciente, uma vez superada a clássica concepção da beneficência paternalista que comandava a ética dos médicos hipocráticos ${ }^{48,49}$.

As legislações reguladoras dos direitos das pessoas, no âmbito da saúde, têm outorgado um protagonismo crescente dos pacientes na tomada de decisão, de modo que os profissionais, apesar dos conhecimentos e da competência técnica, devem ser capazes de ajudar os pacientes a compreender a situação em que se encontram para que possam decidir de maneira autônoma ${ }^{48}$

Para Faden e Beauchamp, apud Gracia, as ações são consideradas autônomas quando cumprem três condições: intencionalidade (capacidade de ação intencional), conhecimento (se o sujeito não entende a ação não pode ser considerada autônoma) e ausência de controles externos (coerção, manipulação e persuasão ${ }^{50}$.

$\mathrm{Na}$ investigação clínica, a operacionalização do principio da autonomia se realiza mediante aplicação TCLE. 
Uma definição de TCLE para pesquisa clínica que contemple todos os aspectos relevantes do processo torna sua descrição um tanto complexa, em virtude da diversidade de conceitos na literatura ${ }^{51}$. Na prática, consiste na aceitação de uma intervenção médica experimental por um paciente, de forma livre, voluntária e consciente após o esclarecimento de todos os riscos e benefícios da pesquisa, alternativas de tratamento, e finalmente a liberdade de não participar ou desistir sem prejuízo para continuidade do tratamento na instituição.

Para Beauchamp e Childress ${ }^{52}$ o TCLE é constituído de dois componentes: o informativo e o de consentimento. $\mathrm{O}$ componente informativo consiste na exposição da informação e que esta deverá ser compreendida pelo sujeito. Já o consentimento remete à decisão voluntária do sujeito de submeter-se ou não a uma intervenção proposta.

$\mathrm{Na}$ concepção de $\operatorname{Lorda}^{49,53}$, em todos os casos os elementos normativos do consentimento compreendem:

1. Um processo contínuo de comunicação, deliberativo, prudencial e que em todas as ocasiões requer apoio escrito e deve ser registrado de maneira adequada. Pensar no consentimento informado como um momento isolado da relação clínica, centrado em um formulário de consentimento tendo em vista a obtenção de uma assinatura é um equivoco do ponto de vista ético e legal ${ }^{49,53}$.

2. Voluntariedade como condição necessária e suficiente para que os atos pudessem ser considerados autônomos ${ }^{52}$. É considerada fator para um processo livre de coações, manipulações e persuasão. O grande 
problema de ordem prática está em determinar quando termina a persuasão e começa a coerção ou a manipulação. Isto, no entanto, é algo que somente a prudência e a honestidade de cada profissional podem determinar em função das circunstâncias de cada situação ${ }^{49,53}$.

3. Informação suficiente. Do ponto de vista ético, parece lógico que a informação a ser dada ao sujeito tenha que ser a que ele subjetivamente necessite para tomar uma decisão ${ }^{49,53}$. Contudo, a adequação da informação se deve em função das necessidades específicas de cada pessoa, uma vez que as necessidades individuais podem variar em função de crenças pouco convencionais, problemas de saúde e antecedentes familiares que justifiquem uma informação adequada ao contexto ${ }^{52}$.

4. Informação compreensível, ou seja, adaptada às peculiaridades socioculturais do paciente. Freqüentemente a linguagem utilizada pela equipe médica é altamente técnica, pouco acessível e distante da realidade $e^{49,53}$.

5. Capacidade por parte do paciente para compreender a informação, avaliá-la e comunicar sua decisão. Em muitas ocasiões, estimular perguntas, conhecer as preocupações e interesses dos sujeitos e propiciar um clima favorável para que as dúvidas sejam esclarecidas é mais favorável para a compreensão do que de fato expor a informação ${ }^{49,53}$. A competência requer da pessoa que está a tomar uma decisão a capacidade de análise do que está fazendo, e para tal se supõe ser necessário o máximo de compreensão da pesquisa ${ }^{54}$. 
6. Processo de tomada de decisão, que consiste na aceitação ou recusa do diagnóstico ou terapêutica proposta pelo profissional| ${ }^{49,53}$.

Portanto, o TCLE não consiste apenas de um formulário assinado para um ensaio clinico prospectivo, mas de um processo que perpassa pela informação, compreensão e voluntariedade do sujeito da pesquisa ${ }^{55}$.

No que concerne à compreensão, os dados encontrados na literatura sugerem que os sujeitos da pesquisa podem freqüentemente não entender a informação no processo de consentimento informado ${ }^{28,56,57,58,59}$.

\subsection{Problemas éticos em investigação clínica}

Com relação ao TCLE na prática clínica, o termo de consentimento nem sempre tem recebido a atenção que merece e às vezes é encarado como mera peça burocrática de isenção de responsabilidades e não como instrumento de natureza ética ${ }^{60}$.

O TCLE muitas vezes tem sido tratado como um ritual vazio, um procedimento rotineiramente limitado ao preenchimento e à assinatura de um formulário, com vistas à evidência legal de obtenção da anuência do usuário para os casos de possíveis pendências jurídicas. Geralmente nessas situações, as informações apresentadas são complexas, pouco ou nada compreendidas, com reduzido impacto na decisão ${ }^{44}$.

Outro fato também a ser considerado deve-se ao conflito acerca do duplo papel de clínico/pesquisador que muitas vezes se confunde na 
pesquisa clínica ${ }^{61,62}$, e a existência de um poder, maior ou menor, mais ou menos visível, do pesquisador sobre o sujeito de pesquisa, em vista da relação entre eles ser assimétrica ${ }^{63,64}$.

Na pesquisa clínica este fato fica claramente evidenciado, uma vez que a maioria das pesquisas são desenvolvidas em grandes centros de pesquisa de serviços públicos e hospitais universitários, onde a grande maioria dos sujeitos de pesquisa são indivíduos de uma classe social menos favorecida e que dependem da continuidade de atendimento no serviço.

$\mathrm{Na}$ atenção à saúde não são raras as práticas perpetuadoras de dependência do usuário, em lugar de se buscar a promoção de sua autonomia e cidadania ${ }^{44}$.

De acordo com Azevedo ${ }^{65}$, é neste ambiente que a aplicação do Termo de Consentimento Livre e Esclarecido tem outra dimensão quanto à ética da pesquisa com seres humanos, ou seja, a dimensão ética do diálogo com os membros de classes mais baixas é muito peculiar em países em desenvolvimento. Para esta autora, inclusive nestas situações circunstanciais de pobreza, o princípio de respeito à autonomia do paciente torna-se, para médicos e pesquisadores, uma prática de auto-ilusão, ou seja, solicitar consentimento para participar de um ensaio clínico a pacientes em evidentes circunstâncias de pobreza impõe sérias complexidades aos princípios de autonomia, beneficência e justiça. Quanto maior a condição de pobreza, maior o poder de oferta e, quanto maior a desigualdade de poderes entre pesquisador e o paciente, maior a probabilidade de violência à dignidade do mais fraco ${ }^{65}$. 
Outro fator que vem à baila nas pesquisas com seres humanos refere-se não só à vulnerabilidade intrínseca dessas pessoas, mas também à própria vulnerabilidade dos pesquisadores, instituições e até mesmo da própria nação ${ }^{23}$.

O considerável aumento de investimentos em pesquisas clínicas no país $^{66}$ e a procura de parceiros em países em desenvolvimento coloca o Brasil entre os países foco de interesse das pesquisas da indústria farmacêutica, junto de México e Argentina na América Latina, Leste Europeu e África do Sul ${ }^{67}$.

Entre os fatores que podem explicar tal interesse da indústria por estes países, destaca-se a prevalência de doenças de países menos desenvolvidos, uma população menos esclarecida em decorrência do baixo nível de escolaridade e submissa às solicitações do médico ${ }^{67}$, e um sistema atual de saúde que gera múltiplas desigualdades que colocam sua população num estado de fragilidade e dependência ${ }^{68}$. Com isso, há interesse dos pacientes na assistência mais personalizada dada nos projetos de pesquisa clínica e na oportunidade de receber o medicamento em teste ${ }^{67}$. Além disso, são países que possuem um grande contingente populacional, pesquisadores qualificados, normas éticas que alicerçam a pesquisa bem estabelecidas e um mercado atrativo ${ }^{69}$. Por outro lado, os pesquisadores acumulam experiências com a participação nos projetos e recebem incentivos financeiros, que muitas vezes revertem em investimentos científicos para as instituições ${ }^{67}$. 
Segundo Hossne ${ }^{60}$, em estudos multicêntricos os pesquisadores de países em desenvolvimento não devem ser encarados como meros prestadores de serviços técnicos ou agenciadores de pacientes, mas ter reconhecida sua capacidade de pesquisa e, para se evitar situações de injustiças com populações vulneráveis, é imprescindível a efetiva participação desses pesquisadores no planejamento e no delineamento da pesquisa.

À guisa das considerações, ainda percebe-se que há uma grande necessidade de que o pesquisador brasileiro alcance uma postura apropriada para o estabelecimento de parcerias justas. Para tanto, o conhecimento e o entendimento das normas poderão suplantar uma certa vulnerabilidade, dando-lhe estatura moral para a discussão e adequação do projeto, apoiado por comitês de ética realmente independentes, fundamentados ambos na missão de resguardar os direitos e interesses dos pacientes acima dos interesses da ciência ou da sociedade ${ }^{67}$.

Diante deste panorama atual, acredita-se que um dos grandes desafios morais do século XXI é não permitir que o poder da tecnologia ofusque o respeito à dignidade das pessoas, principalmente nos países em desenvolvimento; afinal, a ciência deve servir as pessoas, não estas à ciência. Em outras palavras, os avanços científicos e tecnológicos são necessários para melhorar as condições de vida da humanidade, mas não para aviltá-la em sua dignidade ${ }^{65}$.

Partindo desta premissa e considerando que, quando o sujeito ingressa na pesquisa, provavelmente não tem esclarecimento substancial e 
termina por levar em consideração para sua decisão outros fatores como: acesso aos serviços, vulnerabilidade, dependência e autoridade médica. Faz-se necessário conhecer, em nosso meio, qual é o nível de esclarecimento que este sujeito tem acerca da pesquisa e das repercussões desta para sua vida. 


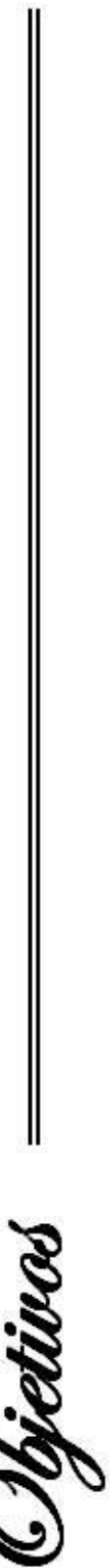




\section{OBJETIVOS}

\subsection{Objetivo Primário}

- Avaliar o entendimento do sujeito da pesquisa sobre sua participação em ensaios clínicos, em hospital terciário, de especialidades.

\subsection{Objetivo Secundário}

- Comparar se há diferença na compreensão e repercussão na vida do sujeito em participar de estudos com ou sem placebo. 


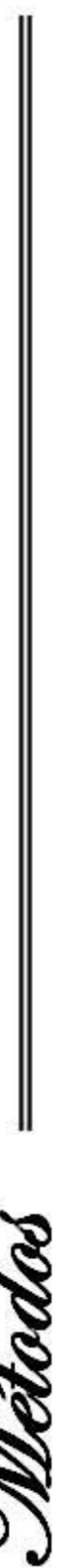




\section{MÉTODOS}

\subsection{Delineamento da pesquisa}

Trata-se de uma pesquisa descritiva-exploratória, de corte transversal e com abordagem quali-quantitativa.

\subsection{Local do estudo}

O estudo foi realizado em um hospital público especializado em cardiologia, no município de São Paulo, credenciado para atendimento de pacientes que requerem procedimentos de alta complexidade, provenientes do Sistema Único de Saúde (82\%), beneficiários de convênios e seguros médicos $(15 \%)$ e particulares $(3 \%)$. Além disso, tal hospital destaca-se pelas atividades de ensino e pesquisa ${ }^{70,71}$.

A instituição dispõe de 460 leitos institucionais ${ }^{72}$ distribuídos nas diversas unidades de especialidades cardiológicas, de acordo com a complexidade das patologias (Unidades de Internação, Unidade Clínica de Emergência e Unidades de Terapia Intensiva Adulto Clínica, Cirúrgica e 
Neonatal-Pediátrico), além de outros vários setores, como Ambulatório, Seção de Apoio ao Diagnóstico e Terapêutica, Laboratórios de Pesquisa e outros.

O ambulatório caracteriza-se pelo atendimento especializado em cardiologia e subdivide-se em geral e de especialidades de acordo com o fluxo de atendimento.

O ambulatório geral tem a finalidade de atender os pacientes previamente agendados e com guia de encaminhamento proveniente de outros serviços.

Já o ambulatório de especialidades destina-se ao atendimento de pacientes matriculados e em acompanhamento regular no serviço pelos seguintes grupos: coronariopatia crônica, valva, cardiopatia geral (miocardiopatias com tratamento clínico), congênitos, hipertensão arterial, arritmia (também marcapasso), pneumologia, lípides, diabetes, transplante cardíaco, hematologia, hemodinâmica, coronariopatia aguda e cardiogeriatria.

O ambulatório especializado, no ano de 2007, realizou 136.457 consultas, sendo que a média mensal foi de $11.371^{72}$.

\subsection{Casuística}

Foram considerados elegíveis para o estudo os sujeitos de pesquisa que participaram de ensaios clínicos conduzidos no ambulatório no período 
de 2002 a 2006. Para podermos testar a hipótese do estudo, dividimos os pacientes em dois grupos de avaliação:

- Com o uso de placebo (Grupo I) e;

- Sem o uso de placebo (Grupo II).

No Grupo I foram incluídos os sujeitos que participaram de ensaios clínicos duplo-cego e que poderiam ter tomado placebo após a randomização, ou seja, participaram de estudos controlados por placebo além da sua medicação previamente em curso.

Já no Grupo II incluíram-se os sujeitos que participaram de ensaios clínicos em que o tratamento em teste foi comparado com outro fármaco após a randomização. Porém, utilizaram placebo no período de wash-out* .

Para inclusão, no estudo, os indivíduos deveriam contemplar os seguintes critérios:

- $\quad$ Ter idade entre 20 e 80 anos;

- Ter participado de ensaios clínicos clínica fase II, III ou IV ambulatoriais e exclusivamente com fármacos.

- Ter participado de ensaios clínicos no período de 2002 a 2006;

- Ter utilizado placebo, em fase de wash-out ou em comparação ao fármaco em teste;

- Ter sido randomizado no estudo;

- Consentir em participar assinando o Termo de Consentimento Livre e Esclarecido.

\footnotetext{
* O washout refere-se ao período em que o paciente fica sem nenhum tratamento, ou com o mínimo necessário para sua segurança, relacionado à variável objeto do estudo, na expectativa de que a variável de desfecho retorne ao normal antes do início da próxima intervenção ${ }^{6}$.
} 
Como critérios de exclusão tivemos indivíduos que (além de excluídos os pacientes que não apresentaram pelo menos um dos critérios acima mencionados):

1. Não tiveram lembrança da sua participação no estudo;

2. Participaram de estudos conduzidos no ambulatório, mas cujos ensaios clínicos não implicavam em seguimento dos sujeitos de pesquisa;

3. Não aceitaram participar desta pesquisa.

Cabe esclarecer que os sujeitos da pesquisa já eram pacientes em acompanhamento no ambulatório de especialidades da instituição, ou seja, não foram recrutados externamente para participação nos ensaios clínicos.

O acompanhamento no ambulatório da instituição assegura aos pacientes do Sistema Único de Saúde retornos pelo menos anuais ao serviço e direito de receber mensalmente os medicamentos prescritos até a data do próximo retorno.

No que concerne à definição do tamanho da amostra, esta dependeu das informações obtidas junto à Instituição quanto aos sujeitos participantes em pesquisas clínicas. Assim, inicialmente eram passíveis de participar aqueles que se encaixaram nos critérios de disponibilidade (capacidade de participação voluntária) e temporalidade (participação durante o período de coleta e análise de dados). 


\subsection{Coleta de dados}

\subsubsection{Instrumento para coleta de dados}

Os dados foram obtidos mediante entrevista e consulta aos prontuários dos pacientes. Para o registro dos dados, utilizou-se um instrumento (Anexo 8.1) composto por duas partes:

A primeira parte destinava-se à obtenção de dados de identificação como: nome, número de registro hospitalar, idade, sexo, estado civil, escolaridade, ocupação, tempo de acompanhamento na instituição, pesquisa de qual participou, o ano da participação e se foi até o final.

Os dados referentes ao ano de início da participação no estudo e tempo de acompanhamento na instituição foram obtidos mediante consulta ao prontuário dos pacientes.

A segunda parte do instrumento foi constituída pelas questões abertas e fechadas acerca de sua participação na pesquisa clínica. Nesta parte, optou-se por questões abertas e fechadas, pois a combinação de respostas de múltipla escolha com questões abertas permite a obtenção de maiores informações a respeito do assunto ${ }^{73}$.

Cabe esclarecer que a questão 21 , sobre o entendimento do Termo de Consentimento Livre e Esclarecido, foi aplicada a todos os pacientes, uma vez que considerou-se também o entendimento verbal recebido. 
Em relação à questão 24 , referente ao entendimento do significado do termo placebo, foi aplicada a todos os sujeitos do grupo I e somente àqueles do grupo II que participaram de ensaios clínicos que continham a palavra placebo explicitada no TCLE, no período de wash-out, mesmo tendo sido esta uma estratégia utilizada no estudo.

Já a questão 25 , na qual é perguntado. " ...sabia que poderia tomar um comprimido sem nenhum efeito durante alguns meses?", foi aplicada somente aos pacientes do grupo I, pois nesse grupo os pacientes poderiam tomar placebo como um controle, além das suas medicações previamente utilizadas, que foram, na sua maioria, mantidas. Só foram eventualmente suspensos os medicamentos que ocasionalmente interferissem com a medicação do estudo e que não eram de uso obrigatório pelos sujeitos da pesquisa.

O fato de não haver homogeneidade na aplicação das questões $24 \mathrm{e}$ 25 deveu-se aos critérios utilizados na pesquisa quanto à seleção dos grupos.

\subsubsection{Procedimento para coleta de dados}

A coleta foi efetuada após a aprovação do projeto pela Comissão de Ética para Análise de Projetos de Pesquisa - CAPPesq, em sessão de 26.01.06, sob n 1223/05 (Anexo 8.2). 
Inicialmente, de um banco de dados institucional de pacientes que participaram de ensaios clínicos, foram identificados os estudos fase II, III e IV com fármacos, conduzidos no ambulatório de especialidades no período de 2002 a 2006, com ou sem a utilização de placebo.

Deste modo, foram selecionados seis ensaios clínicos, que foram conduzidos na Instituição neste período, sendo três para cada grupo, conforme descritos a seguir:

\section{- Grupo I}

1 - Estudo duplo-cego, multicêntrico, randomizado, controlado por placebo, de grupos paralelos, com 8 semanas de duração para avaliar a eficácia e a segurança do Aliskiren administrado isoladamente e em associação com a hidroclorotiazida em pacientes com hipertensão arterial.

2 - Avaliação da segurança e eficácia anti-anginosa da trimetazidina MR $35 \mathrm{mg}$ (35mg 2x/dia e $70 \mathrm{mg}$ 2x/dia) comparada ao placebo em pacientes com angina pectoris estável e $50 \mathrm{mg}$ 1x/dia de atenolol como terapia de base. Estudo de 12 semanas, multicêntrico, internacional, randomizado, duplo-cego, grupos paralelos.

3 - Efeito da trimetazidine (Vastarel) na disfunção ventricular esquerda induzida por isquemia em pacientes com doença arterial coronária. Estudo de fase IV, duplo-cego, comparando vastarel vs placebo, durante 12 semanas de observação. 


\section{- Grupo II}

1 - Estudo multicêntrico, duplo cego, comparativo de avaliação de eficácia e tolerabilidade da associação de anlodipino e enalapril em formulação galênica única versus anlodipino no tratamento da hipertensão arterial estágio I (leve) e estágio II (moderada) em portadores de doença coronária.

2 - Estudo duplo-cego, randomizado, multicêntrico,controlado por medicamento ativo, de grupos paralelos, que compara a associação de valsartana $320 \mathrm{mg}$ mais hidroclorotiazida $12,5 \mathrm{mg}$ e valsartana $320 \mathrm{mg}$ mais hidroclorotiazida $25 \mathrm{mg}$ ao valsartana $320 \mathrm{mg}$ em pacientes com hipertensão leve a moderada não adequadamente controlada com valsartana $320 \mathrm{mg}$.

3 - Estudo nacional, multicêntrico, aberto, randomizado e comparativo da avaliação da eficácia e tolerabilidade da associação de valsartana e anlodipino versus anlodipino isolado no tratamento da hipertensão arterial essencial - estágios I e II (leve a moderada).

Para facilitar o entendimento e os registros de interesse para o estudo, agruparam-se, no Quadro 1, as principais características dos ensaios clínicos incluídos nesta pesquisa. 
Quadro 1. Perfil de desenvolvimento dos ensaios clínicos utilizados no grupo I e II.

\begin{tabular}{||c||c||c||}
\hline \multicolumn{1}{|c||}{ Características } & Grupo I (n) & Grupo II (n) \\
\hline \hline Fase de desenvolvimento & & \\
II & 1 & 0 \\
III & 1 & 1 \\
IV & 1 & 2 \\
\hline Tipo de estudo & 3 & 2 \\
Duplo-cego & 0 & 1 \\
Aberto & & \\
Número de Centros & 1 & 3 \\
Bicêntrico & 2 & 0 \\
Multicêntrico & 1 & 1 \\
8 & 0 & 1 \\
10 & 2 & 1 \\
12 & 0 & 0 \\
20 & 0 & 3 \\
60 & & \\
\hline \hline Duração (em semanas) & 2 & \\
\hline \hline Angina & 1 & \\
Hipertensão & & \\
\hline \hline Finalidade do tratamento & & \\
\hline
\end{tabular}

A seguir, procedeu-se à análise do TCLE dos ensaios clínicos do Grupo II, checando se o termo placebo constava da descrição relativa à fase de wash-out da pesquisa, uma vez que não eram estudos controlados por placebo. Dos três ensaios clínicos selecionados para compor o grupo II do estudo, dois não apresentavam o termo placebo no TCLE, embora tivessem o período de wash-out. Portanto, a questão 24 do instrumento utilizado para coleta de dados, referente ao entendimento do placebo, não foi aplicada aos pacientes que participaram destes ensaios clínicos.

Uma vez selecionados os ensaios clínicos e analisados os TCLE, foi realizado contato com o pesquisador gerente de cada um desses ensaios clínicos, solicitando sua autorização para podermos nos comunicar com os sujeitos da pesquisa. Nesse momento também foi solicitada a relação dos 
indivíduos randomizados em seus estudos, a fim de que a coleta de dados pudesse ser viabilizada.

Desse modo, foi realizado inicialmente um contato telefônico prévio com os indivíduos da pesquisa, a fim de convidá-los para participar de uma pesquisa que teria apenas uma entrevista. Naquele momento também esclareceu-se que as despesas com transporte seriam ressarcidas, e que seria agendada a entrevista com os que aceitassem participar.

$\mathrm{Na}$ impossibilidade de localização dos indivíduos via contato telefônico, realizou-se um levantamento dos endereços cadastrados na instituição, e enviados telegramas solicitando que entrassem em contato com a pesquisadora.

As entrevistas foram realizadas individualmente pela própria pesquisadora, em ambiente tranqüilo e privativo, e teve como etapas:

1. Apresentação inicial, contendo breve exposição sobre os objetivos da pesquisa, orientações sobre o caráter voluntário da participação, anonimato e garantia de confidencialidade dos dados. Os pacientes foram esclarecidos de que a recusa em participar do estudo não implicaria em prejuízo de qualquer natureza na continuidade do tratamento.

2. Após confirmada a compreensão e, mediante o parecer favorável do paciente, solicitou-se sua assinatura do TCLE (Anexo 8.3) para a aplicação deste questionário.

3. As entrevistas foram transcritas, conservando-se as características originais da linguagem dos indivíduos, contendo 
gírias, locuções verbais e os vícios e erros da linguagem corrente.

4. Ao final foram ressarcidas as despesas com transporte.

\subsection{Análise estatística}

Inicialmente, neste estudo, todas as variáveis foram analisadas descritivamente.

Para tanto, as variáveis quantitativas como idade e tempo de seguimento na instituição foram analisadas em termos de médias e desviospadrão. As variáveis classificatórias como sexo, escolaridade, estado civil, atividade profissional, situação frente ao trabalho e ocupação foram apresentadas em tabelas contendo freqüências absolutas (n) e relativas (\%).

A comparação entre as médias dos grupos foi realizada utilizando-se o teste t de Student ou teste da soma de postos de Wilcoxon, no caso de amostras não pareadas $^{74}$.

Com o objetivo de verificar se havia associação entre alguns quesitos, foram feitas análises da possível associação destas variáveis através do teste Qui-quadrado ou teste da razão de Verossimilhança, ou teste exato de Fisher, quando aplicável ${ }^{74}$.

A análise estatística foi realizada com o apoio do software SPSS versão 15.0 (SPSS Inc.,EUA). 
Considerou-se como estatisticamente significante para análise os valores de $p<0,05$.

\subsection{Análise qualitativa}

A análise dos dados descritivos obtidos pelo contato direto do pesquisador com o pesquisado através das questões abertas foi realizada por meio da análise de conteúdo proposta por Bardin ${ }^{75}$.

A análise de conteúdo consiste em "um conjunto de técnicas de análise das comunicações, com o objetivo de obter, por meio de procedimentos sistemáticos e objetivos, a descrição do conteúdo das mensagens, os indicadores que permeiam a inferência de conhecimentos relativos às condições de produção/recepção destas mensagens". É uma técnica que possibilita a busca dos significados a partir dos discursos dos sujeitos da pesquisa ${ }^{75}$.

Assim, operacionalmente os discursos foram analisados seguindo-se as três etapas propostas por Bardin ${ }^{75}$ : pré-análise, exploração do material, tratamento dos resultados obtidos e interpretação.

1 - Pré-análise: é a etapa de organização do material e sistematização das idéias. Tem por objetivo a escolha dos documentos a serem analisados, a formulação das hipóteses e dos objetivos, além da elaboração de indicadores que orientem a interpretação final. 
Essa etapa foi decomposta pela leitura flutuante do conjunto das entrevistas e pela constituição dos corpora (exaustividade, representatividade, homogeneidade e pertinência).

2 - Exploração do material: ocorreu logo após a pré-análise e consistiu essencialmente na operação de categorização dos dados que se realiza na transformação dos dados brutos, visando alcançar o núcleo de compreensão do texto.

A categorização consiste em uma operação de classificação de elementos constitutivos de um conjunto, por diferenciação, seguidos por reagrupamento com critérios previamente definidos. Nesta fase, para organização dos dados, realizou-se o recorte (escolha das unidades de significação) e a categorização.

Na análise temática, o tema é a unidade de significação, que se libera naturalmente de um texto analisado. Deste modo, a partir das falas e processamento dos dados foram identificadas as categorias emergentes, uma vez que as respostas às questões abertas são freqüentemente analisadas tendo o tema por base.

3 - Tratamento dos resultados e interpretação: os resultados brutos são tratados de maneira a torná-los significativos e válidos. A partir disso, o pesquisador pode propor temas e realizar interpretações com seu quadro teórico que digam respeito a seus objetivos ou a outras descobertas. 


\subsection{Grupo Focal}

Com o intuito de complementar os dados obtidos por meio da pesquisa quali-quantitativa, optou-se pela realização do grupo focal por ser uma técnica utilizada para obtenção de dados a partir de discussões previamente planejadas onde os participantes expressam suas experiências, valores, crenças, atitudes e representações sociais sobre questões específicas $^{76}$. Esta técnica é particularmente apropriada quando o entrevistador tem uma série de questões abertas e fechadas e deseja estimular os participantes a explorarem um assunto de importância para eles, em seu próprio vocabulário e seguindo suas próprias prioridades ${ }^{77}$. Além disso, permite que os participantes explorem e esclareçam suas opiniões e pontos de vista de um modo não acessível por meio de outros métodos de entrevista, considerando sua visão no contexto da visão dos outros $^{77,78}$.

\subsubsection{Procedimentos operacionais no uso da técnica de grupo focal}

No sentido de assegurar a aplicação da técnica foram cumpridos os passos metodológicos que estruturam o trabalho em grupo focal, explicitados a seguir: 
1. Construção de um roteiro de temas - guia de tópicos para conduzir as discussões no grupo (Quadro 2), respeitando-se um tempo médio de uma hora e meia de atividade ${ }^{79}$;

2. Formulação de critérios de representatividade, ainda que com flexibilidade para particularizar e consolidar a composição de participantes diante de suas especificidades ${ }^{79}$;

3. O grupo deve ser composto por no mínimo seis e no máximo quinze pessoas ${ }^{76}$

4. Os dados devem ser obtidos a partir de mais de um grupo, com características diferentes a fim de permitir a identificação e a compreensão de diferenças da percepção ${ }^{80}$;

5. Estratégias formais de introdução no grupo focal, obedecendose às recomendações gerais de se proceder à identificação dos participantes, apresentação do moderador, do observador, dos participantes, à explicitação da finalidade do grupo e solicitação de permissão para gravação das sessões ${ }^{79}$;

6. O encaminhamento da discussão propriamente dita, que se inicia assim que o moderador percebe que o grupo já está no clima da temática em pauta ${ }^{79}$. O moderador deve manter $o$ foco da discussão, realizando síntese e retomando, em eventuais desvios $^{76}$

7. Necessidade de fechamento do grupo pelo moderador, com a realização por este de uma recapitulação resumida da discussão, com a manifestação dos participantes, que modificam conforme 
julgam conveniente, ajustadando a interpretação do que poderia ser efetivamente a opinião do grupo ${ }^{79}$;

8. O observador deve ter a função de, após a realização do grupo, complementar o relato dos acontecimentos ${ }^{81,82}$;

9. Ao final das reuniões, a gravação das atividades é transcrita na íntegra e analisada, proporcionando uma visão geral a respeito das questões abordadas. A análise dos dados é qualitativa e segue a metodologia adotada no trabalho ${ }^{76}$.

Quadro 2. Roteiro das questões norteadoras para o grupo focal.

O que vocês entendem por pesquisa?

$O$ que significa participar de uma pesquisa?

Vocês sabiam que estavam participando de uma pesquisa?

O que levou vocês a participarem de uma pesquisa?

Qual a diferença entre pesquisa e tratamento?

$\mathrm{Na}$ opinião de vocês, quais são as razões que levam uma pessoa aceitar ou não participar de uma pesquisa?

Vocês tiveram alguma dúvida durante a pesquisa? Perguntaram?

$O$ que vocês percebem como real benefício de ter participado de uma pesquisa?

$O$ que vocês entendem por termo de consentimento?

$\mathrm{Na}$ opinião de vocês, para que serve?

$O$ médico conversou com a Sr(a). sobre o termo? Explicou?

Vocês se sentiram à vontade para fazer perguntas?

$O$ conteúdo do texto do termo era de difícil compreensão?

Acha importante ler o documento?

Vocês acham importante ler o documento?

Se estavam acompanhados na ocasião, porque não leram o termo?

$O$ que poderia ser feito para melhorar o entendimento do termo?

$O$ que entendem por placebo? 


\subsubsection{Procedimentos para coleta dos dados}

Foram escolhidos aleatoriamente, a partir de sorteio, doze sujeitos de cada grupo e realizado, a seguir, um contato telefônico inicial, para convidá-los para participar de uma atividade em grupo, com data e horário previamente definidos. Neste momento também foi esclarecido que as despesas com transporte seriam ressarcidas, como mencionado anteriormente.

Para tanto, foi elaborado um roteiro com questões de interesse para o moderador e pautado nos resultados obtidos por meio das entrevistas realizadas previamente.

Assim sendo, foram realizados dois grupos focais em dias diferentes e com a presença de uma moderadora da própria instituição, mas sem vínculo com esta pesquisa, e de uma observadora, que neste caso foi a própria pesquisadora.

Ambas as reuniões foram gravadas e transcritas posteriormente (Anexo 8.4 e 8.5). O material obtido foi analisado utilizando-se o método de análise de conteúdo proposto por $\operatorname{Bardin}^{75}$. Nesta fase, realizou-se o recorte do material e demarcação dos "núcleos de sentido", ou seja, das unidades de significação (temas). Após o recorte, as unidades de significação foram classificadas e agregadas em categorias e subcategorias. 


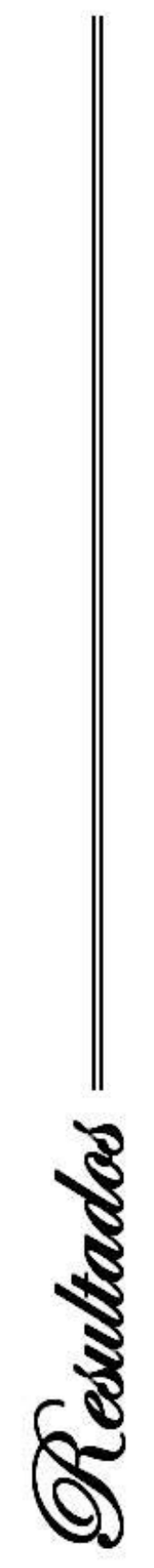




\section{RESULTADOS}

Nesta seção serão apresentados os resultados obtidos neste estudo na seguinte seqüência:

- Inicialmente, serão expostos os resultados referentes às características da população estudada como idade, gênero, escolaridade, tempo de seguimento na instituição, estado civil, ocupação, atividade profissional, situação frente ao trabalho e estudo do qual participou.

- A seguir, serão apresentados os dados quantitativos e qualitativos acerca da participação na pesquisa, relacionados ao Termo de Consentimento Livre e Esclarecido como documento em si, e sobre o impacto da participação. Cabe salientar que a seqüência de apresentação é a mesma das perguntas do questionário aplicado aos sujeitos da pesquisa.

- Na seqüência, serão apresentadas as associações das questões consideradas de relevância para o estudo e a descrição dos discursos que ancoraram as unidades temáticas.

- Por fim, a descrição do grupo focal. 
4.1. Diagrama dos pacientes selecionados para o estudo
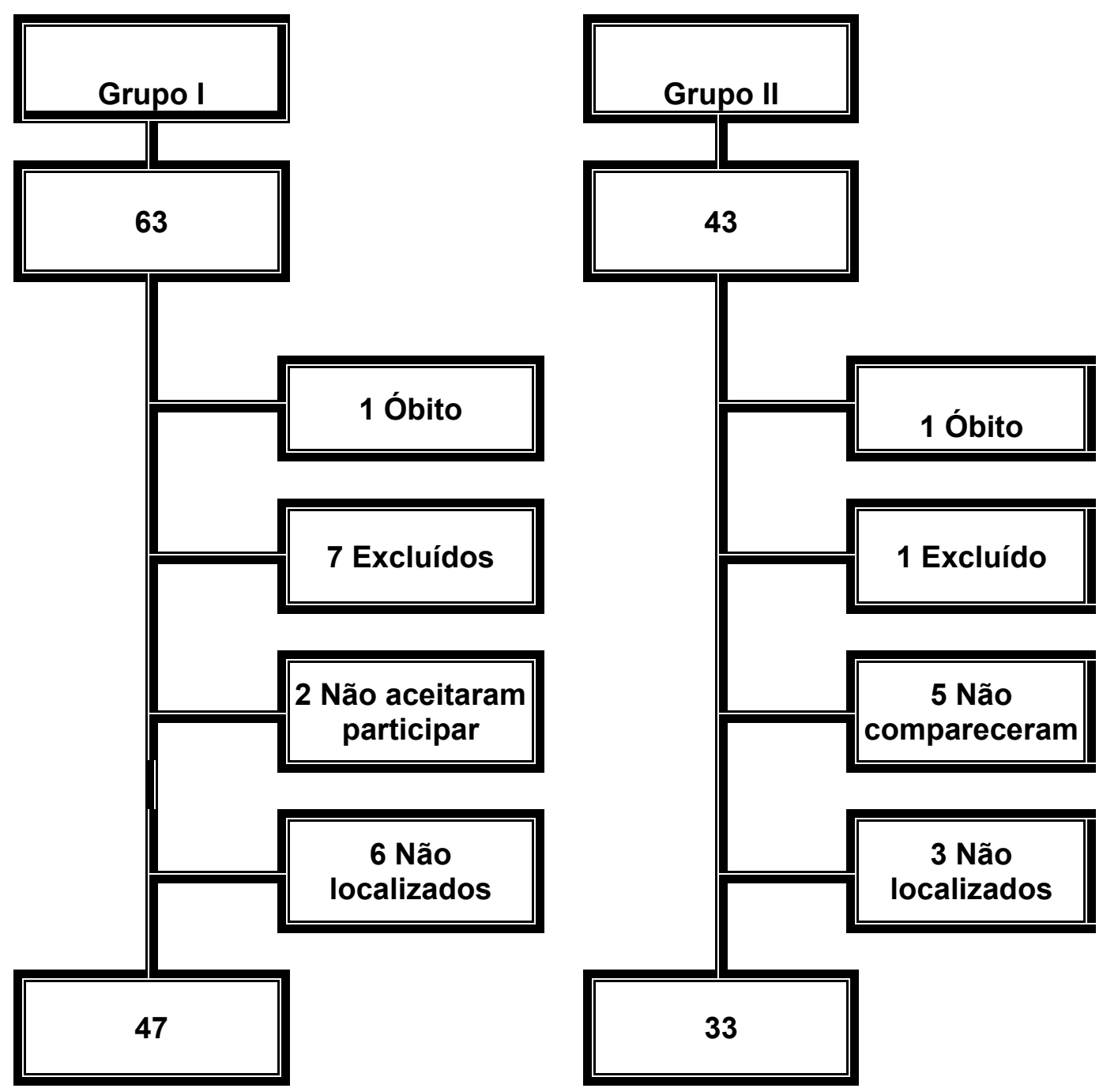


\subsection{Perfil sócio-demográfico da amostra}

Com base nos critérios de inclusão, foram selecionados 80 sujeitos que compuseram a amostra do estudo, sendo 47 no grupo I e 33 no grupo II. A exclusão de sete pacientes do grupo I ocorreu em virtude dos mesmos terem sido randomizados em 2001. Já com relação ao grupo II um paciente foi excluído por apresentar problemas de saúde incapacitantes.

Pelos dados da Tabela 1, pode-se observar que a média das idades ( \pm DP) em anos dos grupos foi de: $58,3 \pm 9,0$ para o grupo I e $59,4 \pm 9,8$ para o grupo II.

Com relação ao tempo de seguimento na instituição, este foi maior em até oito meses nos sujeitos do grupo II $(68,4 \pm 30,1)$, embora sem ser estatisticamente significante.

Tabela 1. Distribuição da amostra quanto à idade e tempo de seguimento na instituição.

\begin{tabular}{ccccc}
\hline \hline Características & \multicolumn{2}{c}{ Grupo } & p & Teste* \\
\cline { 2 - 3 } & I & II & & \\
\hline $\begin{array}{c}\text { Idade (anos) } \\
\text { Média (DP) }\end{array}$ & $58,3( \pm 9,0)$ & $59,4( \pm 9.8)$ & 0,614 & T \\
$\begin{array}{c}\text { Tempo de Seguimento } \\
\text { na instituição (meses) } \\
\text { Média (DP) }\end{array}$ & $60,7( \pm 46,8)$ & $68,4( \pm 30,9)$ & 0,107 & W \\
\hline \hline
\end{tabular}

${ }^{*} \mathrm{~T}=$ Teste $\mathrm{t}$ de Student

${ }^{*} \mathrm{~W}=$ Teste de Wilcoxon 
A Figura 1, a seguir, ilustra a distribuição dos sujeitos de pesquisa nos estudos dos quais participaram.

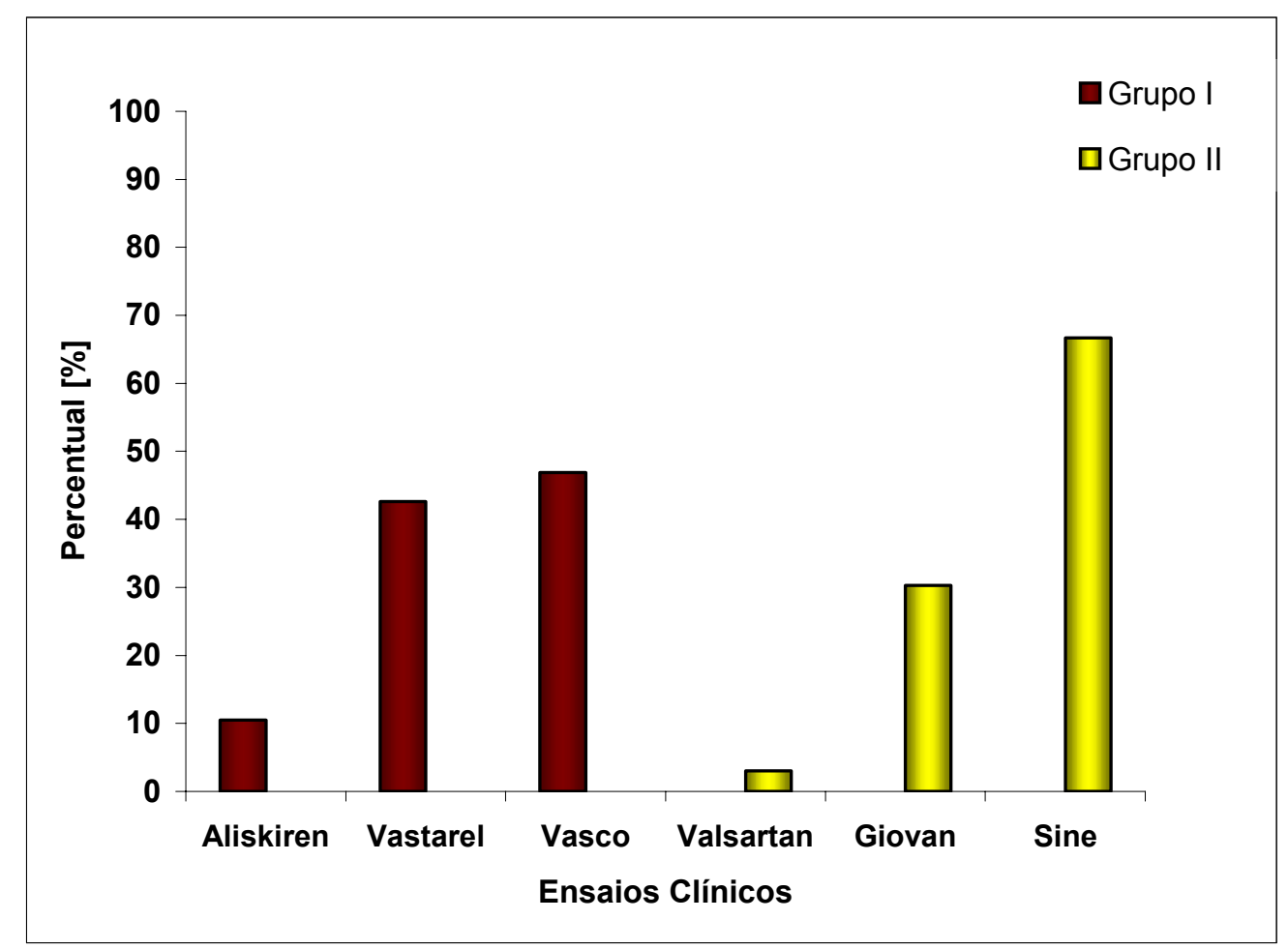

Figura 1. Distribuição da amostra segundo estudo no qual participou.

De acordo com a Tabela 2, pode-se observar que os sujeitos da pesquisa estão representados por sessenta homens $(75,0 \%)$ e somente vinte mulheres $(25,0 \%)$; não houve diferença entre os dois grupos quanto a essas proporções.

Com relação ao nível de instrução, em ambos os grupos a maioria era analfabeta ou tinha apenas o nível fundamental incompleto de ensino, perfazendo um total $63,8 \%$. Apenas $15 \%$ dos sujeitos haviam cursado o nível médio e somente oito $(10,0 \%)$ o nível superior, caracterizando uma amostra de baixo nível educacional. 
Quanto ao estado civil, verifica-se o predomínio de sujeitos com companheiro (80,0\%), ou seja, casados e amasiados.

No que concerne à atividade profissional, nessa amostra foi possível verificar que metade dos entrevistados (52,5\%) não tinha atividade profissional com vínculo empregatício. Por outro lado, deve-se ressaltar que trinta eram aposentados (37,5\%), onze eram do lar $(13,8 \%)$ e somente um $(1,2 \%)$ estava afastado por problemas de saúde, compatível com o perfil da amostra.

Tabela 2. Distribuição da amostra segundo as características sócio demográficas dos sujeitos da pesquisa nos grupos I e II.

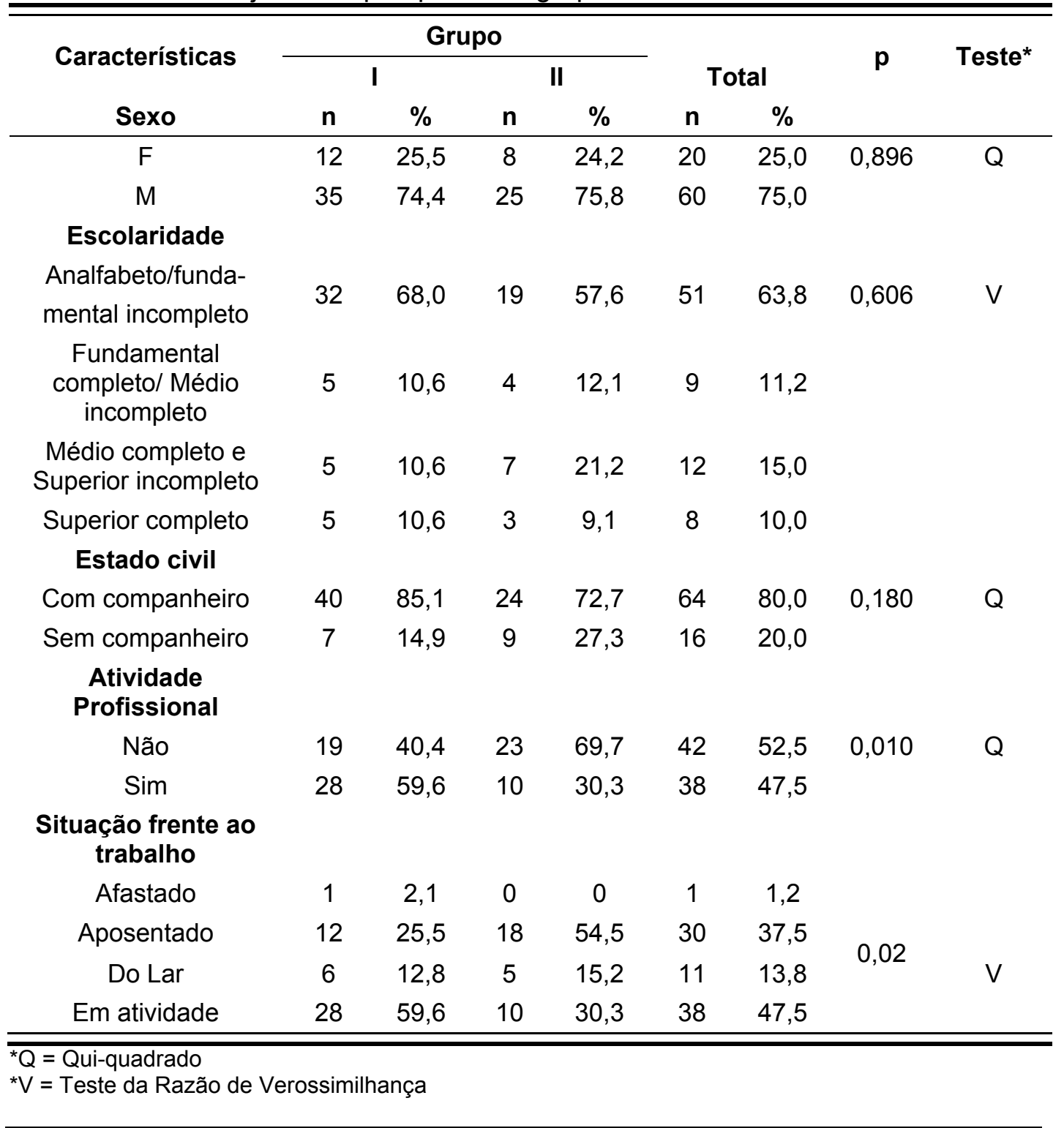


Nota-se, na Tabela 3 a seguir, que há também uma grande diversidade de ocupações em ambos os grupos. Verifica-se que as ocupações atuais dos sujeitos eram, predominantemente, motorista $(17,8 \%)$ e taxista $(14,2 \%)$ no grupo I, e comerciante $(20,0 \%)$ no grupo II.

Tabela 3. Distribuição das ocupações dos sujeitos de pesquisa dos grupos I e II.

\begin{tabular}{|c|c|c|c|c|c|c|}
\hline \multirow{3}{*}{ Ocupações } & \multicolumn{4}{|c|}{ Grupo } & \multirow{2}{*}{\multicolumn{2}{|c|}{ Total }} \\
\hline & \multicolumn{2}{|c|}{ I } & \multicolumn{2}{|c|}{ II } & & \\
\hline & $\mathbf{n}$ & $\%$ & $\mathbf{n}$ & $\%$ & $\mathbf{n}$ & $\%$ \\
\hline Agente carcerário & 1 & 3,6 & 0 & 0,0 & 1 & 2,6 \\
\hline Agente de segurança & 1 & 3,6 & 0 & 0,0 & 1 & 2,6 \\
\hline $\begin{array}{l}\text { Ajudante de serviços } \\
\text { gerais }\end{array}$ & 1 & 3,6 & 0 & 0,0 & 1 & 2,6 \\
\hline Assessorista & 1 & 3,6 & 0 & 0,0 & 1 & 2,6 \\
\hline Auxiliar Técnico & 0 & 0,0 & 1 & 10,0 & 1 & 2,6 \\
\hline Balconista & 1 & 3,6 & 0 & 0,0 & 1 & 2,6 \\
\hline Cabelereira & 0 & 0,0 & 1 & 10,0 & 1 & 2,6 \\
\hline Colorista & 1 & 3,6 & 0 & 0,0 & 1 & 2,6 \\
\hline Comerciante & 0 & 0,0 & 2 & 20,0 & 2 & 5,3 \\
\hline Corretor de imóveis & 1 & 3,6 & 0 & 0,0 & 1 & 2,6 \\
\hline Costureira & 2 & 7,1 & 0 & 0,0 & 2 & 5,3 \\
\hline Eletricista & 2 & 7,1 & 0 & 0,0 & 2 & 5,3 \\
\hline Empresário & 0 & 0,0 & 1 & 10,0 & 1 & 2,6 \\
\hline Farmacêutico & 1 & 3,6 & 0 & 0,0 & 1 & 2,6 \\
\hline Manicure & 1 & 3,6 & 0 & 0,0 & 1 & 2,6 \\
\hline Manobrista & 0 & 0,0 & 1 & 10,0 & 1 & 2,6 \\
\hline Mecânico & 1 & 3,6 & 0 & 0,0 & 1 & 2,6 \\
\hline Motorista & 5 & 17,9 & 1 & 10,0 & 6 & 15,8 \\
\hline Pedreiro & 1 & 3,6 & 0 & 0,0 & 1 & 2,6 \\
\hline Policial & 0 & 0,0 & 1 & 10,0 & 1 & 2,6 \\
\hline Professora & 1 & 3,6 & 0 & 0,0 & 1 & 2,6 \\
\hline Representante Comercial & 0 & 0,0 & 1 & 10,0 & 1 & 2,6 \\
\hline Taxista & 4 & 14,3 & 0 & 0,0 & 4 & 10,5 \\
\hline Vendedor & 2 & 7,1 & 1 & 10,0 & 3 & 7,9 \\
\hline Vigia & 1 & 3,6 & 0 & 0,0 & 1 & 2,6 \\
\hline
\end{tabular}




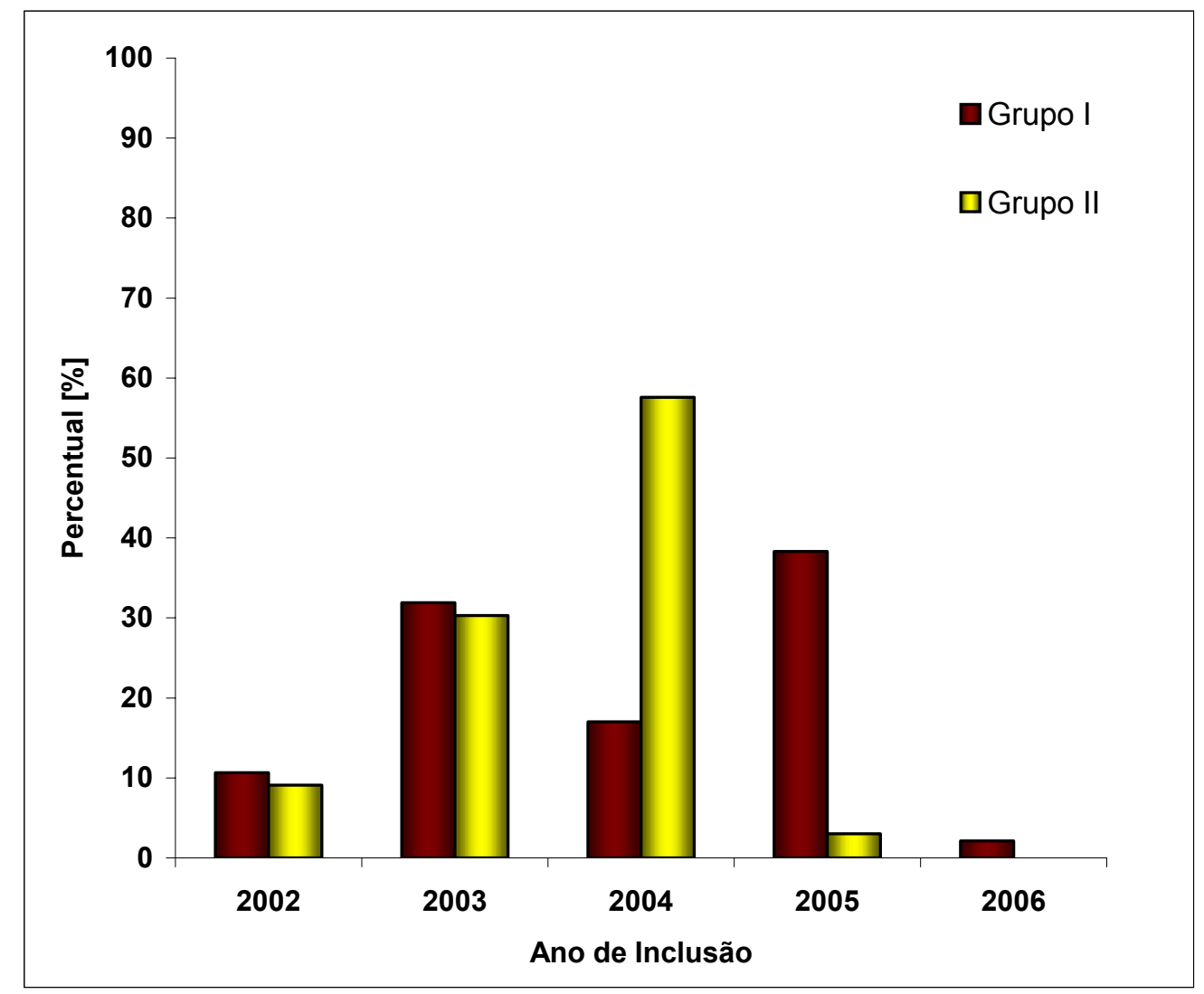

Figura 2. Distribuição dos sujeitos de pesquisa, segundo ano de inclusão nos ensaios clínicos.

Pelos dados da Figura 2, pode-se constatar que $57,6 \%$ (dezenove) dos sujeitos do grupo II participaram de protocolos de pesquisa em 2004, e $38,3 \%$ do grupo I em 2005. Observa-se também menor número de participantes, em ambos os grupos, em 2002 (10,0\%) e 2006 (1,2\%).

Já na Figura 3 observa-se que apenas dois sujeitos $(2,5 \%)$ do grupo II não concluíram a participação no estudo. 


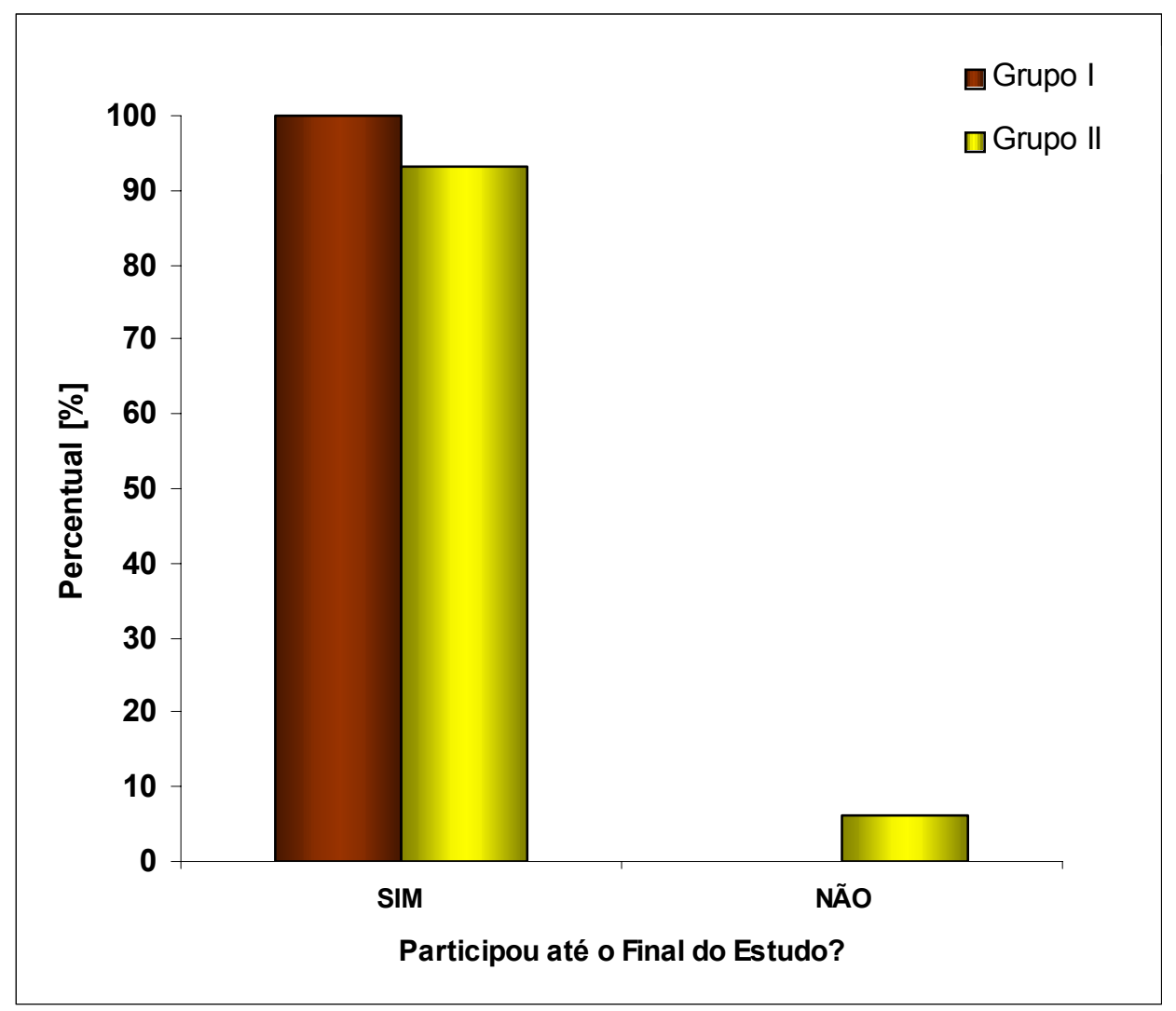

Figura 3. Distribuição dos entrevistados sobre se sua participação no ensaio clínico foi até o final.

\subsection{Informações acerca da participação no ensaio clínico}

Em relação ao convite para participar do ensaio clínico, verifica-se na Figura 4 que vinte e cinco $(53,2 \%)$ dos sujeitos do grupo I foram convidados pela Enfermeira e vinte e três $(69,7 \%)$ do grupo II pelo pesquisador. Os outros representam $1,2 \%$. 
Cabe esclarecer que há menção de $100 \%$ dos sujeitos, de ambos os grupos, considerando importante quem os convidou para participar da pesquisa naquele momento.

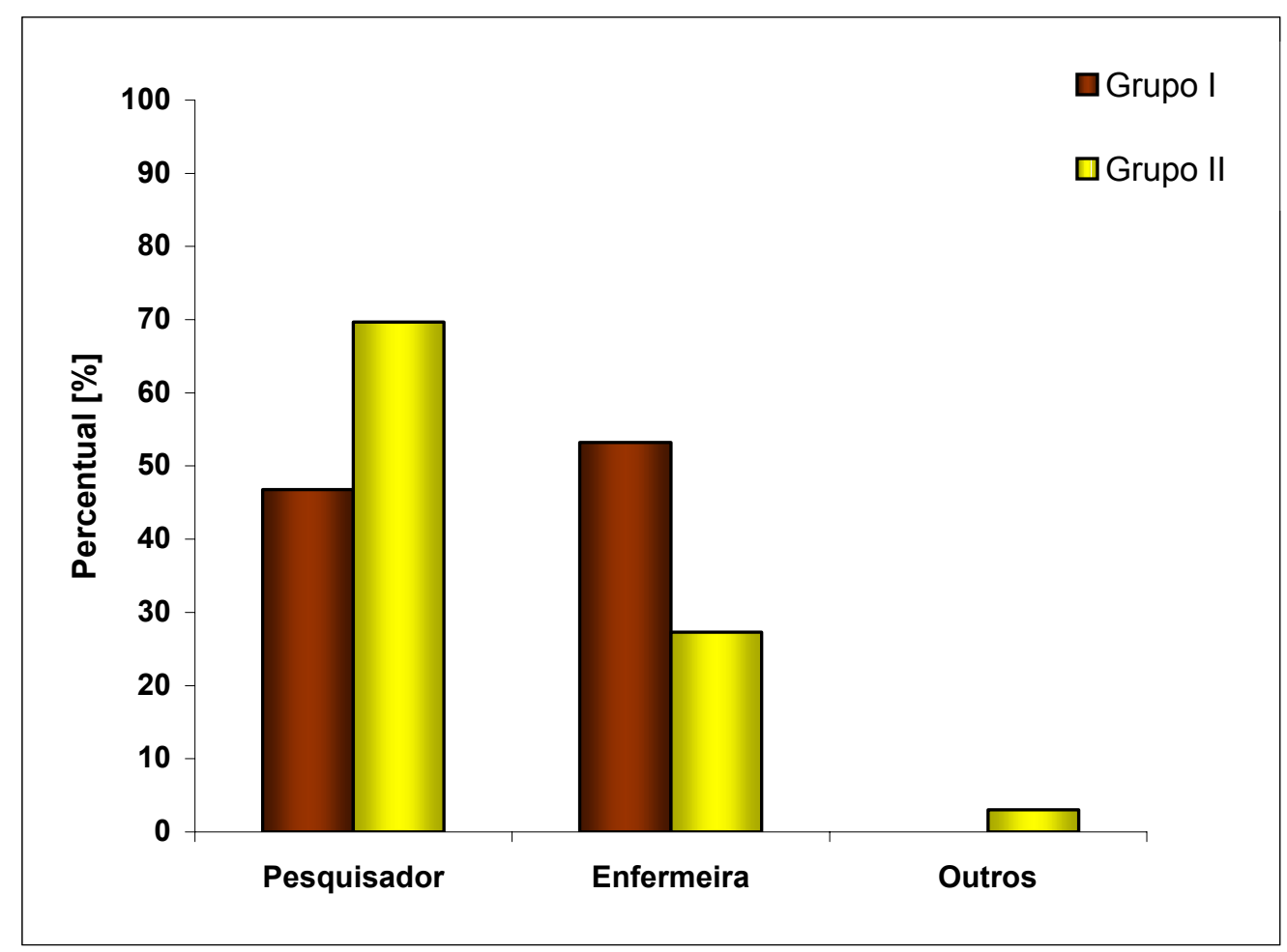

Figura 4. Distribuição dos entrevistados, segundo informação de quem os convidou para participar da pesquisa.

No que tange ao modo de contato para convidar os sujeitos para que participassem das pesquisas clínicas, este teve a seguinte distribuição: $70,2 \%$ destes foram realizados pelo telefone para os do grupo I e $66,6 \%$ destes foram feitos pessoalmente para os do grupo II (Figura 5). 


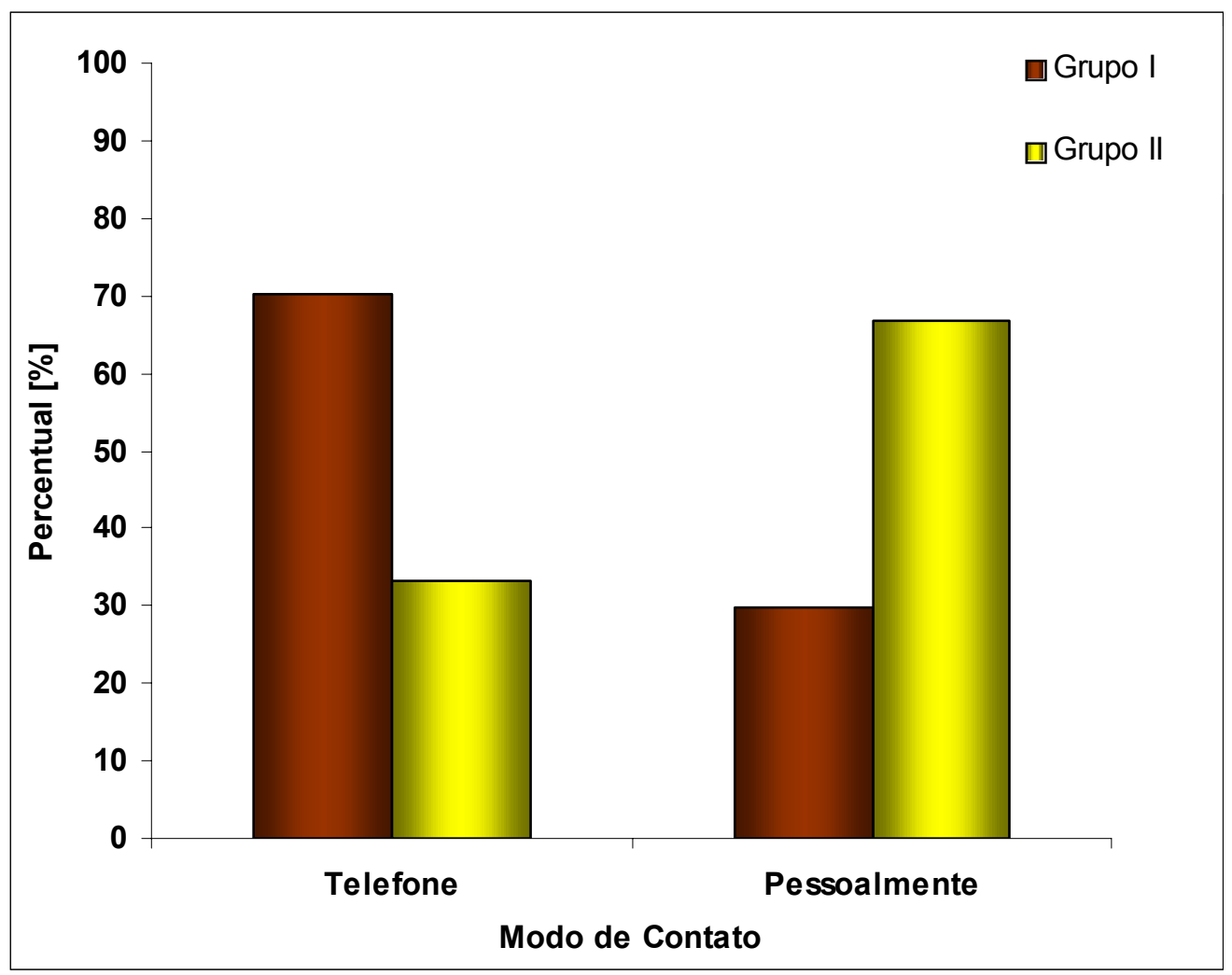

Figura 5. Modo de contato utilizado para convidar o paciente para participar da pesquisa.

Ainda com relação ao convite para participar da pesquisa, observase na Figura 6 , a seguir, que $95,0 \%$ dos sujeitos foram informados no momento deste contato que o objetivo era a participação em uma pesquisa. 


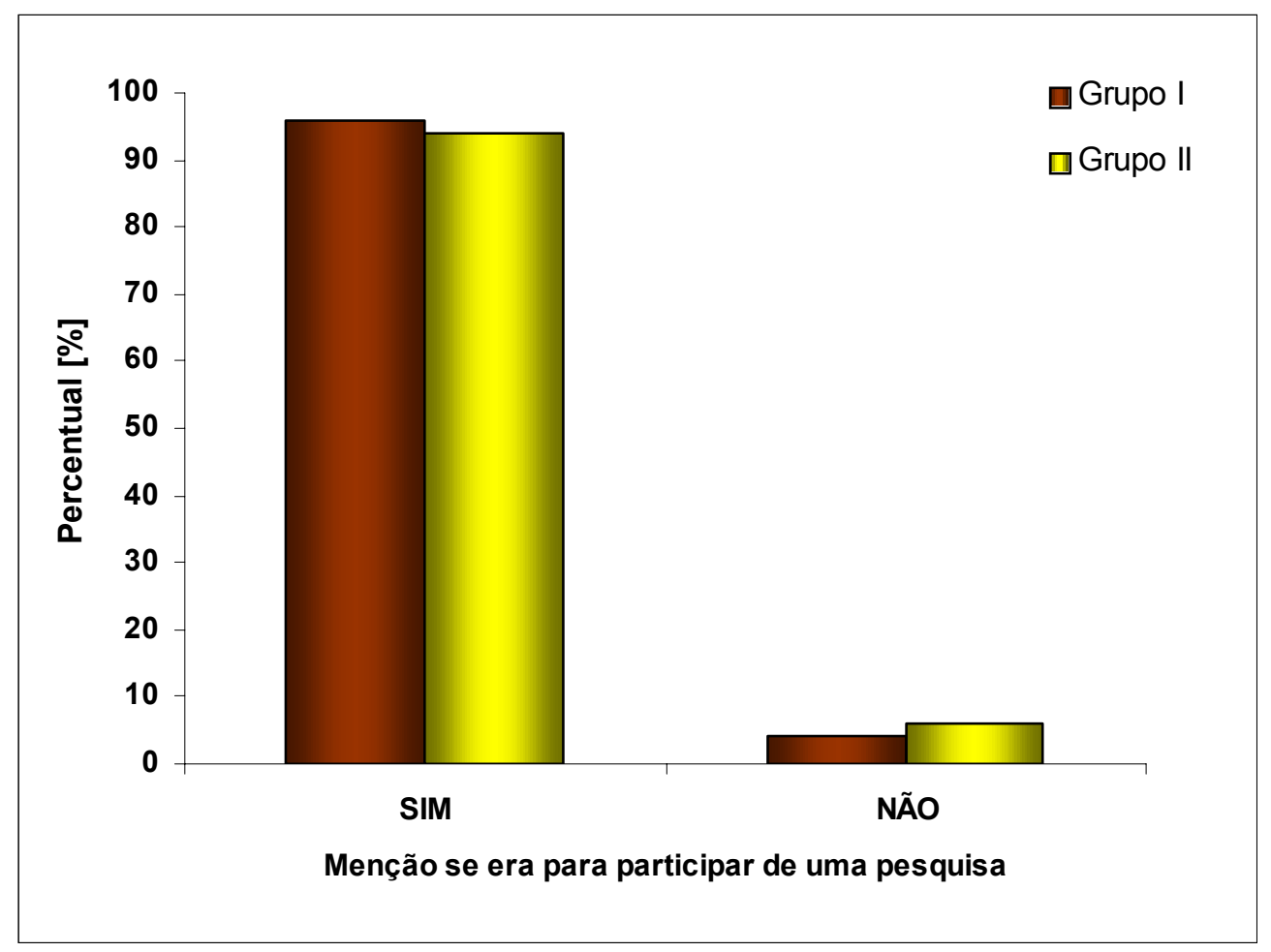

Figura 6. Menção feita pelos pacientes, quanto a se foi informado no momento do contato que o objetivo era a participação em uma pesquisa.

Quando indagados sobre os motivos que os levaram a participar de uma pesquisa, pode-se observar, na Tabela 4, que cinqüenta e três sujeitos $(66,2 \%)$ atribuíram a decisão ao benefício próprio em ambos os grupos, seguidos pelo bem da ciência (42,5\%). 
Tabela 4. Distribuição da amostra estudada segundo o motivo que determinou a participação do sujeito na pesquisa.

\begin{tabular}{|c|c|c|c|c|c|c|c|c|}
\hline \multirow{3}{*}{ Motivos } & \multicolumn{4}{|c|}{ Grupo } & & & \multirow{3}{*}{$\mathbf{p}$} & \multirow{3}{*}{ Teste* } \\
\hline & \multicolumn{2}{|c|}{ I } & \multicolumn{2}{|c|}{ II } & \multicolumn{2}{|c|}{ Total } & & \\
\hline & $\mathbf{n}$ & $\%$ & $\mathbf{n}$ & $\%$ & $\mathbf{n}$ & $\%$ & & \\
\hline \multicolumn{9}{|c|}{ Para o bem da ciência } \\
\hline Não & 26 & 55,3 & 20 & 60,6 & 46 & 57,5 & 0,638 & $Q$ \\
\hline $\operatorname{Sim}$ & 21 & 44,7 & 13 & 39,4 & 34 & 42,5 & & \\
\hline \multicolumn{9}{|c|}{ Em benefício próprio } \\
\hline Não & 17 & 36,2 & 10 & 30,3 & 27 & 33,8 & 0,585 & $Q$ \\
\hline Sim & 30 & 63,8 & 23 & 69,7 & 53 & 66,2 & & \\
\hline \multicolumn{9}{|c|}{$\begin{array}{l}\text { Porque o médico que } \\
\text { ola atendeu pediu }\end{array}$} \\
\hline Não & 42 & 89,4 & 30 & 90,9 & 72 & 90,0 & 1,000 & $\mathrm{~F}$ \\
\hline Sim & 5 & 10,6 & 3 & 9,1 & 8 & 10,0 & & \\
\hline \multicolumn{9}{|c|}{$\begin{array}{l}\text { Porque o médico que } \\
\text { ola atendeu disse que } \\
\text { era bom para você }\end{array}$} \\
\hline Não & 39 & 83,0 & 29 & 87,9 & 68 & 85,0 & 0,752 & $\mathrm{~F}$ \\
\hline $\operatorname{Sim}$ & 8 & 17,0 & 4 & 12,1 & 12 & 15,0 & & \\
\hline \multicolumn{9}{|c|}{$\begin{array}{c}\text { Por medo de não ser } \\
\text { atendido ou perder a } \\
\text { vez }\end{array}$} \\
\hline Não & 45 & 95,7 & 32 & 97,0 & 77 & 96,2 & 1,000 & $\mathrm{~F}$ \\
\hline Sim & 2 & 4,3 & 1 & 3,0 & 3 & 3,8 & & \\
\hline \multicolumn{9}{|c|}{$\begin{array}{l}\text { Porque é um hospital } \\
\text { público }\end{array}$} \\
\hline Não & 41 & 87,2 & 31 & 93,9 & 72 & 90,0 & 0,459 & $\mathrm{~F}$ \\
\hline $\operatorname{Sim}$ & 6 & 12,8 & 2 & 6,1 & 8 & 10,0 & & \\
\hline \multicolumn{9}{|l|}{ Outros } \\
\hline Não & 44 & 93,6 & 31 & 93,9 & 75 & 93,8 & 1,000 & $\mathrm{~F}$ \\
\hline Sim & 3 & 6,4 & 2 & 6,1 & 5 & 6,2 & & \\
\hline
\end{tabular}

Verifica-se também que $25,0 \%$ dos pacientes ou atenderam ao pedido médico ou a sua indicação de que seria bom a eles, demonstrando a influência do profissional neste momento de decisão. E também há os que, mesmo em menor número, participaram por ser um hospital público $(10,0 \%)$ e por medo de não serem mais atendidos na instituição $(3,8 \%)$. Os outros 
motivos, representando $6,2 \%$, referem-se à realização de exames que não fariam na rotina e retribuição ao hospital pelo atendimento.

\subsection{Dados relacionados ao Termo de Consentimento Livre e Esclarecido como documento em si}

Na casuística estudada, observa-se diferenças entre os grupos I e II quanto aos esclarecimentos realizados pelo pesquisador a respeito das informações contidas no Termo de Consentimento Livre e Esclarecido, embora a única diferença estatisticamente significante seja a importância atribuída à pesquisa (Tabela 5).

Verifica-se ainda que $25,0 \%$ dos sujeitos referem não ter recebido qualquer tipo de informação acerca da importância da pesquisa para a qual estavam sendo convidados a participar, e quase a metade $(42,5 \%)$ nem dos riscos e incômodos. O mesmo ocorreu em relação à existência de outros tratamentos diferentes do da pesquisa, onde se observa que 66 sujeitos $(82,5 \%)$ não receberam essa informação.

Ao lado disso, nota-se que a garantia de sigilo, considerada primordial durante a realização de uma pesquisa, também era desconhecida por quase metade dos sujeitos no momento da entrevista $(47,5 \%)$.

Também chama a atenção que trinta e sete sujeitos $(46,2 \%)$ afirmam não haver recebido qualquer tipo de orientação a respeito das formas de reparação diante de eventuais danos ou problemas decorrentes da participação na pesquisa. 
No entanto, $76,2 \%$ foram informados do direito de desistir da pesquisa a qualquer momento, sem nenhum prejuízo para seu tratamento na instituição.

Tabela 5. Freqüência absoluta e percentual dos esclarecimentos realizados pelo pesquisador a respeito das informações contidas no TCLE, segundo resposta dos sujeitos.

\begin{tabular}{|c|c|c|c|c|c|c|c|c|}
\hline \multirow{3}{*}{ Esclarecimentos } & \multicolumn{4}{|c|}{ Grupo } & & & \multirow{3}{*}{ p } & \multirow{3}{*}{ Teste* } \\
\hline & \multicolumn{2}{|c|}{$\mathbf{I}$} & \multicolumn{2}{|c|}{ II } & \multicolumn{2}{|c|}{ Total } & & \\
\hline & $\mathbf{n}$ & $\%$ & $\mathbf{n}$ & $\%$ & $\mathbf{n}$ & $\%$ & & \\
\hline \multicolumn{9}{|c|}{ Importância da pesquisa } \\
\hline Não & 8 & 17,0 & 12 & 36,4 & 20 & 25,0 & 0,049 & $Q$ \\
\hline Sim & 39 & 83,0 & 21 & 63,6 & 60 & 75,0 & & \\
\hline \multicolumn{9}{|l|}{ Riscos e incômodos } \\
\hline Não & 20 & 42,6 & 14 & 42,4 & 34 & 42,5 & 0,991 & Q \\
\hline Sim & 27 & 57,4 & 19 & 57,6 & 46 & 57,5 & & \\
\hline \multicolumn{9}{|c|}{$\begin{array}{l}\text { Existência de outros } \\
\text { tratamentos diferentes } \\
\text { dos da pesquisa }\end{array}$} \\
\hline Não & 41 & 87,2 & 25 & 75,8 & 66 & 82,5 & 0,184 & Q \\
\hline Sim & 6 & 12,8 & 8 & 24,2 & 14 & 17,5 & & \\
\hline \multicolumn{9}{|l|}{ Garantia de sigilo } \\
\hline Não & 25 & 53,2 & 13 & 39,4 & 38 & 47,5 & 0,224 & $Q$ \\
\hline Sim & 22 & 46,8 & 20 & 60,6 & 42 & 52,5 & & \\
\hline \multicolumn{9}{|c|}{$\begin{array}{c}\text { Formas de ressarcimento } \\
\text { das despesas }\end{array}$} \\
\hline Não & 1 & 3,6 & 1 & 3,0 & 2 & 3,3 & 1,000 & $\mathrm{~F}$ \\
\hline Sim & 27 & 96,4 & 32 & 97,0 & 59 & 96,7 & & \\
\hline \multicolumn{9}{|c|}{$\begin{array}{l}\text { Formas de reparação } \\
\text { diante de eventuais } \\
\text { danos ou problemas }\end{array}$} \\
\hline Não & 23 & 48,9 & 14 & 42,4 & 37 & 46,2 & 0,565 & Q \\
\hline Sim & 24 & 51,1 & 19 & 57,6 & 43 & 53,8 & & \\
\hline \multicolumn{9}{|c|}{$\begin{array}{l}\text { Que poderia desistir a } \\
\text { qualquer momento }\end{array}$} \\
\hline Não & 12 & 25,5 & 7 & 21,2 & 19 & 23,8 & 0,655 & Q \\
\hline Sim & 35 & 74,5 & 26 & 78,8 & 61 & 76,2 & & \\
\hline
\end{tabular}

${ }^{*} \mathrm{~F}=$ Teste exato de Fisher

${ }^{*} \mathrm{Q}=$ Qui-quadrado 
Pelos dados da Tabela 6 , nota-se que $97,5 \%$ sujeitos afirmaram ter assinado o Termo de Consentimento Livre e Esclarecido no momento em que decidiram participar da pesquisa, e somente $67,1 \%$ dos sujeitos o leram antes de assinar. Dentre estes, há menção de um participante do grupo I de não ter lembrança no momento.

Tabela 6. Distribuição dos dados a respeito de se os pacientes leram e assinaram o Termo de Consentimento Livre e Esclarecido, antes de participar da pesquisa.

\begin{tabular}{|c|c|c|c|c|c|c|c|c|}
\hline \multirow{3}{*}{$\begin{array}{c}\text { Assinou o } \\
\text { TCLE? }\end{array}$} & \multicolumn{4}{|c|}{ Grupo } & & & \multirow{3}{*}{ p } & \multirow{3}{*}{ Teste* } \\
\hline & \multicolumn{2}{|c|}{ I } & \multicolumn{2}{|c|}{ II } & \multicolumn{2}{|c|}{ Total } & & \\
\hline & $\mathrm{n}$ & $\%$ & $n$ & $\%$ & $\mathrm{n}$ & $\%$ & & \\
\hline Não & 2 & 4,3 & 0 & 0,0 & 2 & 2,5 & 0,509 & $\mathrm{~F}$ \\
\hline Sim & 45 & 95,7 & 33 & 100,0 & 78 & 97,5 & & \\
\hline \multicolumn{9}{|l|}{ Leu O TCLE? } \\
\hline Não & 14 & 30,4 & 12 & 36,4 & 26 & 32,9 & 0,580 & Q \\
\hline Sim & 32 & 69,6 & 21 & 63,6 & 53 & 67,1 & & \\
\hline
\end{tabular}

${ }^{*} \mathrm{~F}=$ Teste exato de Fisher

${ }^{*} \mathrm{Q}=$ Qui-quadrado

Tabela 7. Distribuição dos entrevistados, segundo menção de discutir o TCLE com o pesquisador.

\begin{tabular}{|c|c|c|c|c|c|c|c|c|}
\hline \multirow{3}{*}{$\begin{array}{c}\text { Conversou sobre } \\
\text { o TCLE? }\end{array}$} & \multicolumn{4}{|c|}{ Grupo } & & & \multirow{3}{*}{$p$} & \multirow{3}{*}{ Teste $^{*}$} \\
\hline & \multicolumn{2}{|c|}{ I } & \multicolumn{2}{|c|}{ II } & \multicolumn{2}{|c|}{ Total } & & \\
\hline & $\mathrm{n}$ & $\%$ & $\mathrm{n}$ & $\%$ & $\mathbf{n}$ & $\%$ & & \\
\hline Não & 32 & 68,1 & 20 & 60,6 & 52 & 65,0 & 0,490 & Q \\
\hline Sim & 15 & 31,9 & 13 & 39,4 & 28 & 35,0 & & \\
\hline
\end{tabular}

${ }^{*} \mathrm{Q}=$ Qui-quadrado

Observa-se na Tabela 7 que cinqüenta e dois sujeitos entrevistados $(65,0 \%)$ não conversaram sobre o Termo de Consentimento Livre e Esclarecido com o pesquisador, sendo trinta e dois $(68,1 \%)$ do grupo I. 
Tabela 8. Distribuição dos entrevistados, quanto a ter entendido o conteúdo do TCLE quando o assinou.

\begin{tabular}{|c|c|c|c|c|c|c|c|c|}
\hline \multirow{3}{*}{$\begin{array}{l}\text { Entendimento do } \\
\text { TCLE }\end{array}$} & \multicolumn{4}{|c|}{ Grupo } & & & \multirow{3}{*}{$p$} & \multirow{3}{*}{ Teste $^{*}$} \\
\hline & \multicolumn{2}{|c|}{ I } & \multicolumn{2}{|c|}{ II } & \multicolumn{2}{|c|}{ Total } & & \\
\hline & $\mathbf{n}$ & $\%$ & $\mathbf{n}$ & $\%$ & $\mathbf{n}$ & $\%$ & & \\
\hline Não & 25 & 53,2 & 15 & 45,4 & 40 & 50,0 & 0,496 & $Q$ \\
\hline Sim & 22 & 46,8 & 18 & 54,6 & 40 & 50,0 & & \\
\hline
\end{tabular}

Com relação ao entendimento da informação contida no termo de consentimento, observa-se na Tabela 8 que $53,2 \%$ dos sujeitos do grupo I e $45,4 \%$ do grupo II não entenderam o conteúdo que leram ou as informações que Ihes foram dadas por quem aplicou o TCLE, totalizando $50,0 \%$ da amostra. Verifica-se que não há diferença estatisticamente significante entre os grupos com relação a esta variável.

Tabela 9. Menção de como procederam aqueles que não entenderam o conteúdo do TCLE.

\begin{tabular}{|c|c|c|c|c|c|c|c|c|}
\hline \multirow{3}{*}{$\begin{array}{l}\text { Quando não } \\
\text { entendeu o } \\
\text { TCLE }\end{array}$} & \multicolumn{4}{|c|}{ Grupo } & & & \multirow{3}{*}{$\mathbf{p}$} & \multirow{3}{*}{ Teste* } \\
\hline & \multicolumn{2}{|c|}{ I } & \multicolumn{2}{|c|}{ II } & \multicolumn{2}{|c|}{ Total } & & \\
\hline & $\mathrm{n}$ & $\%$ & $\mathbf{n}$ & $\%$ & $\mathbf{n}$ & $\%$ & & \\
\hline $\begin{array}{l}\text { Assinou } \\
\text { mesmo sem } \\
\text { entender }\end{array}$ & 24 & 96,0 & 15 & 100,0 & 39 & 97,5 & 1,000 & $\mathrm{~F}$ \\
\hline Outro & 1 & 4,0 & 0 & 0,0 & 1 & 2,5 & & \\
\hline
\end{tabular}

${ }^{{ }^{\mathrm{F}} \mathrm{F}=\text { Teste exato de Fisher }}$

Pode-se observar na Tabela 9 que 39 sujeitos $(97,5 \%)$, mesmo não entendendo o conteúdo da informação contida no TCLE, assinaram o documento. 
Tabela 10. Distribuição da amostra estudada segundo informação se recebeu uma cópia do TCLE.

\begin{tabular}{|c|c|c|c|c|c|c|c|c|}
\hline \multirow{3}{*}{$\begin{array}{l}\text { Cópia do } \\
\text { TCLE? }\end{array}$} & \multicolumn{4}{|c|}{ Grupo } & \multirow{2}{*}{\multicolumn{2}{|c|}{ Total }} & \multirow{3}{*}{$\mathbf{p}$} & \multirow{3}{*}{ Teste } \\
\hline & \multicolumn{2}{|c|}{ I } & \multicolumn{2}{|c|}{ II } & & & & \\
\hline & $\mathbf{n}$ & $\%$ & $n$ & $\%$ & $\mathbf{n}$ & $\%$ & & \\
\hline Não & 1 & 2,1 & 1 & 3,0 & 2 & 2,5 & 1,000 & $\mathrm{~F}$ \\
\hline Sim & 46 & 97,9 & 32 & 97,0 & 78 & 97,5 & & \\
\hline
\end{tabular}

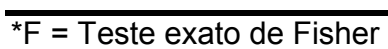

Quanto à informação sobre se recebeu uma cópia do TCLE, nota-se na Tabela 10 que apenas $2,5 \%$ dos sujeitos informaram não ter recebido cópia do TCLE.

Tabela 11. Entendimento dos entrevistados a respeito do significado do termo placebo.

\begin{tabular}{|c|c|c|c|c|c|c|c|c|}
\hline \multirow{3}{*}{$\begin{array}{c}\text { Houve } \\
\text { entendimento do } \\
\text { significado do } \\
\text { termo plabebo? }\end{array}$} & \multicolumn{4}{|c|}{ Grupo } & & & \multirow{3}{*}{ p } & \multirow{3}{*}{ Teste } \\
\hline & \multicolumn{2}{|c|}{ I } & \multicolumn{2}{|c|}{ II } & \multicolumn{2}{|c|}{ Total } & & \\
\hline & $\mathbf{n}$ & $\%$ & $\mathbf{n}$ & $\%$ & $\mathbf{n}$ & $\%$ & & \\
\hline Não & 30 & 63,8 & 16 & 72,7 & 46 & 66,7 & 0,465 & $Q$ \\
\hline Sim & 17 & 36,2 & 6 & 27,3 & 23 & 33,3 & & \\
\hline
\end{tabular}

${ }^{*} \mathrm{Q}=$ Qui-quadrado

No questionamento aos sujeitos sobre o entendimento do significado do placebo, observa-se na Tabela 11 que quarenta e seis entrevistados $(66,7 \%)$ não entenderam o significado. Chama a atenção o fato de trinta $(63,8 \%)$ pertencerem ao grupo I, ou seja, o grupo controlado por placebo. 
Tabela 12. Distribuição das categorias à pergunta temática a respeito do entendimento do termo placebo, em ambos os grupos.

\begin{tabular}{lcc}
\hline \multicolumn{1}{c}{ Categorias } & $\mathbf{n}$ & $\%$ \\
\hline $\begin{array}{l}\text { Não entendimento do } \\
\text { significado }\end{array}$ & 33 & 47,8 \\
Crenças equivocadas & 13 & 18,8 \\
Entendimento correto & 8 & 11,6 \\
$\begin{array}{l}\text { Não ter lembrança no } \\
\text { momento }\end{array}$ & 9 & 13,0 \\
$\begin{array}{l}\text { Entendimento de acordo com } \\
\text { a informação recebida }\end{array}$ & 6 & 8.7 \\
\hline \hline
\end{tabular}

Quando indagados sobre o que haviam entendido ou não a respeito do significado do placebo, verificou-se que quase a metade confirma o não entendimento do termo $(47,8 \%)$ ou tem crenças equivocadas quanto ao significado $(18,8 \%)$. Com isso, observa-se que o entendimento ficou restrito a apenas $20,3 \%$ dos entrevistados. Nota-se também que $13,0 \%$ dos participantes não apresentavam lembrança da informação no momento da entrevista.

Tabela 13. Distribuição das categorias à pergunta temática relacionada ao entendimento do significado do termo placebo, segundo os grupos.

\begin{tabular}{|c|c|c|c|c|c|c|c|c|}
\hline \multirow{3}{*}{ Categorias } & \multicolumn{4}{|c|}{ Grupo } & & & \multirow{3}{*}{ p } & \multirow{3}{*}{ Teste $^{*}$} \\
\hline & \multicolumn{2}{|c|}{ I } & \multicolumn{2}{|c|}{ II } & \multicolumn{2}{|c|}{ Total } & & \\
\hline & $\mathrm{n}$ & $\%$ & $\mathbf{n}$ & $\%$ & $\mathbf{n}$ & $\%$ & & \\
\hline $\begin{array}{l}\text { Entendimento de } \\
\text { acordo com a } \\
\text { informação recebida }\end{array}$ & 4 & 8,5 & 2 & 9,1 & 6 & 8,7 & 0,924 & V \\
\hline $\begin{array}{l}\text { Entendimento } \\
\text { correto }\end{array}$ & 6 & 12,8 & 2 & 9,1 & 8 & 11,6 & & \\
\hline $\begin{array}{l}\text { Crenças } \\
\text { equivocadas }\end{array}$ & 9 & 19,1 & 4 & 18,2 & 13 & 18,8 & & \\
\hline $\begin{array}{l}\text { Não entendimento } \\
\text { do significado }\end{array}$ & 21 & 44,7 & 12 & 54,5 & 33 & 47,8 & & \\
\hline $\begin{array}{l}\text { Não ter lembrança } \\
\text { no momento }\end{array}$ & 7 & 14,9 & 2 & 9,1 & 9 & 13,0 & & \\
\hline
\end{tabular}


Com o propósito de analisar se existiam diferenças entre os grupos com relação às categorias mais freqüentes relacionadas ao significado do placebo, foram comparadas as proporções obtidas em cada grupo.

Embora os grupos analisados não apresentem diferenças significativas, observa-se na Tabela 13 que $47,8 \%$ dos sujeitos não entenderam o significado do placebo, sendo $44,7 \%$ do grupo I e $54,6 \%$ do grupo II. Apenas 11,6\% dos sujeitos entenderam corretamente a informação, $12,8 \%$ do grupo I e $9,1 \%$ do grupo II. As crenças equivocadas ou mitos a respeito do tema representam $18,8 \%$, com percentuais muito semelhantes em ambos os grupos.

Tabela 14. Distribuição das categorias à pergunta temática relacionada ao significado do termo placebo, segundo as respostas afirmativas em ambos os grupos.

\begin{tabular}{lcc}
\hline \hline \multicolumn{1}{c}{ Temáticas } & $\mathbf{n}$ & $\%$ \\
\hline Entendimento de acordo com a informação recebida & 5 & 21,7 \\
Entendimento correto & 7 & 30,4 \\
Crenças equivocadas & 10 & 43,5 \\
Não ter lembrança no momento & 1 & 4,3 \\
\hline \hline
\end{tabular}

Observa-se na Tabela 14 que apenas 23 sujeitos afirmaram ter entendido o significado do termo placebo, e destes somente doze $(52,2 \%)$ de fato externaram o entendimento correto. As crenças equivocadas com relação ao entendimento $(43,5 \%)$ demonstram que, apesar da resposta afirmativa, a compreensão foi incorreta, e 4,3\% não se lembravam no momento apesar da resposta afirmativa. 
Tabela 15. Distribuição das categorias à pergunta temática relacionada ao significado do termo placebo, segundo as respostas negativas.

\begin{tabular}{lcc}
\hline \hline \multicolumn{1}{c}{ Categorias } & $\mathbf{n}$ & $\%$ \\
\hline Entendimento de acordo com a informação recebida & 1 & 2,2 \\
Entendimento correto & 1 & 2,2 \\
Crenças equivocadas & 3 & 6,5 \\
Não entendimento do significado & 33 & 71,7 \\
Não ter lembrança no momento & 8 & 17,4 \\
\hline \hline
\end{tabular}

Ainda com relação ao entendimento do significado do placebo referente às respostas negativas, observa-se na Tabela 15 que $71,7 \%$ dos participantes de fato não entenderam o significado do termo. Além disso, $17,4 \%$ não se lembravam dessa informação no momento da entrevista, $6,5 \%$ apresentam crenças equivocadas e uma minoria, apesar da resposta negativa, entendeu corretamente o significado $(2,2 \%)$.

Tabela 16. Freqüência dos entrevistados que afirmaram ter conhecimento de que poderiam tomar um comprimido sem nenhum efeito durante alguns meses.

\begin{tabular}{cccccc}
\hline \hline $\begin{array}{c}\text { Conhecimento de que poderia tomar } \\
\text { um comprimido sem efeito durante }\end{array}$ & \multicolumn{2}{c}{ Grupo I } & & \multicolumn{2}{c}{ Total } \\
\cline { 2 - 4 } alguns meses & $\mathbf{n}$ & $\%$ & & $\mathbf{n}$ & $\%$ \\
\hline Não & 17 & 36,2 & 17 & 36,2 \\
Sim & 30 & 63,8 & 30 & 63,8 \\
\hline \hline
\end{tabular}

A Tabela 16 evidencia que, dos quarenta e sete sujeitos que participaram de estudos controlados por placebo do grupo I, dezessete $(36,2 \%)$ não tinham conhecimento que poderiam tomar um comprimido sem nenhum efeito durante o período do estudo. 


\subsection{Dados sobre o impacto da participação na pesquisa}

Com relação ao impacto de participar de uma pesquisa clínica, pode-se observar na Tabela 17 que sessenta e cinco sujeitos (81,2\%) participariam de uma pesquisa semelhante. Verifica-se também que a recusa foi maior entre os sujeitos que participaram de pesquisa do grupo I $(23,4 \%)$, provavelmente pelo perfil dos estudos e exames envolvidos na realização da pesquisa.

Tabela 17. Relato dos entrevistados a respeito da participação em uma pesquisa semelhante, caso fosse convidado.

\begin{tabular}{|c|c|c|c|c|c|c|c|c|}
\hline \multirow{3}{*}{$\begin{array}{l}\text { Participaria de } \\
\text { pesquisa } \\
\text { semelhante? }\end{array}$} & \multicolumn{4}{|c|}{ Grupo } & & & \multirow{3}{*}{ p } & \multirow{3}{*}{ Teste* } \\
\hline & \multicolumn{2}{|c|}{ I } & \multicolumn{2}{|c|}{ II } & \multicolumn{2}{|c|}{ Total } & & \\
\hline & $\mathrm{n}$ & $\%$ & $\mathbf{n}$ & $\%$ & $\mathbf{n}$ & $\%$ & & \\
\hline Não & 11 & 23,4 & 4 & 12,1 & 15 & 18,8 & 0,203 & $Q$ \\
\hline Sim & 36 & 76,6 & 29 & 87,9 & 65 & 81,2 & & \\
\hline
\end{tabular}

Tabela 18. Distribuição dos sujeitos, quanto a se pensou em abandonar a pesquisa.

\begin{tabular}{|c|c|c|c|c|c|c|c|c|}
\hline \multirow{3}{*}{$\begin{array}{c}\text { Pensou em } \\
\text { abandonar a } \\
\text { pesquisa? }\end{array}$} & \multicolumn{4}{|c|}{ Grupo } & & & \multirow{3}{*}{$p$} & \multirow{3}{*}{ Teste* } \\
\hline & \multicolumn{2}{|c|}{ I } & \multicolumn{2}{|c|}{ II } & \multicolumn{2}{|c|}{ Total } & & \\
\hline & $n$ & $\%$ & $n$ & $\%$ & $n$ & $\%$ & & \\
\hline Não & 42 & 89,4 & 29 & 87,9 & 71 & 88,8 & 1,000 & $F$ \\
\hline Sim & 5 & 10,6 & 4 & 12,1 & 9 & 11,2 & & \\
\hline
\end{tabular}

${ }^{*} \mathrm{~F}=$ Teste exato de Fisher

Embora a grande maioria não tenha externado o pensamento de abandonar a pesquisa (Tabela 18$)$, nove pacientes $(11,2 \%)$ relataram a ocorrência, apesar de não terem comunicado o pesquisador. 
Tabela 19. Motivos que levaram os entrevistados a pensar em abandonar a pesquisa.

\begin{tabular}{|c|c|c|c|c|c|c|}
\hline \multirow{3}{*}{ Motivos } & \multicolumn{4}{|c|}{ Grupo } & \multirow{2}{*}{\multicolumn{2}{|c|}{ Total }} \\
\hline & \multicolumn{2}{|c|}{ I } & \multicolumn{2}{|c|}{ II } & & \\
\hline & $\mathbf{n}$ & $\%$ & $\mathrm{n}$ & $\%$ & $\mathrm{n}$ & $\%$ \\
\hline $\begin{array}{l}\text { Sentimento de fragilidade } \\
\text { no momento }\end{array}$ & 1 & 2,1 & & & 1 & 1,2 \\
\hline Consultas mais freqüentes & & & 2 & 6,0 & 2 & 2,5 \\
\hline $\begin{array}{l}\text { Risco na realização dos } \\
\text { exames da pesquisa }\end{array}$ & 3 & 6,4 & & & 3 & 3,8 \\
\hline $\begin{array}{l}\text { Efeitos colaterais da } \\
\text { medicação do estudo }\end{array}$ & & & 1 & 3,0 & 1 & 1,2 \\
\hline $\begin{array}{l}\text { Não ter a melhora de } \\
\text { saúde esperada }\end{array}$ & 1 & 2,1 & 1 & 3,0 & 2 & 2,5 \\
\hline
\end{tabular}

Neste estudo houve preocupação em saber o motivo que levou os entrevistados a pensarem em abandonar a pesquisa. Na Tabela 19 observa-se que o risco envolvido na realização de alguns exames do protocolo foi mencionado por três sujeitos $(6,4 \%)$ do grupo I. Já com relação ao grupo II, o principal motivo foi atribuído à freqüência das consultas $(6,0 \%)$.

Tabela 20. Distribuição da amostra estudada segundo o motivo pelo qual não informou que gostaria de desistir da pesquisa.

\begin{tabular}{|c|c|c|c|c|c|c|}
\hline \multirow{3}{*}{ Motivos } & \multicolumn{4}{|c|}{ Grupo } & & \\
\hline & \multicolumn{2}{|c|}{ I } & \multicolumn{2}{|c|}{ II } & \multicolumn{2}{|c|}{ Total } \\
\hline & $\mathbf{n}$ & $\%$ & $\mathbf{n}$ & $\%$ & $\mathbf{n}$ & $\%$ \\
\hline $\begin{array}{l}\text { Tentativa de encontrar } \\
\text { algum tratamento que } \\
\text { melhorasse seu problema } \\
\text { do coração }\end{array}$ & 1 & 2,1 & 1 & 3,0 & 2 & 2,5 \\
\hline Finalizar a pesquisa & 1 & 2,1 & & & 1 & 1,2 \\
\hline $\begin{array}{l}\text { Medo de não controlar a } \\
\text { doença }\end{array}$ & & & 1 & 3,0 & 1 & 1,2 \\
\hline $\begin{array}{l}\text { Medo de ser desligado do } \\
\text { serviço }\end{array}$ & 2 & 4,2 & 2 & 6,0 & 4 & 5,0 \\
\hline $\begin{array}{l}\text { Por que o médico lhe } \\
\text { disse que o que estava } \\
\text { sentindo era por } \\
\text { problemas particulares }\end{array}$ & 1 & 2,1 & & & 1 & 1,2 \\
\hline
\end{tabular}


Verifica-se na Tabela 20 que $5,0 \%$ dos participantes que responderam essa questão explicaram a não desistência da pesquisa em virtude do medo de serem desligados da instituição. Por outro lado, observase que a tentativa de encontrar algum tratamento que melhorasse seu problema do coração fez com que os sujeitos continuassem na pesquisa, apesar da insatisfação (2,5\%). Neste contexto, também fica evidente a opinião médica neste momento de decisão $(1,2 \%)$.

Tabela 21. Distribuição dos entrevistados, segundo a importância atribuída em participar de uma pesquisa.

\begin{tabular}{|c|c|c|c|c|c|c|c|c|}
\hline \multirow{3}{*}{$\begin{array}{l}\text { Foi importante } \\
\text { participar de } \\
\text { uma pesquisa? }\end{array}$} & \multicolumn{4}{|c|}{ Grupo } & \multirow{2}{*}{\multicolumn{2}{|c|}{ Total }} & \multirow{3}{*}{ p } & \multirow{3}{*}{ Teste* } \\
\hline & \multicolumn{2}{|c|}{ I } & \multicolumn{2}{|c|}{ II } & & & & \\
\hline & $\mathbf{n}$ & $\%$ & $\mathbf{n}$ & $\%$ & $\mathrm{n}$ & $\%$ & & \\
\hline Não & 2 & 4,3 & 0 & 0,0 & 2 & 2,5 & 0,509 & $\mathrm{~F}$ \\
\hline Sim & 45 & 95,7 & 33 & 100 & 78 & 97,5 & & \\
\hline
\end{tabular}

${ }^{\star} \mathrm{F}=$ Teste exato de Fisher

Com relação à importância atribuída em participar de uma pesquisa, verifica-se, na Tabela 21 , que setenta e oito sujeitos $(97,5 \%)$ acharam importante a participação na pesquisa. Nota-se também que apenas dois (2,5\%) não atribuíram a isto nenhuma importância. 
Tabela 22. Distribuição das categorias à pergunta temática relacionadas à importância em participar de uma pesquisa.

\begin{tabular}{lcc}
\hline \hline \multicolumn{1}{c}{ Categorias } & $\mathbf{n}$ & $\%$ \\
\hline Em benefício próprio & 30 & 37,5 \\
Para o bem da ciência & 27 & 33,8 \\
Atenção médica diferenciada & 23 & 28,8 \\
Adequação do tratamento após participar da pesquisa & 10 & 12,5 \\
Conscientização da doença e tratamento após participar da & 7 & 8,8 \\
pesquisa & & \\
Atendimento diferenciado durante a pesquisa & 6 & 7,5 \\
Relação cambial & 5 & 6,3 \\
Outros & 11 & 13,4 \\
\hline \hline
\end{tabular}

NOTA: Os resultados somam mais de $100 \%$ em virtude de se identificar mais de uma categoria, nas respostas, para esta questão.

Quando se questionou os sujeitos a respeito da importância atribuída à participação na pesquisa (Tabela 22), 37,5\% mencionaram o benefício pessoal como principal motivo. A seguir, sobressaíram os aspectos relativos ao bem da ciência $(33,8 \%)$ e a atenção médica diferenciada recebida $(28,8 \%)$. Na fala dos entrevistados identificou-se também os significados atribuídos à adequação ao tratamento (12,5\%) e conscientização da doença após a participação na pesquisa $(8,8 \%)$. O atendimento diferenciado foi externado por $7,5 \%$ dos participantes como um dos fatores que contribuíram para a valorização. Os outros motivos, descritos a seguir, representam $13,8 \%$. 
Tabela 23. Distribuição das categorias mais freqüentes relacionadas à importância em participar de uma pesquisa clínica, segundo os grupos.

\begin{tabular}{|c|c|c|c|c|c|c|c|c|}
\hline \multirow{3}{*}{ Categorias } & \multicolumn{4}{|c|}{ Grupo } & & & \multirow{3}{*}{$\mathbf{p}$} & \multirow{3}{*}{ Teste* } \\
\hline & \multicolumn{2}{|c|}{ I } & \multicolumn{2}{|c|}{ II } & \multicolumn{2}{|c|}{ Total } & & \\
\hline & $\mathbf{n}$ & $\%$ & $\mathbf{n}$ & $\%$ & $\mathbf{n}$ & $\%$ & & \\
\hline \multicolumn{9}{|c|}{ Para o bem da ciência } \\
\hline Não & 33 & 70,2 & 20 & 60,6 & 53 & 66,2 & 0,371 & Q \\
\hline Sim & 14 & 29,8 & 13 & 39,4 & 27 & 33,8 & & \\
\hline \multicolumn{9}{|c|}{ Em benefício próprio } \\
\hline Não & 32 & 68,1 & 18 & 54,6 & 50 & 62,5 & 0,218 & Q \\
\hline $\operatorname{Sim}$ & 15 & 31,9 & 15 & 45,4 & 30 & 37,5 & & \\
\hline \multicolumn{9}{|l|}{$\begin{array}{l}\text { Atenção médica } \\
\text { diferenciada }\end{array}$} \\
\hline Não & 34 & 72,3 & 23 & 69,7 & 57 & 71,2 & 0,797 & Q \\
\hline Sim & 13 & 27,7 & 10 & 30,3 & 23 & 28,8 & & \\
\hline \multicolumn{9}{|c|}{$\begin{array}{c}\text { Adequação ao } \\
\text { tratamento após } \\
\text { participar da pesquisa }\end{array}$} \\
\hline Não & 39 & 83,0 & 31 & 93,9 & 70 & 87,5 & 0,184 & $\mathrm{~F}$ \\
\hline Sim & 8 & 17,0 & 2 & 6,1 & 10 & 12,5 & & \\
\hline
\end{tabular}

Com o propósito de analisar se existiam diferenças entre os grupos com relação às categorias mais freqüentes relacionadas à importância em participar de uma pesquisa, foram comparadas as proporções obtidas em cada grupo.

Verifica-se na Tabela 23 que os grupos analisados tampouco diferiram no que concerne à importância atribuída em participar de uma pesquisa.

No que tange às categorias, trinta sujeitos (37\%) atribuíram a importância da participação em benefício próprio, sendo $32 \%$ do grupo I e $45,4 \%$ do grupo 2. "Para o bem da ciência" foi motivo relatado por vinte e sete entrevistados $(33,8 \%)$ com proporções praticamente iguais entre os dois grupos. Em relação à atenção médica $(28,8 \%)$, foi mais abordada pelos 
participantes do grupo I (27,7\%). Identificou-se, também, aspectos valorizados e inerentes à adequação ao tratamento após participar da pesquisa $(12,5 \%)$, principalmente pelos sujeitos do grupo I.

Tabela 24. Distribuição das categorias à pergunta temática relacionada à importância na participação em uma pesquisa, segundo as respostas afirmativas e negativas em ambos os grupos.

\begin{tabular}{|c|c|c|c|c|c|c|}
\hline \multirow{17}{*}{ 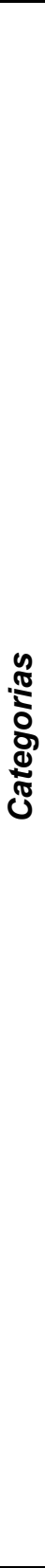 } & Sim & $\mathbf{n}$ & $\%$ & Não & $\mathbf{n}$ & $\%$ \\
\hline & Em benefício próprio & 30 & 37,5 & Outros & & \\
\hline & Para o bem da ciência & 27 & 33,8 & $\begin{array}{l}\text { Não entendimento da } \\
\text { participação no } \\
\text { estudo }\end{array}$ & 1 & 1,2 \\
\hline & $\begin{array}{l}\text { Atenção médica } \\
\text { diferenciada }\end{array}$ & 23 & 28,8 & & & \\
\hline & $\begin{array}{l}\text { Adequação do tratamento } \\
\text { após participar da pesquisa }\end{array}$ & 10 & 12,5 & & & \\
\hline & $\begin{array}{l}\text { Conscientização da doença } \\
\text { e tratamento após } \\
\text { participar da pesquisa }\end{array}$ & 7 & 8,8 & & & \\
\hline & $\begin{array}{l}\text { Atendimento diferenciado } \\
\text { durante a pesquisa }\end{array}$ & 6 & 7,5 & & & \\
\hline & Relação cambial & 5 & 6,3 & & & \\
\hline & Outros & 10 & 12,5 & & & \\
\hline & $\begin{array}{l}\text { Sofrimento durante a } \\
\text { realização dos exames da } \\
\text { pesquisa }\end{array}$ & 2 & 2,5 & & & \\
\hline & Experiência de vida & 2 & 2,5 & & & \\
\hline & $\begin{array}{l}\text { Oportunidade de } \\
\text { aprendizado }\end{array}$ & 1 & 1,2 & & & \\
\hline & $\begin{array}{l}\text { Conhecimento de outra } \\
\text { função do hospital } \\
\text { (pesquisa) }\end{array}$ & 1 & 1,2 & & & \\
\hline & $\begin{array}{l}\text { Validação do seu estado de } \\
\text { saúde }\end{array}$ & 1 & 1,2 & & & \\
\hline & $\begin{array}{l}\text { Insatisfação com a } \\
\text { pesquisa }\end{array}$ & 1 & 1,2 & & & \\
\hline & $\begin{array}{l}\text { Sofrimento com os efeitos } \\
\text { colaterais da medicação } \\
\text { testada }\end{array}$ & 1 & 1,2 & & & \\
\hline & Indiferença & 1 & 1,2 & & & \\
\hline
\end{tabular}

NOTA: Os resultados somam mais de $100 \%$ em virtude de se identificar mais de uma categoria, nas respostas, para esta questão. 
Ao dar oportunidade aos sujeitos para que relatassem porque a participação na pesquisa foi importante ou não em sua vida, verifica-se na Tabela 24 que dentre os que responderam afirmativamente, $37,5 \%$ atribuíram ser em benefício próprio.

Além disso, destacam-se os relatos direcionados ao bem da ciência $(33,8 \%)$ e à sua própria adequação do tratamento após participar da pesquisa $(12,5 \%)$. Neste contexto também vem à baila a relação cambial existente na participação da pesquisa $(6,2 \%)$, demonstrando que os sujeitos atrelam o valor de troca pela participação, ou seja, enxergam uma permuta. Cabe salientar que apesar da resposta afirmativa foram identificados aspectos inerentes à insatisfação com a pesquisa $(1,2 \%)$ e sofrimento com os efeitos colaterais da medicação em teste $(1,2 \%)$.

Embora apenas um sujeito $(1,2 \%)$ não tenha atribuído nenhuma importância, fica evidenciada que a sua participação na pesquisa foi equivocada e não compreendida (conforme descrição de sua fala na seção 4.7.2)

Tabela 25. Posição a respeito de convidar um amigou ou parente para participar de uma pesquisa.

\begin{tabular}{|c|c|c|c|c|c|c|c|c|}
\hline \multirow{3}{*}{ Convite } & \multicolumn{4}{|c|}{ Grupo } & & & \multirow{3}{*}{$\mathbf{p}$} & \multirow{3}{*}{ Teste* } \\
\hline & \multicolumn{2}{|c|}{ I } & \multicolumn{2}{|c|}{ II } & \multicolumn{2}{|c|}{ Total } & & \\
\hline & $\mathbf{n}$ & $\%$ & $\mathbf{n}$ & $\%$ & $\mathbf{n}$ & $\%$ & & \\
\hline Não & 1 & 2,2 & 1 & 3,0 & 2 & 2,6 & 1,000 & $\mathrm{~F}$ \\
\hline Sim & 46 & 97,8 & 32 & 97 & 76 & 97,4 & & \\
\hline
\end{tabular}

${ }^{\star} \mathrm{F}=$ Teste exato de Fisher

No que concerne ao convite a outra pessoa para participar de uma pesquisa, pode se observar, na Tabela 25 , que $97,4 \%$ dos entrevistados 
indicaria um amigo ou parente. Apenas dois (2,6\%), um de cada grupo, não fariam o convite.

Tabela 26. Distribuição das categorias à pergunta temática no que se refere à indicação de um amigo ou parente para participar de uma pesquisa.

\begin{tabular}{lcc}
\hline \multicolumn{1}{c}{ Categorias } & $\mathbf{n}$ & \% \\
\hline Em benefício próprio do outro & 27 & 33,8 \\
Para o bem da ciência & 20 & 25,0 \\
Atenção médica & 17 & 21,2 \\
Atendimento diferenciado & 9 & 11,2 \\
Relação cambial & 4 & 5,0 \\
Oportunidade de aprendizado & 4 & 5,0 \\
Reconhecimento dos riscos em participar de uma & 3 & 3,8 \\
pesquisa & & \\
Percepção de ser cobaia & 3 & 3,8 \\
Outros & 9 & 11,2 \\
\hline \hline
\end{tabular}

NOTA: Os resultados somam mais de $100 \%$ em virtude de se identificar mais de uma categoria, nas respostas, para esta questão.

Quando indagados porque convidariam um amigo ou parente para participar da pesquisa, verifica-se na Tabela 26 que o principal motivo foi atribuído em benefício próprio do outro $(33,8 \%)$. 
Tabela 27. Distribuição das categorias à pergunta temática no que se refere à indicação de um amigo ou parente para participar de uma pesquisa, segundo os grupos.

\begin{tabular}{|c|c|c|c|c|c|c|c|c|}
\hline \multirow{3}{*}{ Categorias } & \multicolumn{4}{|c|}{ Grupo } & & & \multirow{3}{*}{ p } & \multirow{3}{*}{ Teste $^{*}$} \\
\hline & \multicolumn{2}{|c|}{$I$} & \multicolumn{2}{|c|}{ II } & \multicolumn{2}{|c|}{ Total } & & \\
\hline & $\mathbf{n}$ & $\%$ & $\mathbf{n}$ & $\%$ & $\mathbf{n}$ & $\%$ & & \\
\hline \multicolumn{9}{|c|}{$\begin{array}{l}\text { Para o bem da } \\
\text { ciência }\end{array}$} \\
\hline Não & 36 & 76,6 & 24 & 72,7 & 60 & 75,0 & 0,694 & $\mathrm{Q}$ \\
\hline Sim & 11 & 23,4 & 9 & 27,3 & 20 & 25,0 & & \\
\hline \multicolumn{9}{|c|}{$\begin{array}{l}\text { Em benefício } \\
\text { próprio do outro }\end{array}$} \\
\hline Não & 32 & 68,1 & 21 & 63,6 & 53 & 66,2 & 0,679 & $\mathrm{Q}$ \\
\hline Sim & 15 & 31,9 & 12 & 36,4 & 27 & 33,8 & & \\
\hline \multicolumn{9}{|c|}{$\begin{array}{l}\text { Atenção médica } \\
\text { diferenciada }\end{array}$} \\
\hline Não & 37 & 78,7 & 26 & 78,8 & 63 & 78,8 & 0,994 & Q \\
\hline Sim & 10 & 21,3 & 7 & 21,2 & 17 & 21,2 & & \\
\hline
\end{tabular}

Com o propósito de analisar se existiam diferenças entre os grupos com relação às temáticas mais freqüentes relacionadas à indicação de um amigo ou parente para participar de uma pesquisa, foram comparadas as proporções obtidas em cada grupo.

Embora os grupos analisados não apresentem diferenças significativas, observa-se na Tabela 27 que a proporção de entrevistados do grupo 2 que indicaria para benefício próprio do outro $(36,4 \%)$ foi superior a do grupo $1(31,9 \%)$. Pouca diferença pode ser observada entre os grupos com relação ao bem da ciência.

Verifica-se também que os significados atribuídos à atenção médica foram semelhantes em ambos os grupos $(21,2 \%)$. 
Tabela 28. Distribuição das categorias à pergunta temática no que se refere à indicação de um amigo ou parente para participar de uma pesquisa, segundo as respostas afirmativas e negativas em ambos os grupos.

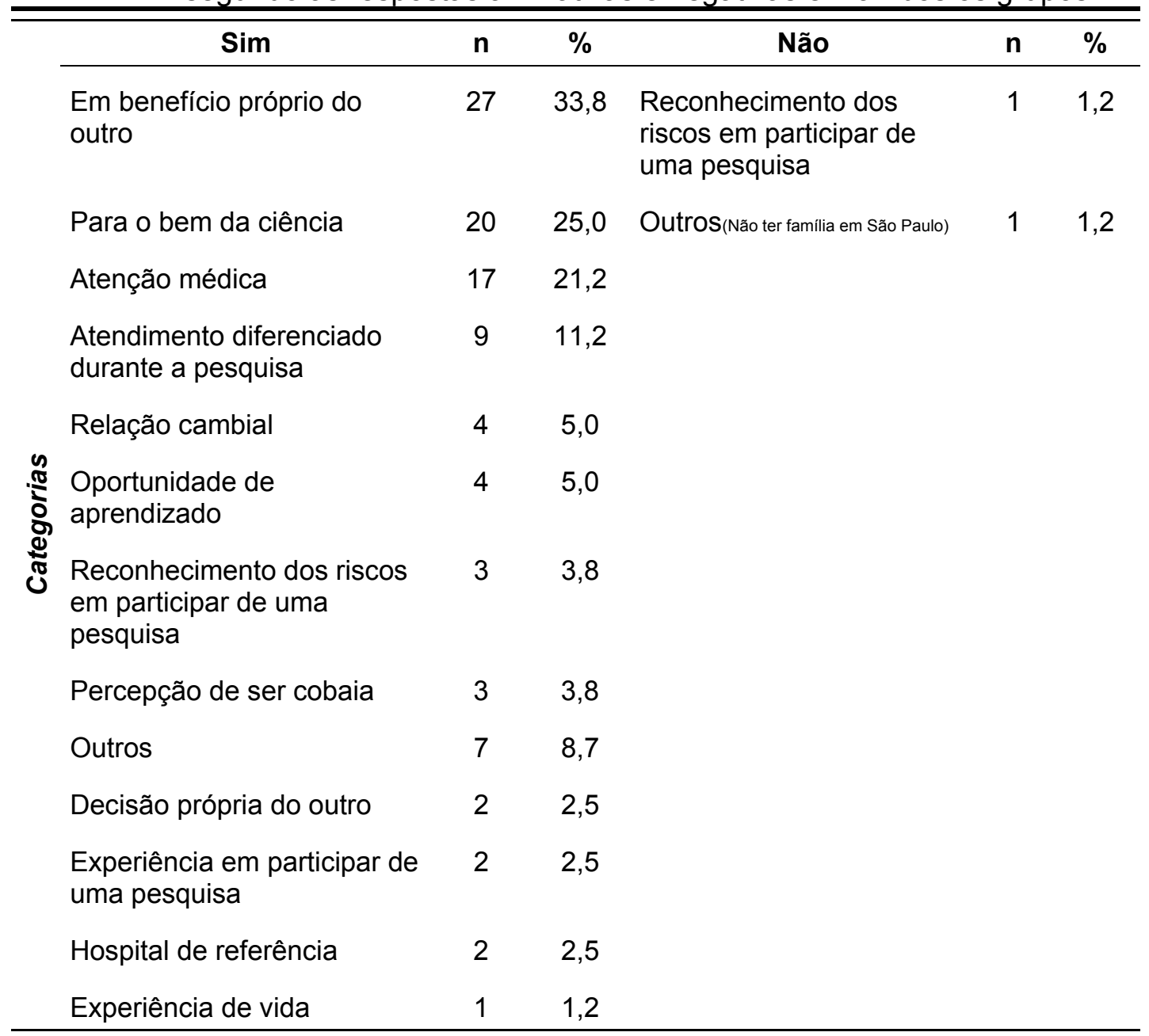

NOTA: Os resultados somam mais de 100\% em virtude de se identificar mais de uma categoria, nas respostas, para esta questão.

Ao serem abordados a respeito de convidar ou não um amigo para participar da pesquisa, nota-se na Tabela 28 que 33,8\% dos entrevistados realizariam o convite em benefício próprio do outro. Nos depoimentos também são identificados aspectos valorizando a contribuição em benefício da ciência por vinte participantes (25,0\%). Chama atenção o fato de que, embora mencionado por apenas três sujeitos $(3,8 \%)$, ainda se tem a percepção de cobaia com a pesquisa. 


\subsection{Associação entre as questões e as variáveis quantitativas e classificatórias}

Conforme descrito previamente, foi realizado neste estudo a associação de algumas questões consideradas relevantes para ambos os grupos. Para tanto, selecionaram-se algumas variáveis de interesse para o estudo, incluindo sexo, idade, escolaridade, presença de companheiro, ocupação, tempo de seguimento na instituição e participação até o final do estudo. 
Tabela 29. Distribuição da idade, sexo, escolaridade, companheiro e atividade profissional segundo leitura do TCLE antes da assinatura.

\begin{tabular}{|c|c|c|c|c|c|c|c|c|}
\hline \multirow{3}{*}{ Variável } & \multicolumn{4}{|c|}{$\begin{array}{l}\text { Leu o documento antes de } \\
\text { assinar? }\end{array}$} & & & \multirow{3}{*}{$\mathbf{p}$} & \multirow{3}{*}{ Teste* } \\
\hline & \multicolumn{2}{|c|}{ Não } & \multicolumn{2}{|c|}{ Sim } & \multicolumn{2}{|c|}{ Total } & & \\
\hline & $\mathrm{n}$ & $\%$ & $\mathrm{n}$ & $\%$ & $\mathrm{n}$ & $\%$ & & \\
\hline \multicolumn{9}{|l|}{ Idade } \\
\hline Média & & 59,1 & & 58,5 & & & \multirow{2}{*}{0,802} & \multirow{2}{*}{$\mathrm{T}$} \\
\hline DP & & $\pm 10,7$ & & $\pm 8,7$ & & & & \\
\hline \multicolumn{9}{|l|}{ Sexo } \\
\hline $\mathrm{F}$ & 7 & 26,9 & 12 & 22,6 & 19 & 24,0 & 0,676 & $Q$ \\
\hline M & 19 & 73,1 & 41 & 77,3 & 60 & 76 & & \\
\hline \multicolumn{9}{|l|}{ Escolaridade } \\
\hline $\begin{array}{l}\text { Analfabeto / } \\
\text { Fundamental incompleto }\end{array}$ & 16 & 61,5 & 34 & 64,2 & 50 & 63,3 & 0,679 & V \\
\hline $\begin{array}{l}\text { Fundamental completo / } \\
\text { Médio incompleto }\end{array}$ & 2 & 7,7 & 7 & 13,2 & 9 & 11,4 & & \\
\hline $\begin{array}{l}\text { Médio completo / } \\
\text { Superior incompleto }\end{array}$ & 4 & 15,4 & 8 & 15,1 & 12 & 15,2 & & \\
\hline Superior completo & 4 & 15,4 & 4 & 7,6 & 8 & 10,1 & & \\
\hline \multicolumn{9}{|l|}{ Companheiro } \\
\hline Sim & 24 & 92,3 & 39 & 73,6 & 63 & 79,8 & 0,052 & Q \\
\hline Não & 2 & 7,7 & 14 & 26,4 & 16 & 20,2 & & \\
\hline \multicolumn{9}{|l|}{ Atividade Profissional } \\
\hline $\operatorname{Sim}$ & 15 & 57,7 & 26 & 49,1 & 41 & 51,9 & 0,470 & Q \\
\hline Não & 11 & 42,3 & 27 & 50,9 & 38 & 48,1 & & \\
\hline \multicolumn{9}{|l|}{$\begin{array}{l}\text { Quem convidou para } \\
\text { participar? }\end{array}$} \\
\hline Pesquisador & 14 & 53,8 & 31 & 58,5 & 45 & 57,0 & 0,594 & V \\
\hline Enfermeira & 12 & 46,2 & 21 & 39,6 & 33 & 41,8 & & \\
\hline Outros & 0 & 0,0 & 1 & 1,9 & 1 & 1,3 & & \\
\hline
\end{tabular}

${ }^{*} T$ = Teste $t$ de Student

${ }^{*} \mathrm{Q}=$ Qui-quadrado

${ }^{*} \mathrm{~V}=$ Teste da Razão de Verossimilhança

Nota-se na Tabela 29 que houve tendência negativa na associação entre companheiro e leitura do TCLE antes da assinatura, ou seja, os que tinham companheiro com maior freqüência não leram o documento antes de assiná-lo, conforme ilustrado a seguir na Figura 7. Já com relação às demais variáveis analisadas não houve diferença significante. 


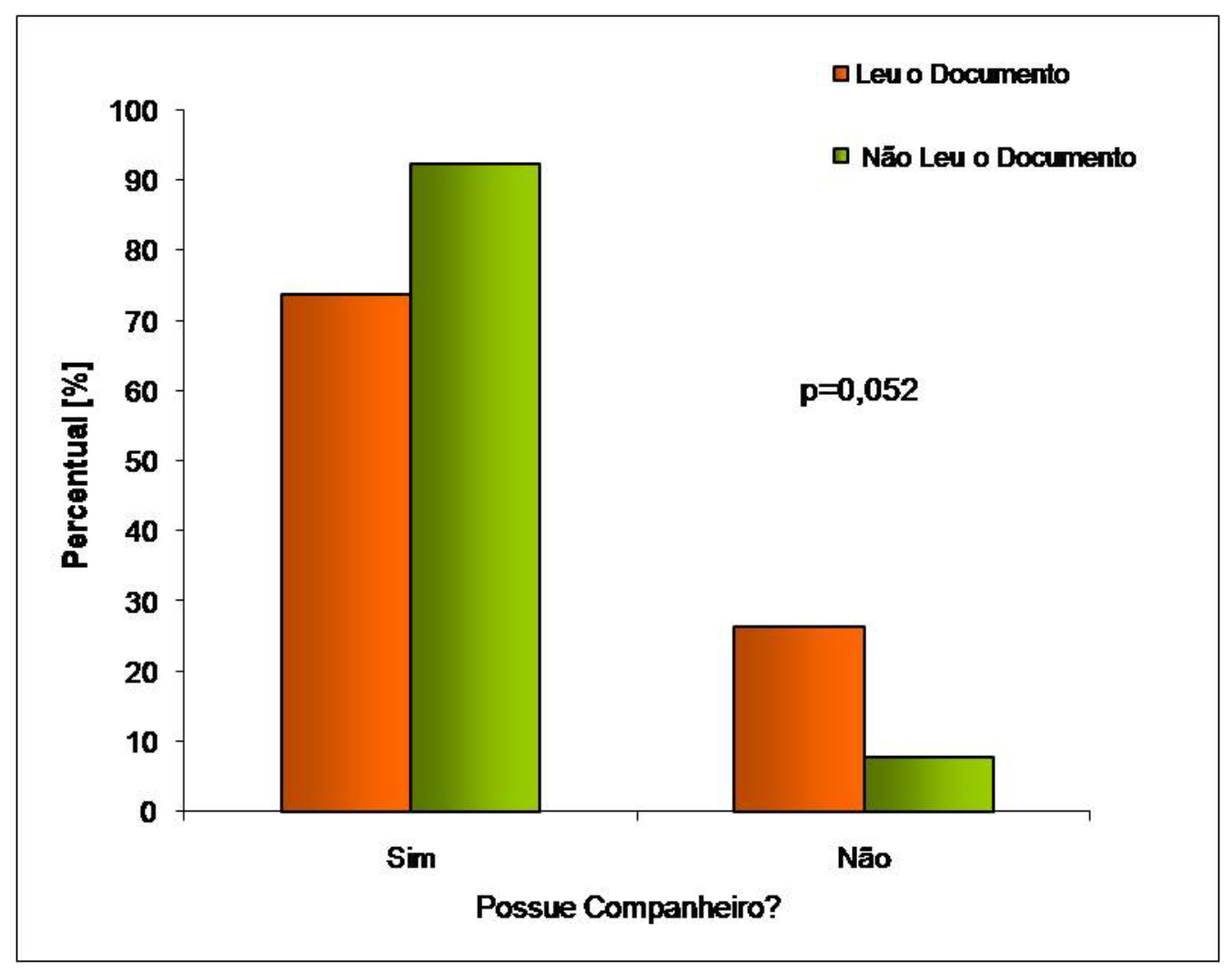

Figura 7. Associação quanto a terem companheiro e terem realizado a leitura do termo de consentimento livre e esclarecido antes de assinar. 
Tabela 30. Descrição da idade, sexo, escolaridade, companheiro, atividade profissional e participação até o final do estudo, segundo informação a respeito de conversa sobre o TCLE.

\begin{tabular}{|c|c|c|c|c|c|c|c|c|}
\hline \multirow{3}{*}{ Variável } & \multicolumn{4}{|c|}{$\begin{array}{c}\text { Conversou sobre TCLE } \\
\text { com o pesquisador? }\end{array}$} & & & \multirow{3}{*}{ p } & \multirow{3}{*}{ Teste $^{*}$} \\
\hline & \multicolumn{2}{|c|}{ Não } & \multicolumn{2}{|c|}{ Sim } & \multicolumn{2}{|c|}{ Total } & & \\
\hline & $\mathrm{n}$ & $\%$ & $\mathrm{n}$ & $\%$ & $\mathrm{n}$ & $\%$ & & \\
\hline \multicolumn{9}{|l|}{ Idade } \\
\hline Média & & 59,4 & & 57,5 & & & \multirow{2}{*}{0,390} & \multirow{2}{*}{$\mathrm{T}$} \\
\hline DP & & $\pm 9,6$ & & $\pm 8,7$ & & & & \\
\hline \multicolumn{9}{|l|}{ Sexo } \\
\hline $\mathrm{F}$ & 13 & 25,0 & 7 & 25,0 & 20 & 25 & 1,000 & Q \\
\hline M & 39 & 75,0 & 21 & 75,0 & 60 & 75,0 & & \\
\hline \multicolumn{9}{|l|}{ Escolaridade } \\
\hline $\begin{array}{l}\text { Analfabeto / Fundamental } \\
\text { incompleto }\end{array}$ & 36 & 69,2 & 15 & 53,6 & 51 & 63,8 & 0,053 & V \\
\hline $\begin{array}{l}\text { Fundamental completo / } \\
\text { Médio incompleto }\end{array}$ & 3 & 5,8 & 6 & 21,4 & 9 & 11,2 & & \\
\hline $\begin{array}{l}\text { Médio completo / Superior } \\
\text { incompleto }\end{array}$ & 6 & 11,5 & 6 & 21,4 & 12 & 15,0 & & \\
\hline Superior completo & 7 & 13,5 & 1 & 3,6 & 8 & 10,0 & & \\
\hline \multicolumn{9}{|l|}{ Companheiro } \\
\hline Sim & 41 & 78,8 & 23 & 82,1 & 64 & 80,0 & 0,725 & Q \\
\hline Não & 11 & 21,2 & 5 & 17,9 & 16 & 20,0 & & \\
\hline \multicolumn{9}{|l|}{ Atividade profissional } \\
\hline Sim & 26 & 50,0 & 16 & 57,1 & 42 & 52,5 & 0,542 & Q \\
\hline Não & 26 & 50,0 & 12 & 42,9 & 38 & 47,5 & & \\
\hline \multicolumn{9}{|l|}{$\begin{array}{l}\text { Participou até o final do } \\
\text { estudo? }\end{array}$} \\
\hline Não & 2 & 3,8 & 0 & 0,0 & 2 & 2,5 & 0,539 & $\mathrm{~F}$ \\
\hline Sim & 50 & 96,2 & 28 & 100,0 & 78 & 97,5 & & \\
\hline
\end{tabular}

${ }^{*} T=$ Teste $t$ de Student

${ }^{*} \mathrm{Q}=$ Qui-quadrado

*V = Teste da Razão de Verossimilhança

${ }^{*} \mathrm{~F}=$ Teste exato de Fisher

Conforme ilustra a Tabela 30 , verifica-se que houve uma tendência no tocante à escolaridade, demonstrando que quanto menor a escolaridade dos sujeitos menos estes conversaram com o pesquisador a respeito do TCLE (Figura 8). Também não se verifica nenhuma outra associação significante entre as demais variáveis estudadas. 


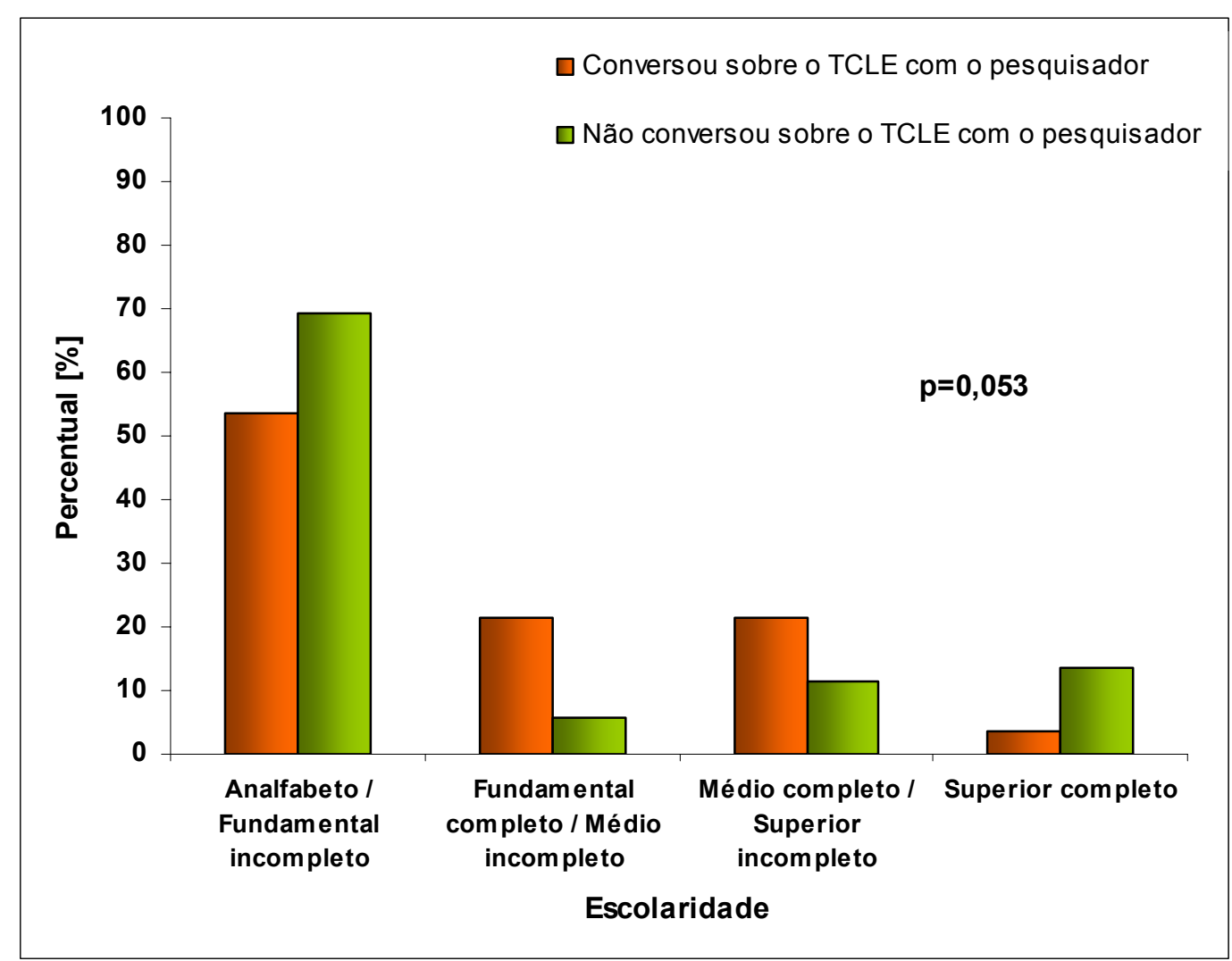

Figura 8. Associação entre o nível de escolaridade dos sujeitos da pesquisa e ter conversado sobre o termo de consentimento livre e esclarecido com o pesquisador. 
Tabela 31.Distribuição da idade, sexo, escolaridade, companheiro, atividade profissional e participação até o final do estudo segundo entendimento do TCLE quando assinou.

\begin{tabular}{|c|c|c|c|c|c|c|c|c|}
\hline \multirow{3}{*}{ Variável } & \multicolumn{4}{|c|}{$\begin{array}{l}\text { Ao assinar estava certo de } \\
\text { ter entendido o que o termo } \\
\text { explicava? }\end{array}$} & & & \multirow{3}{*}{$\mathbf{p}$} & \multirow{3}{*}{ Teste $^{*}$} \\
\hline & \multicolumn{2}{|c|}{ Não } & \multicolumn{2}{|c|}{ Sim } & \multicolumn{2}{|c|}{ Total } & & \\
\hline & $\mathrm{n}$ & $\%$ & $\mathrm{n}$ & $\%$ & $\mathrm{n}$ & $\%$ & & \\
\hline \multicolumn{9}{|l|}{ Idade } \\
\hline Média & & 59,2 & & 58,3 & & & \multirow{2}{*}{0,712} & \multirow{2}{*}{$\mathrm{T}$} \\
\hline DP & & $\pm 10,7$ & & $\pm 7,7$ & & & & \\
\hline \multicolumn{9}{|l|}{ Sexo } \\
\hline $\mathrm{F}$ & 12 & 30,0 & 8 & 20,0 & 20 & 25,0 & 0,302 & Q \\
\hline M & 28 & 70,0 & 32 & 80,0 & 60 & 75,0 & & \\
\hline \multicolumn{9}{|l|}{ Escolaridade } \\
\hline $\begin{array}{l}\text { Analfabeto / Fundamental } \\
\text { incompleto }\end{array}$ & 28 & 70,0 & 23 & 57,5 & 51 & 63,8 & 0,330 & $\mathrm{~V}$ \\
\hline $\begin{array}{l}\text { Fundamental completo / } \\
\text { Médio incompleto }\end{array}$ & 2 & 5,0 & 7 & 17,5 & 9 & 11,2 & & \\
\hline $\begin{array}{l}\text { Médio completo / } \\
\text { Superior incompleto }\end{array}$ & 6 & 15,0 & 6 & 15,0 & 12 & 15,0 & & \\
\hline Superior completo & 4 & 10,0 & 4 & 10,0 & 8 & 10,0 & & \\
\hline \multicolumn{9}{|l|}{ Companheiro } \\
\hline Sim & 35 & 87,5 & 29 & 72,5 & 64 & 80,0 & 0,094 & Q \\
\hline Não & 5 & 12,5 & 11 & 27,5 & 16 & 20,0 & & \\
\hline \multicolumn{9}{|l|}{ Atividade profissional } \\
\hline Sim & 18 & 45,0 & 24 & 60,0 & 42 & 52,5 & 0,179 & Q \\
\hline Não & 22 & 55,0 & 16 & 40,0 & 38 & 47,5 & & \\
\hline \multicolumn{9}{|l|}{$\begin{array}{l}\text { Participou até o final do } \\
\text { estudo? }\end{array}$} \\
\hline Não & 1 & 2,5 & 1 & 2,5 & 2 & 2,5 & 1,000 & $\mathrm{~F}$ \\
\hline Sim & 39 & 97,5 & 39 & 97,5 & 78 & 97,5 & & \\
\hline \multicolumn{9}{|l|}{$\begin{array}{l}\text { Quem convidou para } \\
\text { participar da pesquisa }\end{array}$} \\
\hline Pesquisador & 21 & 52,5 & 24 & 60,0 & 45 & 56,2 & 0,357 & V \\
\hline Enfermeira & 19 & 47,5 & 15 & 37,5 & 34 & 42,5 & & \\
\hline Outros & 0 & 0,0 & 1 & 2,5 & 1 & 1,2 & & \\
\hline
\end{tabular}

${ }^{*} T=$ Teste $t$ de Student

${ }^{*} \mathrm{Q}=$ Qui-quadrado

*V = Teste da Razão de Verossimilhança

${ }^{*} \mathrm{~F}=$ Teste exato de Fisher

Com relação ao entendimento do TCLE no momento da sua assinatura, verifica-se que variáveis correlacionadas na Tabela 31 não diferiram em relação às respostas afirmativas ou negativas. No entanto, 
observa-se que $70,0 \%$ dos sujeitos que não entenderam eram predominantemente homens, de baixo nível de escolaridade (analfabeto/fundamental incompleto) e que foram convidados a participar da pesquisa pelo pesquisador $(52,5 \%)$. 
Tabela 32. Entendimento do significado do termo placebo, segundo idade, sexo, escolaridade, ocupação e informação de quem o convidou para participar da pesquisa.

\begin{tabular}{|c|c|c|c|c|c|c|c|c|}
\hline \multirow{3}{*}{ Variável } & \multicolumn{4}{|c|}{$\begin{array}{c}\text { Entendimento do significado } \\
\text { do placebo }\end{array}$} & & & \multirow{3}{*}{$\mathbf{p}$} & \multirow{3}{*}{ Teste* } \\
\hline & \multicolumn{2}{|c|}{ Não } & \multicolumn{2}{|c|}{ Sim } & \multicolumn{2}{|c|}{ Total } & & \\
\hline & $\mathrm{n}$ & $\%$ & $\mathrm{n}$ & $\%$ & $\mathrm{n}$ & $\%$ & & \\
\hline \multicolumn{9}{|l|}{ Idade } \\
\hline Média & & 59,3 & & 59,0 & & & \multirow{2}{*}{0,920} & \multirow{2}{*}{$\mathrm{T}$} \\
\hline $\mathrm{DP}$ & & $\pm 9,0$ & & $\pm 7,2$ & & & & \\
\hline \multicolumn{9}{|l|}{ Sexo } \\
\hline $\mathrm{F}$ & 12 & 26,1 & 6 & 26,1 & 18 & 26,1 & 1,000 & Q \\
\hline M & 34 & 73,9 & 17 & 73,9 & 51 & 73,9 & & \\
\hline \multicolumn{9}{|l|}{ Escolaridade } \\
\hline $\begin{array}{l}\text { Analfabeto / Fundamental } \\
\text { incompleto }\end{array}$ & 36 & 78,3 & 11 & 47,8 & 47 & 68,1 & 0,022 & V \\
\hline $\begin{array}{l}\text { Fundamental completo / } \\
\text { Médio incompleto }\end{array}$ & 4 & 8,7 & 4 & 17,4 & 8 & 11,6 & & \\
\hline $\begin{array}{l}\text { Médio completo / Superior } \\
\text { incompleto }\end{array}$ & 5 & 10,9 & 3 & 13,0 & 8 & 11,6 & & \\
\hline Superior completo & 1 & 2,2 & 5 & 21,7 & 6 & 8,7 & & \\
\hline \multicolumn{9}{|l|}{ Atividade Profissional } \\
\hline Sim & 23 & 50,0 & 14 & 60,9 & 37 & 53,6 & 0,482 & Q \\
\hline $\begin{array}{c}\text { Não } \\
\text { Companheiro }\end{array}$ & 23 & 50,0 & 9 & 39,1 & 32 & 46,4 & & \\
\hline Sim & 40 & 87,0 & 19 & 82,6 & 59 & 85,5 & 0,721 & $\mathrm{~F}$ \\
\hline Não & 6 & 13,0 & 4 & 17,4 & 10 & 14,5 & & \\
\hline \multicolumn{9}{|l|}{$\begin{array}{l}\text { Participou até o final do } \\
\text { estudo? }\end{array}$} \\
\hline Não & 1 & 2,2 & 1 & 4,4 & 2 & 2,9 & 0,061 & $\mathrm{~F}$ \\
\hline Sim & 45 & 97,8 & 22 & 95,6 & 67 & 97,1 & & \\
\hline \multicolumn{9}{|l|}{$\begin{array}{l}\text { Quem convidou para } \\
\text { participar da pesquisa? }\end{array}$} \\
\hline Pesquisador & 26 & 56,5 & 12 & 52,2 & 38 & 55,1 & 0,732 & Q \\
\hline Enfermeira & 20 & 43,5 & 11 & 47,8 & 31 & 44,9 & & \\
\hline Outros & 0 & 0,0 & 0 & 0,0 & 0 & 0,0 & & \\
\hline
\end{tabular}

No que concerne ao entendimento do significado do placebo, fica nítida a interferência da escolaridade $(p=0,022)$ na compreensão do sujeito, 
evidenciando que quanto menor o nível de instrução menor também o entendimento, conforme ilustra a Figura 9 a seguir. Com relação às demais variáveis analisadas, não foram identificadas diferenças significativas (Tabela 32).

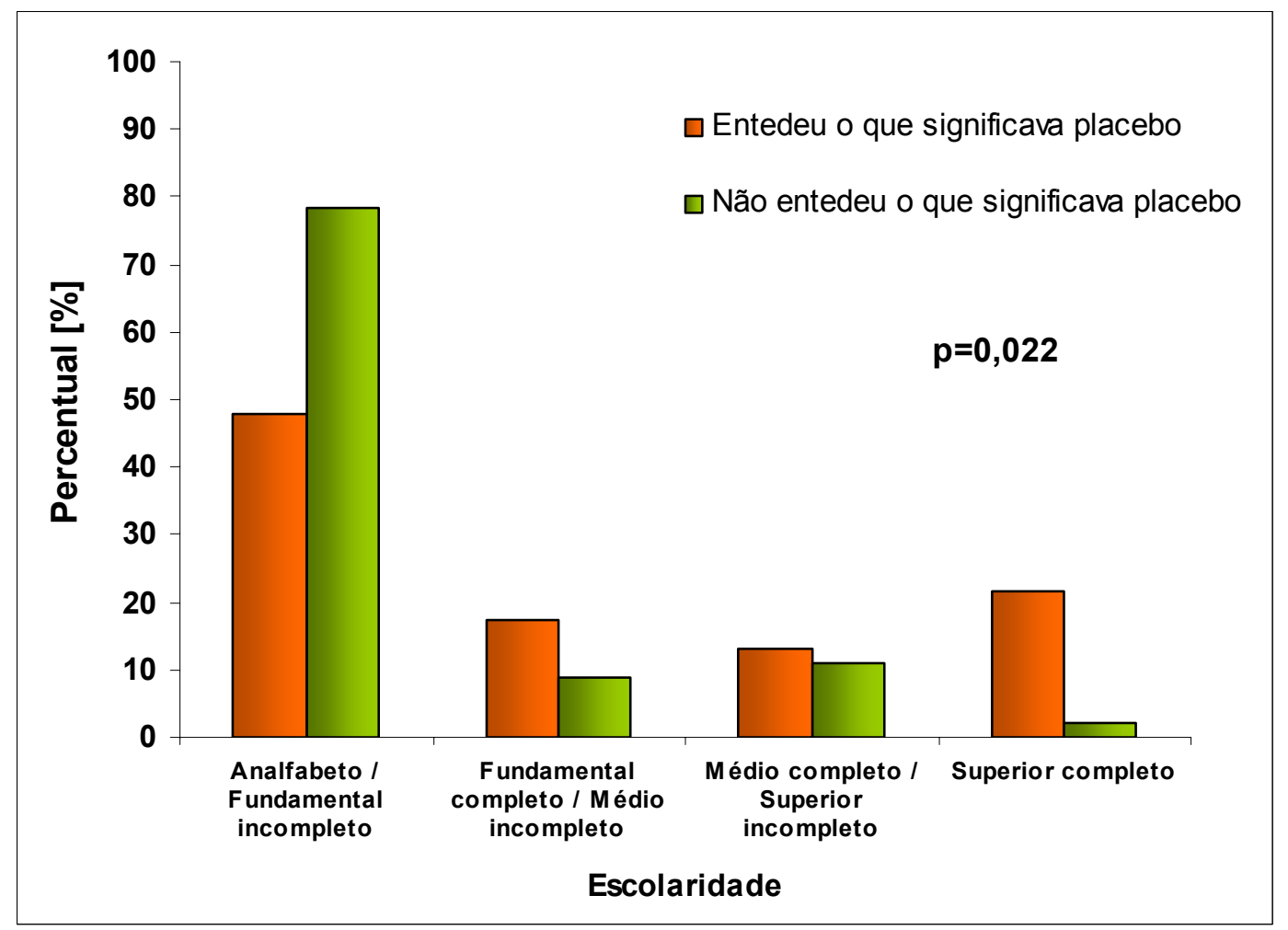

Figura 9. Associação entre o nível de escolaridade dos sujeitos da pesquisa e o entendimento do significado do placebo. 
Tabela 33. Distribuição da idade, sexo, escolaridade, companheiro, atividade profissional e informação de que poderia tomar um comprimido sem nenhum efeito durante alguns meses.

\begin{tabular}{|c|c|c|c|c|c|c|c|c|}
\hline \multirow[t]{3}{*}{ Variável } & \multicolumn{4}{|c|}{$\begin{array}{l}\text { Sabia que poderia tomar } \\
\text { um comprimido sem } \\
\text { nenhum efeito durante } \\
\text { alguns meses? }\end{array}$} & & & \multirow[t]{3}{*}{$\mathbf{p}$} & \multirow[t]{3}{*}{ Teste* } \\
\hline & \multirow{2}{*}{\multicolumn{2}{|c|}{$\begin{array}{c}\text { Não } \\
\mathrm{n}\end{array}$}} & \multirow{2}{*}{\multicolumn{2}{|c|}{$\begin{array}{c}\text { Sim } \\
\%\end{array}$}} & \multicolumn{2}{|c|}{ Total } & & \\
\hline & & & & & $\mathrm{n}$ & $\%$ & & \\
\hline \multicolumn{9}{|l|}{ Idade } \\
\hline Média & \multicolumn{2}{|c|}{57,8} & \multicolumn{2}{|c|}{58,6} & & & \multirow{2}{*}{0,754} & \multirow{2}{*}{$\mathrm{T}$} \\
\hline DP & \multicolumn{2}{|c|}{ $\pm 10,9$} & \multicolumn{2}{|c|}{ $\pm 7,9$} & & & & \\
\hline \multicolumn{9}{|l|}{ Sexo } \\
\hline $\mathrm{F}$ & 3 & 17,6 & 9 & 30,0 & 12 & 25,5 & 0,284 & $\mathrm{~F}$ \\
\hline M & 14 & 82,4 & 21 & 70,0 & 35 & 74,5 & & \\
\hline \multicolumn{9}{|l|}{ Escolaridade } \\
\hline $\begin{array}{l}\text { Analfabeto / Fundamental } \\
\text { incompleto }\end{array}$ & 11 & 64,7 & 21 & 70,0 & 32 & 68,1 & 0,593 & $\mathrm{~V}$ \\
\hline $\begin{array}{l}\text { Fundamental completo / Médio } \\
\text { incompleto }\end{array}$ & 3 & 17,6 & 2 & 6,7 & 5 & 10,6 & & \\
\hline $\begin{array}{l}\text { Médio completo / Superior } \\
\text { incompleto }\end{array}$ & 3 & 17,6 & 2 & 6,7 & 5 & 10,6 & & \\
\hline Superior completo & 0 & 0,0 & 5 & 16,6 & 5 & 10,6 & & \\
\hline \multicolumn{9}{|l|}{ Companheiro } \\
\hline Sim & 15 & 88,2 & 25 & 83,3 & 40 & 85,1 & 1,000 & $\mathrm{~F}$ \\
\hline Não & 2 & 11,8 & 5 & 16,7 & 7 & 14,9 & & \\
\hline \multicolumn{9}{|l|}{ Atividade profissional } \\
\hline Sim & 5 & 29,4 & 14 & 46,7 & 19 & 40,4 & 0,324 & Q \\
\hline Não & 12 & 70,6 & 16 & 53,3 & 28 & 59,6 & & \\
\hline \multicolumn{9}{|l|}{$\begin{array}{l}\text { Participou até o final do } \\
\text { estudo? }\end{array}$} \\
\hline Não & 0 & 0,0 & 0 & 0,0 & 0 & 0,0 & & \\
\hline Sim & 17 & 100,0 & 30 & 100,0 & 47 & 100,0 & & \\
\hline \multicolumn{9}{|l|}{$\begin{array}{l}\text { Quem convidou para } \\
\text { participar da pesquisa? }\end{array}$} \\
\hline Pesquisador & 6 & 35,3 & 16 & 53,3 & 22 & 46,8 & 0,234 & Q \\
\hline Enfermeira & 11 & 64,7 & 14 & 46,7 & 25 & 53,2 & & \\
\hline Outros & 0 & 0,0 & 0 & 0,0 & 0 & 0,0 & & \\
\hline
\end{tabular}

${ }^{*} \mathrm{~T}=$ Teste $\mathrm{t}$ de Student

${ }^{*} \mathrm{Q}=$ Qui-quadrado

*V = Teste da Razão de Verossimilhança

${ }^{*} \mathrm{~F}=$ Teste exato de Fisher

Embora as variáveis analisadas não apresentem nenhuma correlação significativa com as respostas afirmativas e negativas, chama 
atenção quanto à escolaridade o percentual de entrevistados analfabetos/fundamental incompleto que entenderam que poderiam tomar um comprimido sem nenhum efeito durante três meses $(70 \%)$ conforme ilustra a Figura 10 a seguir, sugerindo que há o entendimento verbal da informação e na linguagem que lhes é acessível.

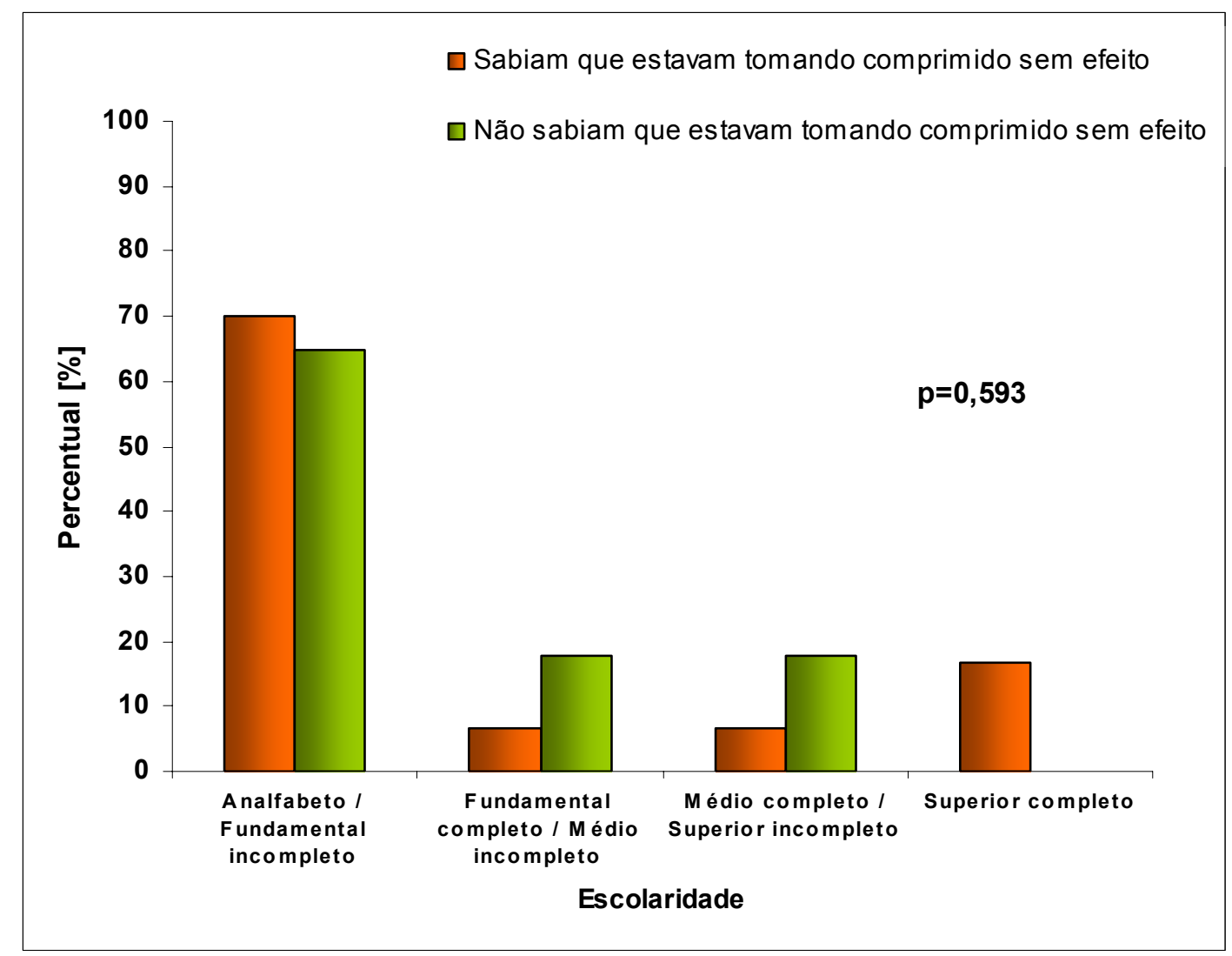

Figura 10. Associação entre o nível de escolaridade dos sujeitos da pesquisa e se sabiam que poderiam tomar um comprimido sem nenhum efeito durante alguns meses. 


\subsection{Descrição das respostas que ancoraram as unidades temáticas}

No contexto da análise das temáticas e permeando as categorias, serão citadas as falas dos participantes do estudo, exatamente como foram expressas pelos sujeitos da pesquisa, com o propósito de clarificar e detalhar os significados da análise dos dados.

\subsubsection{Entendimento do significado do termo placebo}

No questionamento aos sujeitos a respeito do entendimento do significado do termo placebo, verificou-se, como já descrito anteriormente, que todos os participantes pronunciaram-se a respeito do tema.

\footnotetext{
"Que era um remédio que não era um remédio era só imitação." (fem.,49 anos)

"Que era uma pírula de farinha." (fem., 62 anos)

"Não conheço esse termo, mas sei que tomei um comprimido de farinha." (fem., 49 anos)

"Placebo é um remédio sem efeito." (masc, 66 anos)

"Que era um comprimido de farinha e que poderia tomar durante todo o estudo." (masc., 62 anos)

"Placebo é um comprimido sem valor." (masc., 52 anos)

"É um comprimido sem nenhum efeito" (masc., 68 anos)

"É um medicamento de farinha" (fem., 46 anos)
}

As crenças equivocadas emergem nos relatos demonstrando o comprometimento do entendimento.

"... era uma mola colocada no coração." (masc., 72 anos)

"É um falso medicamento para as pessoas que tem mania de tomar remédio". (masc., 50 anos)

“...era um remédio novo.” (masc., 72 anos) 
"...que era uma coisa boa para mim." (masc., 49 anos)

"...é um remédio dado mas que não se sabia as propriedades." (masc., 56 anos)

“... era um remédio que fazia bem." (masc., 55 anos)

"...era um remédio para meu bem." (fem., 67 anos)

"... que era um medicamento para o coração." (masc., 52 anos)

Por vezes há os que, de fato, não entenderam o significado do termo placebo.

"Não sei o que era esse comprimido". (masc., 64 anos)

"... que fazia parte do tratamento." (masc., 63 anos)

"... não sabia o que era, somente algum tempo depois fui me informar." (masc., 72 anos)

"... nem sabia que tinha isso no estudo." (masc., 62 anos)

"Não entendi o que significava isso." (fem., 51 anos)

"Não tenho idéia do que seja isso." (masc., 68 anos)

"Nunca ouvi falar nessa palavra." (masc., 69 anos)

"Não sei o que significava, nem tampouco que poderia utilizar." (masc., 55 anos)

"Não entendi para que significava placebo e nem a medicação do estudo. Se para colesterol ou diabetes." (masc. 64 anos)

"Não sei, pois o estudo só tinha remédio para o coração." (masc., 58 anos)

\subsubsection{Importância atribuída à participação na pesquisa}

Indagados a respeito da importância em participar de uma pesquisa, percebe-se na fala dos entrevistados que o fator determinante traduz-se no benefício pessoal na busca da melhora do estado de saúde.

"...porque a dor que sentia no peito melhorou durante a participação no estudo." (masc., 63 anos)

"... o medicamento do estudo estava fazendo bem." (masc., 49 anos)

“... me dei bem com os remédios e a pressão arterial não subiu mais. (masc., 28 anos)

"Tentei investir na minha melhoria e tentaria tudo para melhorar." (fem., 46 anos)

"Porque me senti bem tomando o remédio do protocolo." (masc.,58 anos)

"Porque tratou a pressão." (masc., 61 anos) 
"... me senti outra pessoa, acho que melhorei bastante em função da participação na pesquisa." (masc., 72 anos)

"Não subia ladeira, hoje ando para todos os lugares e não sinto mais nada." (masc., 72 anos)

Neste contexto, identificam-se também aspectos valorizando a

contribuição em prol da ciência, além do benefício próprio.

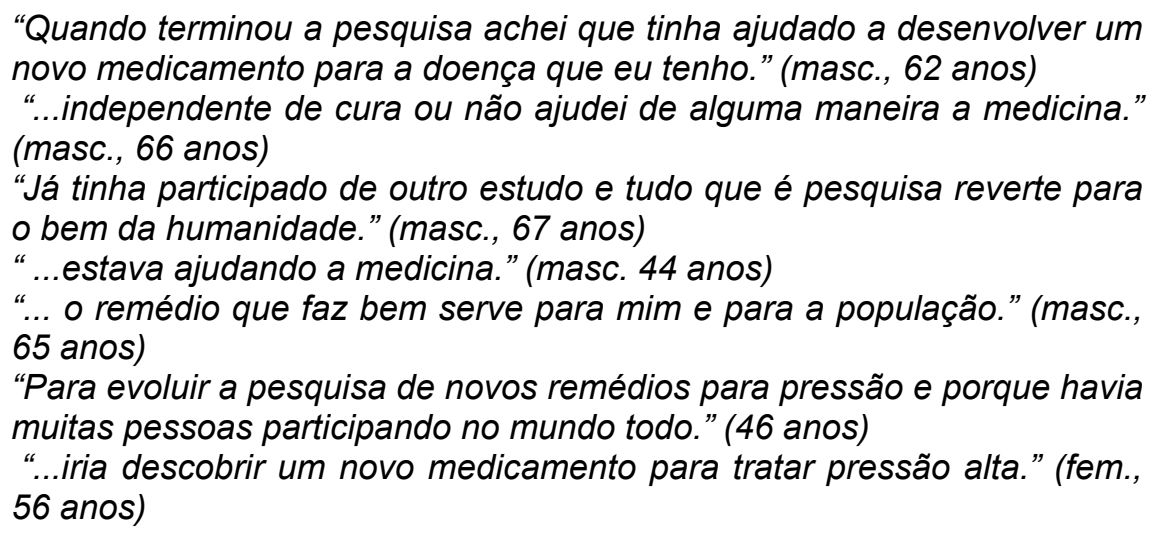

A atenção médica recebida e o atendimento diferenciado durante a pesquisa são externados como diferenciais que favoreceram a valorização da participação.

"Fazia exames mais freqüentes, fui bem tratado e bem cuidado." (masc., 72 anos)

“...durante o período da pesquisa fui mais valiado do que seria tradicionalmente no ambulatório. Fiz mais exames e se tivesse alguma coisa de mais grave teria sido avisado." (masc., 57 anos)

"... as consultas eram mais constantes e eu era mais observado." (masc., 59 anos)

"...estava sendo bem acompanhado, fazia exames com freqüência, a pressão estava controlada." (masc., 54 anos)

"...devido ao tratamento e assistência diferenciada". (masc., 64 anos)

"... fazia os exames de sangue e outros com freqüência e depois da pesquisa perdeu esse acompanhamento." (masc., 63 anos)

"... foi mais acompanhada e fez mais exames." (fém., 49 anos)

"...porque me senti bem, o tratamento foi ótimo e fiz vários exames." (masc, 62 anos)

"...fiz mais exames e se fossem realizados normalmente demoraria muito." (masc., 50 anos)

"...fiz exames que nunca tinha feito antes." (masc., 69 anos)

"... o acompanhamento é mais rigoroso." (masc., 64 anos) 
“...fiz eletro, exames, esteira e se não tivesse participado não teria feito." (fem., 61 anos)

"... fiz exames que não faria na rotina do ambulatório." (masc., 59 anos)

O significado atribuído à experiência vivenciada influenciou na adequação ao tratamento e conscientização da doença.

“...não tomava o remédio corretamente antes de participar da pesquisa." (fem., 54 anos)

“... aprendi muito, e acertei o tratamento". (fem, 70)

"...fiz todos os exames, a utilização da medicação foi correta e continuo tomando a mesma medicação do estudo até hoje." (masc., 35)

“... acho que até fiquei bom porque passei a tomar o remédio direitinho." (mas., 72 anos)

“... comecei a entender melhor o que estava acontecendo comigo. Tinha acabado de fazer um cate e estava no início de um tratamento confuso." (fem., 49 anos)

A relação cambial fica evidente quando o sujeito atrela o valor de troca pela participação na pesquisa.

"Foi bom para mim e para vocês." (fem., 57 anos)

"... é uma troca porque de alguma forma estava me beneficiando e colaborando." (masc., 62 anos)

"Porque deram condições para que fosse feito o cateterismo e a angioplastia.". (masc.72)

"... tive a oportunidade de fazer novos exames, uma vez que tinha perdido a guia de retorno." ( fem., 59 anos)

As experiências negativas encontram-se aliadas a uma diversidade

de sentimentos e atitudes intimamente influenciados pelo sofrimento durante os exames, insatisfação, indiferença e incompreensão.

“...não perdi nada com a participação e também não prejudicou minha saúde." (masc., 70 anos)

“... sofri nos exames, mas aprendi muita coisa." (masc. 64 anos)

“... não me explicaram o motivo porque tudo aquilo estava sendo feito. Me chamaram para participar e eu vim. Importante foi fazer o cateterismo." (masc., 71 anos)

“... achei muito forte a medicação e o contraste.” ( masc., 55 anos) 
"... tive muitos efeitos colaterais da medicação do estudo." (masc. 34 anos)

\subsubsection{Informação a respeito do convite a um amigo ou parente para participar de uma pesquisa}

Como se observa, a beneficência pessoal também é o fator determinante para a indicação de outra pessoa participar de uma pesquisa, principalmente quando se leva em consideração a experiência vivenciada.

"... porque tudo que foi feito comigo foi bom." (masc., 65 anos)

“... como foi bom para mim, seria também para ele." (masc., 63 anos)

“... porque foi bom para mim.” (fem., 67 anos)

“... porque para mim deu resultado, por isso é favorável." (masc., 57 anos)

Há a preocupação em contribuir para o avanço da ciência.

"... porque o hospital precisa e a medicina também precisa da pesquisa para as pessoas viverem mais, mas é difícil convencer os outros." (masc., 70 anos)

"... para ajudar na descoberta de novos remédios e a ciência." (fem., 46 anos)

“... estar cooperando com a ciência." (masc. 64 anos)

"... só vai se conseguir alguma coisa na medicina se tiver alguém que colabore." (masc., 64 anos)

".. . a tecnologia precisa ser testada." (fem., 46 anos)

A atenção médica recebida e atendimento diferenciado emergem nas falas, transferindo-se a experiência pessoal.

"... em cada consulta esclarecia minhas dúvidas e muita gente não tem essa oportunidade." (masc. 35 anos)

"... porque vai ser mais bem tratado, todos dão assistência." (masc., 64 anos) 
"... por todos os benefícios que se tem com a pesquisa, pelo carinho com que as pessoas são tratadas." (fem., 54 anos)

"... o cuidado durante o protocolo foi redobrado, nem na fila eu ficava mais." (fem., 53 anos)

A relação cambial em troca de atendimento também é mencionada.

"... porque os médicos precisam dos pacientes para esta pesquisa e os pacientes precisam do médico." (masc., 64 anos)

"Iniciando na pesquisa pode continuar o tratamento na instituição." (masc., 60 anos)

"Teria mais um lugar para se tratar." (masc., 71 anos)

A oportunidade de aprendizado durante a pesquisa.

"... os pacientes tiram muito proveito e ensinamento. Têm oportunidade de ficar sabendo mais sobre sua doença." (masc., 52 anos)

O reconhecimento dos riscos é uma preocupação quando se pensa na indicação do procedimento a outrem. Assim sendo, ocorre a transferência da responsabilidade pessoal em decidir.

“...é importante desde que não traga prejuízo para a pessoa. A pesquisa é sempre para melhorar e se há risco as pessoas têm que ser informadas. Tem que haver sinceridade e honestidade para confiar no médico e na pesquisa." (fem., 62 anos)

"... embora para mim não tenha sido dito os riscos e eu aceitei, se a pessoa aceitar também poderá participar." (masc., 72 anos)

"Informaria que perigo existe e que o único risco seria morrer, mas é difícil estando no meio de tantos médicos." (masc., 59 anos)

"É um teste e a pessoa pode não se dar bem." (masc., 34 anos)

E para alguns ainda persiste a concepção de cobaia quando se fala em pesquisa.

“... para mim foi bom, mas tem muita gente que ainda tem medo de ser cobaia." (fem. 59 anos) 
“... mas não pode ter medo de ser cobaia." (masc, 72 anos)

-“... Só depois que assinei o termo e levei para os filhos é que percebi que seria uma cobaia." (masc., 72 anos)

\subsubsection{Pontos negativos identificados na análise das respostas}

Apesar da resposta positiva referente à participação no ensaio clínico, há algumas avaliações consideradas negativas acerca de alguns pontos do processo. Dentre as mais relevantes podem ser observadas as seguintes:

- Não ficar sabendo dos resultados dos exames realizados durante a pesquisa

- Não ter retorno quanto à possibilidade de utilizar a medicação após o término da pesquisa

- Retorno à rotina de agendamento institucional

- Não continuidade da medicação utilizada durante o estudo

- Supor que o protocolo seria utilizado para diminuir a quantidade de remédios que tomava

- Supor que pelo fato dos pacientes serem acompanhados durante a pesquisa não haveria nenhum perigo de "fazer mal"

- Não saber o que estava tomando ao final do estudo

- Supor que as pessoas que participaram da pesquisa deveriam ter mais facilidades após seu término 


\subsection{Descrição do grupo focal}

\subsubsection{Diagrama dos sujeitos que participaram do grupo focal}
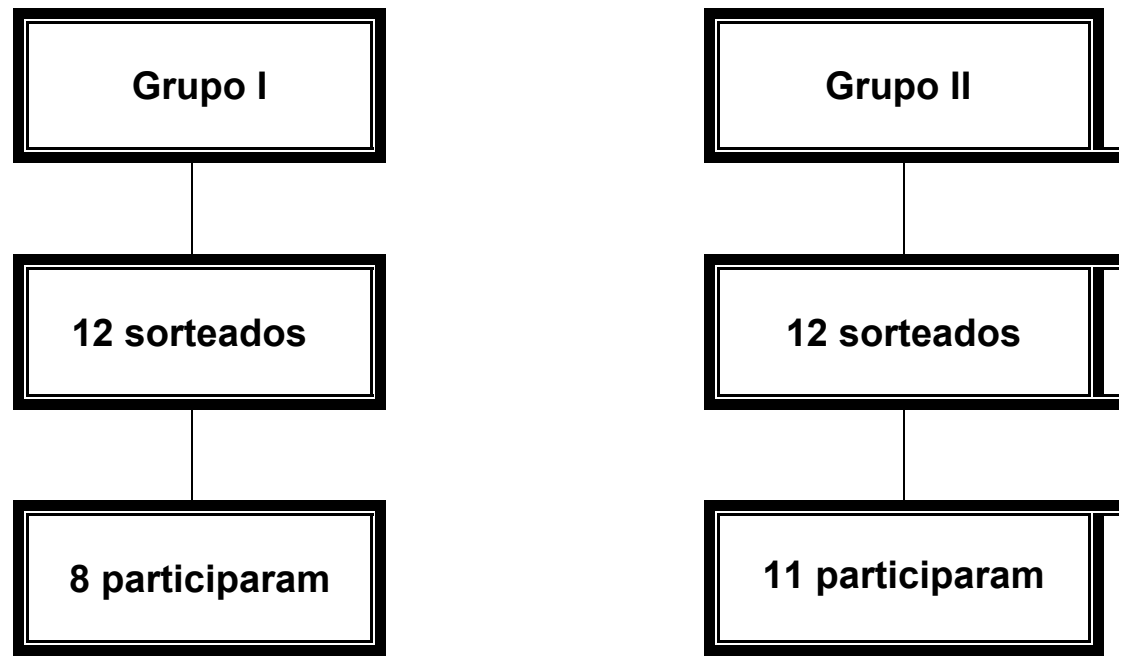

\subsubsection{Perfil da amostra do grupo focal}

Após sorteio, foram selecionados 19 sujeitos de pesquisa participantes do estudo e que compuseram a amostra do grupo focal, sendo 8 do grupo I e 11 do grupo II. Cabe salientar que no grupo I dois sujeitos chegaram atrasados e foram excluídos.

Pelos dados da Tabela 34, pode-se observar que a média das idades $( \pm D P)$ em anos dos grupos foi de $54,2( \pm 8,0)$ para o grupo 1 e 54,6 $( \pm 8,4)$ para o grupo 2 .

Com relação ao tempo de seguimento na instituição, pode-se observar que este foi maior em até 17 meses nos sujeitos do grupo II. 
Tabela 34. Distribuição da amostra do grupo focal quanto à idade e tempo de seguimento na instituição.

\begin{tabular}{ccc}
\hline \hline Características & \multicolumn{2}{c}{ Grupo } \\
\cline { 2 - 3 } & \multicolumn{1}{c}{ I } \\
\hline $\begin{array}{c}\text { Idade (anos) } \\
\text { Média (DP) }\end{array}$ & $54,2( \pm 8,0)$ & $54,6( \pm 8,4)$ \\
$\begin{array}{c}\text { Tempo de seguimento na instituição (meses) } \\
\text { Média (DP) }\end{array}$ & $35,6( \pm 19,1)$ & $52,3( \pm 23,0)$ \\
\hline \hline
\end{tabular}

De acordo com a Tabela 35, a seguir, pode-se constatar que os gêneros foram representados por 10 homens $(52,6 \%)$ e nove mulheres $(47,4 \%)$.

No que tange à escolaridade, em ambos os grupos a maioria era analfabeta ou tinha apenas o nível fundamental incompleto de ensino, ou seja, $63,2 \%$. Apenas $15,8 \%$ cursaram o nível médio.

Tabela 35. Distribuição da amostra do grupo focal quanto ao sexo e escolaridade.

\begin{tabular}{|c|c|c|c|c|c|c|}
\hline \multirow{3}{*}{ Características } & \multicolumn{4}{|c|}{ Grupo } & & \\
\hline & \multicolumn{2}{|c|}{ I } & \multicolumn{2}{|c|}{ II } & \multicolumn{2}{|c|}{ Total } \\
\hline & $\mathbf{n}$ & $\%$ & $\mathbf{n}$ & $\%$ & $\mathbf{n}$ & $\%$ \\
\hline \multicolumn{7}{|l|}{ Sexo } \\
\hline $\mathrm{F}$ & 4 & 50,0 & 5 & 45,5 & 9 & 47,4 \\
\hline M & 4 & 50,0 & 6 & 54,5 & 10 & 52,6 \\
\hline \multicolumn{7}{|l|}{ Escolaridade } \\
\hline $\begin{array}{c}\text { Analfabeto/Fundamental } \\
\text { incompleto }\end{array}$ & 6 & 75,0 & 6 & 54,5 & 12 & 63,2 \\
\hline Fundamental completo/Médio & & & & & 4 & 21,0 \\
\hline Incompleto & 1 & 25,0 & 3 & 27,3 & & \\
\hline $\begin{array}{l}\text { Médio completo e Superior } \\
\text { incompleto }\end{array}$ & 1 & 25,0 & 2 & 18,2 & 3 & 15,8 \\
\hline Superior completo & 0 & 00,0 & 0 & 00,0 & 0 & \\
\hline
\end{tabular}


Quadro 3. Descrição das temáticas, categorias e sub-categorias identificadas na análise das transcrições do grupo focal, segundo os grupos I e II.

\begin{tabular}{|c|c|c|c|}
\hline Temáticas & Categorias & Sub-categorias & Grupo* \\
\hline \multirow{19}{*}{$\begin{array}{c}\text { Percepção da } \\
\text { pesquisa }\end{array}$} & \multirow[t]{3}{*}{$\begin{array}{l}\text { Pesquisa do } \\
\text { medicamento }\end{array}$} & $\begin{array}{l}\text {-Desenvolvimento da } \\
\text { medicação }\end{array}$ & G I e G II \\
\hline & & $\begin{array}{l}\text {-Descobrimento de novos } \\
\text { métodos de tratamento }\end{array}$ & G II \\
\hline & & $\begin{array}{l}\text {-Garantida por um termo de } \\
\text { responsabilidade }\end{array}$ & G II \\
\hline & \multirow[t]{3}{*}{ Tratamento } & -Psicológico & G II \\
\hline & & $\begin{array}{l}\text {-Continuação do tratamento } \\
\text { convencional }\end{array}$ & G II \\
\hline & & -Tratamento não convencional & G I e G II \\
\hline & $\begin{array}{l}\text { Concepção de } \\
\text { cobaia }\end{array}$ & & G I e G II \\
\hline & Relação cambial & & G I \\
\hline & \multirow{3}{*}{$\begin{array}{l}\text { Riscos e } \\
\text { benefícios }\end{array}$} & -Insegurança & G I e G II \\
\hline & & -Atendimento diferenciado & G I e G II \\
\hline & & -Avaliação criteriosa & G II \\
\hline & \multirow{8}{*}{$\begin{array}{l}\text { Motivação para } \\
\text { participação }\end{array}$} & -Em benefício próprio & G I e G II \\
\hline & & -Satisfação pessoal & G II \\
\hline & & -Segurança & G I e G II \\
\hline & & -Em benefício dos outros & G I e G II \\
\hline & & -Para o bem da ciência & G I e G II \\
\hline & & -Renome da instituição & G I e G II \\
\hline & & -Atenção recebida & G I \\
\hline & & -Convite da enfermeira & G I \\
\hline \multirow{6}{*}{$\begin{array}{l}\text { Compreensão do } \\
\text { Termo de } \\
\text { Consentimento } \\
\text { Livre e Esclarecido }\end{array}$} & Dispensa Leitura & $\begin{array}{l}\text {-Vínculo de confiança com a } \\
\text { equipe }\end{array}$ & G I e G II \\
\hline & \multirow{2}{*}{$\begin{array}{l}\text { Favorecida pela } \\
\text { equipe }\end{array}$} & -Esclarecimentos claros & G I \\
\hline & & -Complementa a informação & G I \\
\hline & \multirow[t]{3}{*}{ Difícil } & -Termos técnicos & G I \\
\hline & & -Linguagem inacessível & G I \\
\hline & & -Conteúdo complexo & G I \\
\hline \multirow{3}{*}{$\begin{array}{l}\text { Entendimento do } \\
\text { significado do } \\
\text { placebo }\end{array}$} & $\begin{array}{l}\text { Crenças } \\
\text { equivocadas }\end{array}$ & & G I \\
\hline & $\begin{array}{l}\text { Entendimento de } \\
\text { acordo com a } \\
\text { informação } \\
\text { recebida }\end{array}$ & & G I \\
\hline & $\begin{array}{l}\text { Entendimento } \\
\text { correto }\end{array}$ & & G I \\
\hline
\end{tabular}

${ }^{*} \mathrm{G}$ I = Grupo I / G II = Grupo II

NOTA: Em virtude da palavra placebo não constar do TCLE de todos os ensaios clínicos do grupo II, embora tivessem o período de wash-out, esta questão não foi abordada na realização do grupo focal. 


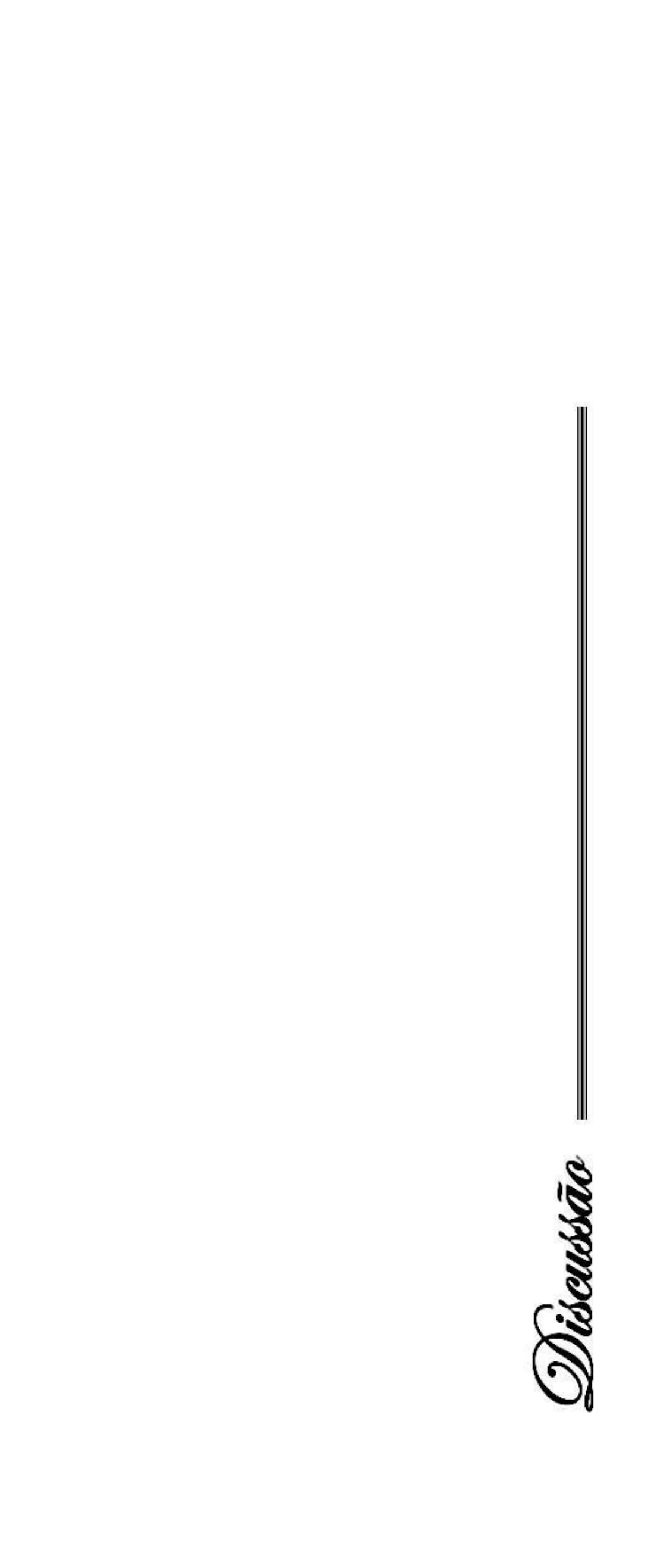




\section{DISCUSSÃO}

\subsection{As características da população estudada}

O conjunto de dados deste estudo demonstra os vários aspectos relacionados à percepção do sujeito da pesquisa em participar de um ensaio clínico, porém com diferença significativa entre os grupos 1 e 2 .

Ao lado disso, confirma e estende conceitos importantes para implantação de estratégias de aplicação do Termo de Consentimento Livre e Esclarecido aos pacientes menos instruídos que participam de pesquisa clínica em instituições públicas.

No que concerne ao nível educacional, em ambos os grupos, a maioria era analfabeta ou tinha apenas o nível fundamental incompleto de ensino, representando $63,8 \%$ da amostra.

Resultados semelhantes foram observados por Souza ${ }^{83}$ ao analisar os dados de 793 pacientes que foram convidados a participar de diferentes protocolos de pesquisa clínica conduzidos em instituições públicas e privadas. Os dados foram coletados de fichários de pesquisa científica para avaliar a aderência do sujeito de pesquisa ao protocolo, correlacionando-a 
com fatores demográficos, sociais, relação risco-benefício envolvida e nível de escolaridade. Nesse estudo, $53 \%$ dos sujeitos eram do sexo masculino, com idade média de 58,2 anos, e $58,3 \%$ tinham oito anos ou menos de estudo. Vale destacar que esse foi o nível de instrução predominante entre os $444(96,1 \%)$ participantes de instituição pública.

Esses dados sinalizam a grande dívida educacional do país, e provavelmente é o reflexo dos $47 \%$ dos brasileiros na faixa etária entre 14 a 64 anos que não chegaram a completar a $8^{\mathrm{a}}$ série do ensino fundamental ${ }^{84}$. Dentre os que chegaram a completar esse nível, apenas $11 \%$ podem ser considerados plenamente alfabetizados ${ }^{85}$. Analogamente, a proporção de analfabetos funcionais na faixa etária entre 55 a 64 anos chega a $61 \%{ }^{85}$.

O conceito de analfabetismo ao longo dos anos tem passado por revisões que refletem as mudanças sociais ocorridas nas últimas décadas. $\mathrm{Na}$ década de 90, o IBGE, seguindo as recomendações da UNESCO, passou a divulgar os índices de analfabetismo funcional, tendo como o critério o número de séries escolares concluídas ${ }^{84}$. Pelo critério adotado, a inclusão na categoria de analfabetismo funcional passou a contemplar, no país, todas as pessoas com menos de quatro séries de estudos concluídos $^{84,86}$.

Já o Instituto Paulo Montenegro ${ }^{85}$ considera analfabeta funcional toda pessoa que mesmo sabendo ler e escrever não tem as habilidades de leitura, de escrita e de cálculo para viabilizar seu desenvolvimento profissional e pessoal. 
Com base nos dados do Indicador Nacional de Alfabetismo Funcional (INAF) $)^{*}$, a condição de analfabetismo aplicável às pessoas que não conseguem realizar tarefas simples envolvendo decodificação de palavras e frases é predominante no sexo masculino (64\%), em indivíduos com mais de 35 anos (77\%), pertencentes à classe D e E (81\%), e que completaram de um a três anos de estudo $(60 \%)^{84}$. Desse modo, pode-se inferir que os maiores índices de analfabetismo estão concentrados nas faixas etárias mais elevadas e na população de baixa renda ${ }^{87,88}$.

Outro conceito amplamente abordado, segundo Castell et al. apud Ribeiro $^{89}$, refere-se conceito de alfabetismo funcional surgido nos Estados Unidos na década de 30 , e utilizado pelo exército americano durante a Segunda Guerra Mundial como indicador da capacidade de entender as instruções escritas necessárias para a realização de tarefas militares. Desde então, passou a ser utilizado para designar a capacidade de utilizar a leitura e escrita para fazer frente às demandas de seu contexto social e usar suas habilidades para continuar aprendendo e se desenvolvendo ao longo da vida $^{84}$.

No entanto, a variação do número de anos de escolaridade, considerados como indicador do nível de alfabetismo de um país ou região, atesta a maleabilidade deste conceito. Essa variação do número de anos

\footnotetext{
* Com base nos resultados do teste de leitura, o $\operatorname{INAF}^{84}$ classifica a populaçao estudada em quatro níveis:

-Analfabeto: não consegue realizar tarefas simples que envolvem decodificaçao de palavras e frases. -Analfabeto Nível Rudimentar: consegue ler títulos ou frases, localizando uma informação bem explícita

-Alfabetizado Nível Básico: consegue ler um texto curto, localizando uma informação explícita ou que exija uma pequena inferência.

-Alfabetizado Nível Pleno: conseguer ler textos mais longos, localizar e relacionar mais de uma informaçao, comparar vários textos, identificar fontes.
} 
de escolaridade considerados como mínimo não deriva necessariamente de diferentes graus de exigências impostos pelos diferentes contextos, mas das metas educacionais consideradas como factíveis para os países, de acordo com seu nível de desenvolvimento socioeconômico ${ }^{89}$.

Na América do Norte, apesar de se considerar como critério 8-9 anos de escolaridade como patamar mínimo para se atingir o alfabetismo funcional ${ }^{84}$, dados do National Adult Literacy Survey mostram que $21 \%$ dos adultos americanos são considerados analfabetos funcionais e $27 \%$ apresentam habilidades de leitura marginais ${ }^{90}$. O impacto desses dados também tem repercussão na pesquisa clínica, uma vez que proporção substancial de pacientes pode não ser capaz de ler e entender os termos de consentimento normalmente usados na pesquisa clínica ${ }^{91}$.

De fato, no estudo de Sudore et al ${ }^{92}$ com 204 pacientes de um hospital público de San Francisco, descrevendo uma nova estratégia para aplicação do consentimento informado baseada na alteração da forma escrita do formulário padrão (escrito para $\circ 6^{\text {th }}$ grade level) e na leitura e repetição dos dados (teach-to-goal) concluiu-se que o baixo nível de escolaridade é fator determinante para o entendimento das informações do termo de consentimento. Neste estudo, o consentimento foi lido em voz alta para os participantes e a compreensão foi avaliada, a seguir, por meio de sete questões com opções de verdadeiro ou falso. Quando o sujeito não acertava a resposta da questão, o respectivo trecho do consentimento era relido. Num primeiro momento, somente $28 \%$ dos participantes responderam corretamente todas as questões. 
A exemplo deste estudo a literatura é unânime em reconhecer o nível de instrução dos sujeitos como um fator consistentemente associado com o nível de entendimento. Na revisão sistemática realizada por Flory e Emanuel $^{57}$, no período de 1966 a março de 2004, doze estudos mostraram que os participantes com alto nível de instrução ou de leitura apresentaram níveis de entendimento significativamente superiores (todos $p<0,05$ ).

Outro dado de interesse neste estudo refere-se à avaliação da inserção social dos sujeitos que participam de ensaios clínicos, o que conseqüentemente incluiu a investigação de suas participações no mercado de trabalho. Observou-se, neste estudo, que a metade dos participantes $(52,5 \%)$ não tinha atividade profissional com vínculo empregatício. Contudo, deve-se salientar que trinta eram aposentados $(37,5 \%)$, onze do lar $(13,8 \%)$ e somente um $(1,2 \%)$ estava afastado por problemas de saúde. A idéia de que o envelhecimento está atrelado à dependência econômica é corroborada nesta pesquisa. Em termos demográficos, como apontou-se em dados recentes do $\mathrm{IBGE}^{87}$, dos 19 milhões de pessoas com 60 anos ou mais 76,6\% são beneficiárias da previdência. Nesta pesquisa censitária nacional, quando são incluídos os idosos de 65 anos ou mais, esse percentual elevase para $84,6 \%$. 


\subsection{Informações acerca da participação na pesquisa}

Com relação ao convite para participar da pesquisa, $53,1 \%$ dos sujeitos do grupo 1 foram convidados por enfermeiras e $69,7 \%$ do grupo 2 pelo pesquisador. Esta diferença estatisticamente significante pode ser justificada pelo perfil de estudos, ou seja, os estudos do grupo 2 apresentavam critérios de inclusão encontráveis na grande maioria dos pacientes atendidos no ambulatório diariamente. Já os estudos do grupo 1 , pela dificuldade em encontrar pacientes que atendessem aos critérios de inclusão, após a pré-seleção realizada pelo médico mediante consulta ao prontuário, o convite para vir ao hospital era formalizado pela enfermeira responsável.

No que diz respeito aos motivos que os levaram a participar de uma pesquisa, observou-se que a maioria dos participantes $(66,2 \%)$ atribuíram-no ao benefício próprio, seguidos pelo bem da ciência $(42,5 \%)$.

Comparando os dados deste estudo com os de Sakaguti ${ }^{93}$, constatamos que, apesar do autor ter estudado 50 sujeitos de pesquisa, atendidos nas unidades do âmbito da Secretaria Municipal de Saúde e Faculdade de Odontologia da Universidade de São Paulo, os resultados são concordantes quanto aos principais motivos que levam os pacientes a aceitar participação na pesquisa. Neste estudo, $68 \%$ dos sujeitos aceitaram participar em benefício próprio, $18 \%$ em prol da ciência e $2 \%$ a pedido do médico. 
Para o paciente, sua doença é vivida como o foco central de sua vida. Nesse contexto, o coração, do ponto de vista do senso comum, é um órgão binário, que define o estado de vida ou morte, e se caracteriza por carregar uma representação afetivo-emocional muito grande, pelas implicações e conseqüências advindas quando se adoece. Por isso, a doença coronária e tudo que a envolve pode tornar-se mais ou menos fonte de fortes emoções, dependendo do significado atribuído ao coração por

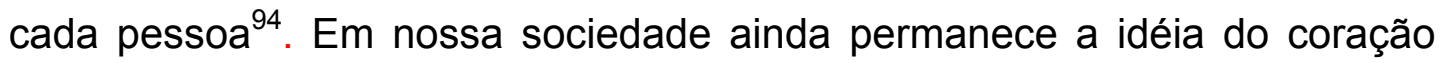
como fonte da vida, portanto a ocorrência de qualquer doença que o comprometa gera insegurança e medo de morte iminente, levando as pessoas a buscar qualquer tratamento que possa melhorar sua condição.

No estudo conduzido com 35 pacientes que estavam participando de ensaios clínicos patrocinados pela indústria farmacêutica em um centro de oncologia no México, $46 \%$ dos pacientes aceitaram participar da pesquisa e assinaram o consentimento para ter acesso ao tratamento, 29\% para livrar os médicos e o hospital de alguma responsabilidade e nenhum pensou que a proposta do consentimento serviria para protegê-los enquanto pacientes ${ }^{95}$.

Outro dado de interesse em nosso estudo foi o fato de $25 \%$ dos sujeitos terem atendido ao convite para participar da pesquisa em virtude do pedido ou indicação formalizada pelo médico. As palavras de um médico podem mudar o curso de vida de um paciente ou exercer grande influência no processo de tomada de decisão ${ }^{96}$.

Por outro lado, deve-se também considerar o fato das pessoas possuírem uma tendência a mudar seu comportamento quando são alvos de 
interesse e de atenção, independentemente da natureza específica da intervenção, fenômeno este definido por Fletcher e Fletcher ${ }^{97}$ como efeito Hawthorne. Nesta situação, os pacientes ficam ansiosos para agradar seus médicos e para fazê-los sentirem-se bem-sucedidos. Além disso, querem fazer a sua parte para que os "bons" resultados no estudo possam ser obtidos.

Vale também assinalar que, embora os médicos que conduziram os ensaios clínicos, incluídos nesta pesquisa, nem sempre tenham sido os mesmos que acompanhavam os pacientes no ambulatório, há de se considerar os conflitos de interesse existentes nas pesquisas patrocinadas pela indústria farmacêutica ${ }^{98,99}$.

O conflito de interesse é definido por Thompson ${ }^{100}$ como uma situação na qual os interesses secundários influenciam indevidamente o julgamento profissional de uma pessoa no que diz respeito aos seus interesses primários.

Para este autor, são definidos classicamente três interesses primários: saúde e bem-estar do paciente, integridade da pesquisa clínica e educação dos futuros profissionais. Como interesses secundários: retorno financeiro, progresso na carreira, fundo para pesquisas, publicações de resultados em periódicos de renome, desejo de fama, obrigações familiares e outros.

Vale assinalar que os interesses secundários não são um mal em si e o problema não se concentra em sua natureza "boa" ou "ruim". O problema em questão é que os danos acontecem quando os interesses secundários 
se sobrepõem, e indevidamente influenciam, distorcem ou corrompem a integridade e o julgamento do profissional em relação à saúde do paciente, ao ensaio clínico ou à educação ${ }^{100}$.

\subsection{Dados relacionados ao Termo de Consentimento Livre e Esclarecido como documento em si}

Conforme foi mencionado, constatou-se nítida diferença entre os grupos 1 e 2 quanto aos esclarecimentos realizados pelo pesquisador a respeito das informações contidas no TCLE; mais especificamente, não há um padrão de orientação seguido com relação aos itens abordados no documento.

Neste contexto verifica-se que $25 \%$ dos sujeitos informaram não haver recebido qualquer tipo de informação acerca da importância da pesquisa para a qual estavam sendo convidados a participar, e quase a metade $(42,5 \%)$ nem dos riscos e incômodos. O mesmo procede em relação à existência de outros tratamentos diferentes do da pesquisa, onde se observa que 66 sujeitos $(82,5 \%)$ não receberam essa informação. Evidentemente pode haver ocorrido falha da memória desses sujeitos em função do tempo passado da participação nos estudos e o momento da entrevista para este estudo.

Desse modo, fica implícita a importância da comunicação médicopaciente na discussão sobre a efetividade das informações fornecidas ao 
paciente no processo de obtenção do TCLE, o que não foi observado neste estudo. Assim, pode-se inferir que a maneira pela qual o médico comunicase com o paciente irá influenciar no seu julgamento dos riscos, benefícios e barreiras para participar do estudo ${ }^{101}$.

A eficácia do tratamento proposto pelo médico depende não apenas de seus conhecimentos e habilidades técnicas, mas também de sua capacidade de criar um relacionamento entre si próprio e o paciente que apóie os objetivos terapêuticos ${ }^{102}$. Talvez, se um médico reconhecesse seu poder e a vulnerabilidade de um paciente, poderia ser mais fácil apresentar todas as opções de tratamento disponíveis aos seus pacientes ${ }^{98}$.

Por outro lado, cabe salientar que a percepção de risco quando se aplica o TCLE é pouco entendida pelos pacientes e as evidências sugerem que há uma relação inversa entre a percepção de risco e benefício esperado $^{103}$.

Para Beauchamp e Childress $^{52}$ a utilização de métodos de percepção seletiva pelos pacientes faz com que pareça ocorrer um excesso de informação quando se utilizam termos técnicos ou se a informação não pôde ser bem organizada, ainda que tenha sido compacta. Neste contexto, os autores fazem referência a um trabalho que aborda a dificuldade na hora de processar a informação sobre os riscos, demonstrando que ao receber informação sobre os mesmos os sujeitos acabam distorcendo-a e dando lugar a temores desproporcionados. 
No entanto, as pesquisas também sugerem que o entendimento do risco melhora quando a informação é adaptada às características pessoais e preferências individuais dos pacientes ${ }^{104}$.

Com relação à garantia de sigilo, considerada primordial durante a realização de qualquer pesquisa, também era desconhecida por quase metade dos sujeitos $(47,5 \%)$. Da mesma forma, chama a atenção o fato de $46,2 \%$ dos sujeitos terem informado que não receberam qualquer tipo de orientação a respeito das formas de reparação diante de eventuais danos ou problemas decorrentes da participação na pesquisa. Isto porque tanto o fornecimento adequado da informação quanto o sigilo das mesmas são responsabilidade exclusivamente dos profissionais envolvidos na pesquisa $^{105}$. Esses resultados indicam que a obtenção do consentimento informado provavelmente não é um processo orientado, mas limitado a uma simples apresentação da proposta do estudo ${ }^{106}$.

Observou-se também, em nossa casuística, que somente $67,1 \%$ dos participantes leram o TCLE antes da assinatura. Resultados semelhantes foram encontrados por Verástegui ${ }^{95}$ com pacientes oncológicos. Nesta pesquisa, $57 \%$ dos pacientes leram o consentimento, e a principal razão para não terem lido foi o analfabetismo, presente em $31 \%$ da amostra. $A$ autora também observou que $8 \%$ dos pacientes não leram o documento por considerarem a explicação médica suficiente para a decisão de assinar o termo, e dos que leram somente 8 pacientes acreditaram que seu entendimento do tratamento proposto melhorou após a leitura do documento. 
No estudo de Cassileth et $\mathrm{al}^{107}$, conduzido na Filadélfia, $60 \%$ dos participantes entenderam o objetivo e a natureza dos procedimentos médicos em avaliação feita no dia seguinte à sua obtenção do TCLE; no entanto, somente $40 \%$ dos participantes leram-no antes de assinar.

Isso reforça o consenso de que o TLCE nem sempre tem recebido a atenção que merece independente do país em que a pesquisa é conduzida, e é encarado, muitas vezes, com uma mera peça burocrática, na expectativa de eximir o profissional de futuras conseqüências, caracterizando-se como um termo de isenção de responsabilidades ${ }^{60,108}$. Muito freqüentemente, os profissionais consideram o consentimento informado como um requerimento legal, mais do que uma oportunidade para facilitar a autonomia do sujeito da pesquisa $^{109}$.

Em nossa pesquisa pode-se constatar uma tendência de uma associação negativa entre companheiro e leitura do TCLE antes da assinatura, ou seja, os que tinham companheiro como maior freqüência não leram o documento antes de assinar. Dentre várias interpretações, é de se supor que isso ocorra pelo fato de se atribuir ao outro a co-responsabilidade pela decisão em participar do estudo.

Por outro lado, o paciente não lê o documento em virtude da confiança na informação fornecida pelo médico, e acaba concordando com tudo que Ihe é proposto, abrindo mão de sua autonomia. No entanto, o respeito pela autonomia dos pacientes não está baseado no pressuposto da paridade, mas no reconhecimento do direito de autodeterminação do paciente, que é a parte mais vulnerável da relação ${ }^{110}$. Talvez isto também 
explique o que ocorreu quanto à interação com o pesquisador, verificando-se que $68,1 \%$ dos participantes do grupo 1 e $60,6 \%$ do grupo 2 não conversaram sobre o termo com o pesquisador. É de se supor que isso ocorra em virtude da assimetria existente na relação entre o pesquisador e o sujeito de pesquisa e que guarda estreita analogia com a relação médicopaciente, onde a figura do médico geralmente expressa a imagem do poder e detenção do conhecimento, de forma que questionar ou contestar sua fala pode não ser um facilitador da relação pesquisador-sujeito ${ }^{111,112}$.

No que concerne ao entendimento, nota-se que a metade dos indivíduos do nosso estudo, tanto do grupo 1 quanto do grupo 2, não entenderam o conteúdo do TCLE, mas assinaram-no mesmo assim. Isso demonstra que muitos pacientes assinam o consentimento e concordam em participar sem de fato entender o que foi proposto a eles. É nestas circunstâncias que a realização da pesquisa em populações vulneráveis suscita questões éticas, representa uma grande responsabilidade para o pesquisador e pode trazer riscos pessoais para os sujeitos da pesquisa ${ }^{113}$. Deste modo, as pessoas com autonomia reduzida, ou seja, as que são sujeitos vulneráveis, devem ser protegidos para que não sejam usadas apenas como meros meios para os fins de condução da pesquisa e desenvolvimento da ciência ${ }^{114}$.

No entanto, o respeito à autonomia das pessoas traz como condição a necessidade de situá-la no contexto social a que pertence. Por isso, há que se considerar a vulnerabilidade dos indivíduos nas suas diferentes dimensões, ou seja, individual (comportamento e as crenças pessoais), 
social (pobreza, desigualdades sociais, acesso aos serviços de saúde e educação, o respeito as diferenças culturais e religiosas e marginalização de grupos) e programática (programa nacional de combate à Aids) $)^{114}$.

Nesse âmbito, muitos estudos têm questionado a efetividade das práticas comuns de esclarecimento do TCLE utilizadas na pesquisa clínica $^{115}$. Essa preocupação tem surgido porque muitos pacientes, a exemplo dos deste estudo, são incapazes de entender os detalhes da informação do termo de consentimento informado apresentado a eles ${ }^{28,62}$.

Para entender o tratamento ou a pesquisa o sujeito deve ser capaz de receber, codificar, reter e processar a informação. Tal fato envolve necessariamente modalidades sensoriais de atenção, memória e cognição ${ }^{59}$.

Além disso, a compreensão está inserida no contexto do processo para tomada de decisão, que é essencialmente subjetivo e, como tal, está à mercê de crenças, valores e sentimentos do indivíduo no momento da sua tomada de decisão.

Segundo Grisso e Apelbaum ${ }^{116}$, a capacitação para o processo de tomada de decisão exige do indivíduo quatro habilidades funcionais: a habilidade de compreender informações relevantes; a habilidade de apreciar a natureza de uma situação e suas prévias conseqüências; a habilidade de raciocinar com as informações obtidas; habilidade de comunicar a sua decisão.

Cabe salientar que a falta de uma habilidade não significa que o paciente tenha um déficit em todas as habilidades para tomar uma decisão. Isto pode ser aplicado aos pacientes com baixo nível de escolaridade, com 
hábitos culturais diversificados ou com pouca experiência prévia em relação ao ambiente médico, que podem não entender completamente todas as alternativas ou a maioria dos riscos do tratamento proposto. Contudo, mesmo assim podem ter entendimento suficiente para tomar sua própria decisão $^{117}$.

Outro fator a ser destacado refere-se à adequação da comunicação de quem aborda o sujeito para participar da pesquisa, considerada indispensável neste processo, e que deve abarcar não somente os aspectos inerentes à pesquisa clínica, mas também as características e valores específicos do sujeito $^{118}$. Além disso, o tempo dispensado para decidir sobre o TCLE também tem influência direta neste processo, podendo prejudicá-lo (ao apressar o sujeito para decidir) ou até mesmo facilitá-lo (quando é dado um tempo adequado para que o sujeito possa tomar uma decisão mais autônoma $)^{119}$. Neste particular, deve-se considerar também que a avaliação da capacidade do paciente para tomar uma decisão é um aspecto intrínseco da relação médico-paciente ${ }^{120}$.

No entanto, a capacidade para tomada de decisão é o elemento do TCLE que suscita maiores dificuldades no contexto clínico-assistencial uma vez que não há critérios, padrões e protocolos consensuados para uma adequada avaliação, em virtude da inúmeras variáveis envolvidas neste processo $^{121}$ :

- A avaliação da capacidade consiste na valorização de um certo número de atitudes ou habilidades psicológicas que o paciente deve possuir em um grau suficiente (padrão); 
- A capacidade de um sujeito deve sempre ser avaliada em relação a uma tarefa completa;

- A capacidade de um paciente não é necessariamente estável ao longo do tempo. Por isso, a avaliação deve ser um processo contínuo, integrado ao seguimento clínico do paciente e não um ato isolado no tempo;

- As escalas para avaliação de capacidade desenvolvidas na bibliografia americana fazem referência às atitudes dos pacientes para receber, compreender e processar racionalmente a informação e tomar uma decisão. Esses critérios se fixam mais na gênesis da decisão do que no processo como um todo;

- O elemento fundamental que diferencia as decisões na área da saúde de outras é a repercussão que esta pode ter na vida do próprio paciente.

No entanto, na concepção deste autor, a capacidade de uma pessoa para tomar uma decisão pode ser mensurada por dois critérios complementares: o cognitivo (entendimento) e a livre escolha (volitivoafetivo). Todavia, não há uma definição clara de quando se satisfazem em um grau adequado (padrão) e tampouco como devem ser mensurados (protocolos) $)^{122}$

É de se supor que essa dificuldade ocorra porque as razões para as limitações cognitivas e emocionais que interferem na compreensão e memória acerca de uma informação são complexas e relacionadas às características individuais de cada paciente, também pelo modo como estes 
têm sido influenciados por suas condições socioeconômicas e pelo ambiente onde vivem $^{123}$

Como aditivo, há muitas circunstâncias envolvidas neste processo que podem limitar a capacidade de compreensão da informação, como a própria imaturidade do sujeito frente a uma situação desconhecida e as barreiras culturais e emocionais entre um paciente e um médico ou entre um paciente e a própria instituição ${ }^{124}$. Além disso, a idade do sujeito e o nível de instrução também têm sido apontados pela literatura como preditores demográficos que podem influenciar o entendimento do sujeito no processo de consentimento informado. Não observamos isto em nossa amostra, provavelmente porque a maioria dos sujeitos tinham mais do que 50 anos e quae a metade estavam acima dos 60 anos.

Na revisão sistemática realizada por Flory e Emanuel $^{57}$, a idade foi associada com pouco entendimento em cinco estudos (todos com $p<0,05$ ) que incluíram participantes com idade média superior a 50 anos. Apesar da associação negativa entre idade e entendimento descrita na literatura, os pacientes mais idosos tendem a se beneficiar de estratégias utilizadas para otimizar a compreensão do TCLE. No entanto, os pacientes com idade mais avançada e baixo nível de instrução mostram-se mais vulneráveis à compreensão da informação ${ }^{59}$.

No que concerne ao nível de instrução, na revisão realizada por Dunn e Jeste ${ }^{59}$, dos nove estudos que abordavam a associação entre nível de instrução e entendimento oito apresentaram uma associação positiva, 
comprovando que o nível de escolaridade está associado com o entendimento do sujeito.

No estudo de Taub et al. ${ }^{125}$ realizado com 188 pacientes um dia antes do cateterismo cardíaco, a compreensão variou inversamente com a idade e diretamente com o nível de instrução. Neste estudo a compreensão foi avaliada utilizando-se dez questões de múltipla escolha com quatro alternativas. A idade dos pacientes variou de 27 a 69 anos, sendo que $44,7 \%$ se encontravam na faixa etária de 50 a 59 anos e, destes, $54,8 \%$ possuíam nível de instrução acima de doze anos.

No entanto, as variáveis que dificultam a compreensão das informações e a tomada de decisão pelo sujeito não estão restritas apenas a pacientes com disfunções cognitivas ou psiquiátricas, uma vez que várias doenças ou medicações também podem prejudicar entendimento da pesquisa $^{62,116}$. Entretanto, na ausência de déficit cognitvo, algumas doenças crônicas como angina instável ${ }^{126}$ e diabetes melitus ${ }^{127}$ não têm sido associadas com incapacidade para tomadas de decisão.

Esses dados podem ser corroborados pelo estudo de Ferguson com setenta e oito pacientes portadores de doença crônica que participaram de ensaios clínicos fase II, III e IV. As entrevistas foram realizadas utilizando-se um instrumento que combinava avaliação subjetiva com entendimento objetivo acerca dos principais componentes do TCLE. Quase todos os participantes (99\%) afirmaram entender "completamente" ou "quase completamente" a pesquisa $^{128}$. 
No que tange a esta pesquisa, outros fatores também devem ser considerados diante dos resultados, como a presença de termos técnicos no documento, tradução do consentimento utilizado nas pesquisas patrocinadas pela indústria farmacêutica e número de páginas do documento, que direta ou indiretamente acabam por ter impacto no processo decisório.

A complexidade das informações que são apresentadas no TCLE, bem como a presença de termos técnicos e o excessivo número de páginas, são fatores que contribuem para dificultar o entendimento dos participantes da pesquisa ${ }^{108,129,130}$. No estudo de Bulla et al. ${ }^{131}$ analisando quarenta e oito termos de consentimento informado em quinze diferentes serviços da área médica do Hospital das Clínicas de Porto Alegre, a média do índice de legibilidade foi de $31,1 \%$, ou seja, considerados de difícil compreensão. Já com relação à escolaridade necessária para leitura dos mesmos, a média foi de 16,4 anos, considerada também superior à média de escolaridade dos pacientes atendidos neste serviço.

Embora em nosso estudo não se tenha analisado os termos de consentimento utilizados na condução dos ensaios clínicos, a literatura é unânime em reconhecer as habilidades literárias do sujeito como um fator determinante no processo de compreensão do TCLE. Os participantes com inadequadas habilidades literárias entendem uma quantidade mínima das informações do termo de consentimento ${ }^{132}$.

Outro importante fator a ser destacado refere-se ao fato de que os consentimentos freqüentemente utilizados na pesquisa clínica são elaborados em outros países e não adaptados ao contexto local. Os 
aspectos operacionais inerentes ao processo de adequação a outro idioma envolvem desde traduções imperfeitas, estruturas gramaticais inadequadas e complexidade da informação apresentada - dentre outros, que também podem interferir na efetividade do processo de obtenção do TCLE. No estudo de Hardy et al. ${ }^{133}$ com 34 pesquisadores que participaram de pesquisas na área de regulação da fecundidade, somente $44 \%$ disseram que o termo havia sido adaptado e a mesma proporção afirmou ter sido traduzido e adaptado, sendo que pouco mais da metade das traduções/adaptações haviam sido realizadas com a participação do pesquisador responsável (59\%).

No que tange aos instrumentos utilizados para mensurar o entendimento, na revisão realizada por Cohn e $\operatorname{Larson}^{58}$ analisando vinte e três trabalhos publicados no período de 1996 a 2007 acerca da compreensão do consentimento informado na pesquisa clínica e as estratégias utilizadas para melhorar a intervenção, mostrou-se que há dificuldade dos sujeitos em compreender a pesquisa da qual estão participando, bem como há uma grande diversidade de instrumentos utilizados para mensuração e avaliação, dificultando com isso a comparação dos estudos. Estes instrumentos são constituídos de questões objetivas acerca dos elementos do consentimento informado bem como questões subjetivas acerca da percepção de compreensão. 


\subsection{Considerações a respeito do termo placebo}

No que tange ao entendimento do significado do placebo, faz-se necessário esclarecer que houve uma tentativa prévia de se incluir no grupo II somente os protocolos que tivessem a palavra placebo explicitada no Termo de Consentimento Livre e Esclarecido, a fim de que a questão referente ao entendimento do significado do termo placebo pudesse ser aplicada a todos os sujeitos da pesquisa. No entanto, isso foi inviabilizado pela dificuldade de se encontrar nos consentimentos dos ensaios clínicos esse padrão de uniformidade de esclarecimento, ou seja, mesmo o estudo tendo um período de wash-out a palavra placebo não foi encontrada em todos os documentos. Deste modo, essa questão foi aplicada somente a 69 indivíduos.

Quando indagados sobre o que haviam entendido ou não a respeito do significado do placebo, verificou-se que quase a metade confirma o não entendimento do termo $(47,8 \%)$ ou tem crenças equivocadas quanto ao seu significado $(18,8 \%)$. Com isso, observa-se que o entendimento ficou restrito a apenas $20,3 \%$ dos entrevistados. Nota-se também que $13 \%$ dos participantes não apresentavam lembrança da informação no momento da entrevista. Embora não ter lembrança do estudo tenha sido critério de exclusão, neste contexto fica implícito o viés do tempo comprometendo a resposta de alguns dos participantes.

Moodley et al. ${ }^{134}$ entrevistaram 334 sujeitos num período de 4 a 12 meses após finalização de um estudo conduzido na África do Sul para testar 
a vacina para influenza. Os dados mostram que embora $91 \%$ tenham considerado a explicação acerca do estudo clara, $81 \%$ também não entenderam o significado do placebo.

Outro dado que chama a atenção foi o fato de apenas dez sujeitos $(21,3 \%)$ do grupo I terem entendido o significado do placebo. Considerando que todos os estudos deste grupo eram controlados por placebo, pode-se inferir que o entendimento do termo foi mínimo. Fazendo-se um paralelo, observa-se que as crenças equivocadas ou mitos representaram um percentual superior $(18,8 \%)$ ao entendimento correto $(12,8 \%)$, no total. Ainda com relação ao significado do placebo observa-se, na tabela 14, que dos 23 sujeitos que afirmaram terem entendido o significado do termo, quase a metade (dez sujeitos) possuía crenças equivocadas, demonstrando o comprometimento do entendimento.

De fato, Santos e Luis ${ }^{135}$ dizem que quando a pessoa não entende ou não obtém uma informação clara, ela tende a interpretá-la de acordo com o seu conhecimento, o que pode aumentar o grau de ansiedade e medo diante do desconhecido. Já para Beauchamp e Childress ${ }^{52}$ essa dificuldade na compreensão também pode estar relacionada a problemas inerentes ao processamento da informação pelo sujeito. Nestas circunstâncias, há pelo sujeito uma perda da capacidade de aceitar a informação como verdadeira ou não manipulada, mesmo sendo capaz de compreendê-la adequadamente. O mesmo não aconteceu com relação às respostas negativas, onde $71,7 \%$ dos participantes de fato não entenderam o significado. 
Como conseqüência nota-se, na tabela 16 , que $36,2 \%$ dos sujeitos que participaram dos estudos controlados por placebo, ou seja, do grupo 1 , não tinham conhecimento de que poderiam tomar um comprimido sem nenhum efeito durante o período do estudo; em outras palavras, acreditavam estar tomando um medicamento específico para o tratamento da sua doença.

No estudo transversal de Jofee et al. ${ }^{136}$, com 207 participantes de ensaios clínicos de oncologia, aproximadamente $30 \%$ acreditavam que seu tratamento já havia sido comprovado como o melhor tratamento para seu câncer.

Por outro lado, cabe destacar o elevado percentual (70\%) de entrevistados analfabetos/fundamental incompleto que entenderam que poderiam tomar um comprimido sem nenhum efeito durante três meses. Isso pode ser tomado como evidência de que há o entendimento verbal da informação na linguagem que é acessível ao sujeito. Tal fato evidencia a necessidade de instituir e subsidiar mudanças na prática assistencial de aplicação do termo de consentimento.

Cabe salientar que na literatura há uma grande diversidade de estratégias utilizadas para melhorar o entendimento dos participantes, compreendendo a utilização de multimídia, alterações no formulário escrito (contexto, estilo de escrever, formato ou extensão), encontros com um profissional para discutir as informações inerentes ao estudo, testes orais/feedback sobre as informações dadas a respeito do estudo, além de outras. 
$\mathrm{Na}$ revisão sistemática realizada por Flory e Emanuel $^{57}$ foram analisados quarenta e dois estudos, publicados no período de 1966 a 2004, que abordavam as intervenções utilizadas para melhorar o entendimento dos participantes no processo de consentimento informado. Para análise dos estudos, os autores levaram em consideração quatro critérios: se o estudo foi randomizado, se avaliou o processo de consentimento real ou simulado, o número de participantes e se foi publicado em uma revista com peerreviewed. Na conclusão destes autores, alguns métodos parecem ser mais efetivos do que outros neste processo:

- A utilização de multimídia substituindo ou adicionalmente à apresentação do termo de consentimento padrão utilizado não foi considerada um investimento confiável para melhorar o entendimento, devido ao alto custo e poucos efeitos demonstrados; de doze estudos que utilizaram esta estratégia, somente três comprovaram melhora significante no entendimento. Para estes autores, porém, pode ser um bom recurso para pacientes analfabetos de países em desenvolvimento.

- No que se refere às alterações nos formulários do TCLE, seja no contexto, estilo de escrever, formato ou extensão, também parece improvável que tenham grande efeito no entendimento por ser muitas vezes um processo irrealístico em alguns estudos e por não haver uma discussão atrelada ao processo, somente leitura. Não obstante, algumas evidências sugiram que um 
formulário resumido e exclusão de informações irrelevantes possam facilitar o entendimento dos participantes. De quinze estudos analisados, somente seis mostraram melhora significativa, mas nem todos foram considerados de boa qualidade.

- A utilização de um consentimento padrão e adicionalmente encontros à parte com um profissional qualificado parecem constituir uma abordagem mais confiável para melhorar o entendimento baseado nas atuais evidências disponíveis. Para tanto, o ideal seria uma enfermeira ou um educador neutro, e não necessariamente o investigador para reduzir o viés de interesses no estudo, o que poderia indevidamente influenciar os sujeitos no seu processo de decisão. Foram analisados cinco estudos que utilizaram esta estratégia, sendo que três comprovaram a melhora significativa do entendimento e dois mostraram uma tendência. Cabe salientar que também partilhamos da mesma opnião em relação à utilização desta estratégia para aplicação do TCLE.

- Com relação aos testes de feedback orais realizados acerca da informação ministrada e revisão das questões respondidas incorretamente, de cinco estudos todos mostraram melhora no entendimento. No entanto, há defeito metodológico sério, pois qualquer melhora na contagem do escore do teste poderia 
refletir uma decoração do texto, sem uma real melhora na assimilação do seu significado.

- Outros cinco estudos utilizaram uma miscelânea de intervenções e apresentaram impacto variado no entendimento.

\subsection{Dados sobre o impacto da participação na pesquisa}

No tocante ao impacto de participação em uma pesquisa clínica, constatamos que $81,2 \%$ dos sujeitos participariam de uma pesquisa semelhante. No entanto, a recusa foi maior entre os sujeitos que participaram de ensaios clínicos do grupo I $(23,4 \%)$, provavelmente pelo perfil de complexidade dos estudos e exames envolvidos na realização da pesquisa. Neste contexto, fica implícita a percepção do risco atrelada aos procedimentos e conseqüentemente à participação na pesquisa, ou então à dificuldade quanto à necessidade de comparecer ao hospital com freqüência por conta das várias visitas do estudo.

Além disso, vem à baila o sentimento de abandono externado por nove pacientes, mas que não foi comunicado ao pesquisador durante a condução do estudo. Dentre os motivos mencionados verificou-se que o mais freqüente entre os pacientes do grupo I foi o risco existente na realização dos exames da pesquisa $(6,4 \%)$, e para os do grupo 2 a freqüência das consultas $(6 \%)$, o que poderia ser justificado pelo perfil dos estudos de cada grupo, como mencionado anteriormente. Nesses achados, 
surgem questões que nos remetem a questionamentos não somente em relação ao comprometimento do entendimento a respeito do ensaio clínico, mas à inclusão de um participante que assinou um documento sem saber de fato o propósito da pesquisa e suas implicações.

Em contraposição, observou-se que 5\% dos participantes não desistiram da pesquisa em virtude do medo de serem desligados da instituição. Esse dado contrasta radicalmente com o princípio da autonomia, levando-nos a refletir o quanto de fato o sujeito da pesquisa é livre para decidir participar ou continuar na pesquisa quando depende da instituição.

No que concerne à importância atribuída em participar de uma pesquisa, $37,5 \%$ mencionaram o benefício pessoal - busca da melhora do estado de saúde - como o principal motivo.

Nos casos em que o sujeito erroneamente acredita que o estudo pode oferecer um benefício clínico substancial, o entendimento acerca da pesquisa pode ser questionado e relacionado ao conceito de "therapeutic misconception"137. Nesta condição, um paciente que entende ser a meta principal de seu médico encontrar o melhor tratamento para sua doença pode superestimar o benefício terapêutico no participar da pesquisa ${ }^{138}$. Em paralelo, no entanto, os ensaios clínicos podem acrescentar um corpo de conhecimentos e benefícios a futuros pacientes, como sabido, e não propriamente um benefício direto ao atual paciente participante ${ }^{58}$. Além disso, como pesquisador ou investigador, o médico toma decisões sobre o tratamento baseado no delineamento específico de cada estudo ${ }^{139}$. 
Por outro lado, as pessoas, na maioria das vezes, planejam suas vidas sem imaginar que em algum momento possam adoecer, e se sentem fragilizadas diante da doença, principalmente a cardíaca, que traz consigo conotações simbólicas que envolvem múltiplos significados e sentimentos. Ficar doente é um acontecimento da vida para o qual não se está preparado, pelo confronto com a vulnerabilidade do corpo e a temporalidade da vida ${ }^{94}$. Por isso, o convite para participar da pesquisa é visto, muitas vezes, por estes indivíduos como uma nova possibilidade de cura diante de um problema grave.

Na seqüência, sobressaíram os relatos valorizando a contribuição em prol da ciência $(33,8 \%)$ e à atenção médica diferenciada recebida $(28,8 \%)$. Vale acentuar que durante o período da pesquisa o agendamento dos retornos é mais freqüente, bem como a realização de exames exigidos pelo protocolo, o que leva as pessoas a se sentirem mais "cuidadas". Esse acompanhamento acaba tendo repercussão no tratamento de rotina, uma vez que há espaço para o paciente expressar seus sentimentos e se sentir ouvido, valorizado, e deste modo enfrentar melhor a situação que permeia sua vida.

Ainda dentro desta temática, foi mencionada a relação cambial, atrelando o valor de troca pela participação na pesquisa. É de se supor que nestes casos a participação na pesquisa tenha ocorrido por motivos particulares e motivados pela dependência do atendimento institucional.

Pelos dados do estudo, reconhecem-se também nos depoimentos que as experiências negativas encontram-se aliadas à diversidade de 
sentimento e atitudes influenciadas pelo sofrimento atrelado à realização dos exames inerentes ao ensaio clínico, e insatisfação, indiferença e incompreensão com a pesquisa. Essas questões remetem inicialmente ao modo particular de como cada pessoa reage diante do mesmo evento em decorrência de fatores ligados a experiências anteriores, ao significado atribuído à vivência, aos problemas presentes e a própria expectativa criada com relação à pesquisa. Outro fator a ser considerado diz respeito à incompreensão acerca da pesquisa, o que acaba gerando um grande descontentamento quando as expectativas são frustradas.

Com relação à indicação de um amigo ou parente para participar de uma pesquisa, observou-se que as temáticas identificadas estão em consonância com as identificadas na importância atribuída à participação.

No entanto, aparece o reconhecimento do risco decorrente da participação e a percepção de cobaia não mencionados anteriormente.

\subsection{Grupo focal}

O grupo focal foi realizado, nesta pesquisa, com intuito de complementar as informações obtidas por meio das questões objetivas sobre os elementos do consentimento informado, bem como as questões subjetivas acerca da percepção da pesquisa. Neste sentido constituiu importante contribuição, porque permitiu corroborar alguns dados já descritos anteriormente, e esclarecer aspectos importantes inerentes ao 
Termos de Consentimento Livre e Esclarecido e a participação na pesquisa, até então não verbalizados pelos sujeitos que integram a pesquisa presente.

\subsubsection{Percepção na pesquisa}

Com relação à percepção da pesquisa percebe-se na fala dos entrevistados, de ambos os grupos, que se tem consciência de estar participando do teste de uma nova medicação e/ou da descoberta de novos métodos de tratamento. No entanto, o Termo de Consentimento Livre e Esclarecido é visto como uma garantia institucional e não pessoal.

"É um trabalho para desenvolver novos medicamentos ou talvez até para testar um novo tipo de medicamento."

"É uma pesquisa pra ver se aquela medicação com o tempo pode ser lançada no mercado"

"É para descobrir novos métodos de tratamento, associação de drogas diferentes."

"...Se não for boa tem até um termo de responsabilidade que assina do InCor."

A pesquisa também é considerada para alguns participantes um tratamento que pode ser uma continuidade do convencional ou não, e até mesmo apenas um tratamento "psicológico".

"...É a continuação do tratamento que a gente tava fazendo antes, então para mim foi uma beleza, foi bom".

"Eu acho que a pesquisa é uma forma diferente de tratamento."

"...Vai proporcionar o tratamento diferente."

"O tratamento também é psicológico." 
Há também o reconhecimento, pelos sujeitos de ambos os grupos, do risco inerente à participação na participação e a insegurança diante do desconhecido. Por outro lado, também é considerada benéfica porque propicia um atendimento diferenciado e uma avaliação mais criteriosa, que muitas vezes não se tem na rotina de atendimento institucional,

\footnotetext{
“...Não pode ter medo."

“...Não melhorei, não piorei. Foi Deus, né?”

"Durante a pesquisa a gente tem aquele atendimento, até vamos dizer, um atendimento vip."

"Aqui você faz exame uma vez por ano quando eu tava na pesquisa fazia diretamente."

"O médico começa uma avaliação mais periódica."
}

Com relação à motivação para participação percebe-se na fala dos entrevistados que muitas vezes se busca na pesquisa a atenção não recebida e a segurança de estar sendo "bem cuidado". Contudo, o benefício pessoal esperado do ganho terapêutico ainda predispõe o sujeito a tomar uma decisão baseada, muitas vezes, em esperanças não realísticas.

\footnotetext{
"Se aquilo lá for muito bom você é um dos primeiros a sarar."

"...Pra melhorar a saúde."

"Eu entro em qualquer coisa desde que tenha uma atenção."

"...se tivesse um problema mais sério nós seríamos informados."
}

Por outro lado, alguns valorizaram a oportunidade de beneficiar indiretamente outras pessoas e contribuir para o avanço da ciência. Neste contexto, a discussão também polarizou-se em função do renome da instituição e do convite realizado pela enfermeira, demonstrando a influência do profissional neste momento de decisão. 
"Se não fosse a pesquisa como seria esse povo no mundo sem uma pesquisa pra tomar um remédio?"

Foi uma maneira que achei para retribuir para as pessoas, não só para mim."

"Você fala InCor todo mundo participa."

Não obstante, ainda persiste para alguns a noção de transformar-se em cobaia para o teste de um novo medicamento e o valor de troca (relação cambial) atrelado à participação.

"...é um tipo de cobaia, nós estamos participando pra ver se a medicação vai ser boa."

"Eu fui usado como uma cobaia."

"No fundo a gente foi uma cobainha."

"..dentro da ciência você tem que aceitar porque é bom pra gente, bom pra eles que estão precisando porque vão descobrir outras coisas."

\subsubsection{Compreensão do Termo de Consentimento Livre e Esclarecido}

No que tange ao TCLE, percebe-se na fala dos participantes do grupo I que o mesmo é considerado um documento complexo, de difícil compreensão, com termos muito técnicos e numa linguagem praticamente inacessível.

"Como sou curioso algumas palavras que não entendia eu perguntava para ele..."

"Eu li a palavra, mas não entendi o que era."

"As palavras do termo precisam ser em linguagem popular."

"...poderia simplificar mais aquilo que está lá mesmo porque nem todos conseguem entender."

Neste contexto, a compreensão do mesmo é favorecida pelos esclarecimentos adicionais realizados pela equipe e a leitura do termo é 
dispensada em virtude do vínculo de confiança estabelecido. A confiança mencionada tem um sentido amplo e significa confiança na integridade pessoal e na competência profissional. Percebe-se também que, muitas vezes, mesmo compreendendo a informação acerca da proposta do estudo o sujeito não necessariamente deseja fazer suas próprias escolhas, preferindo deixar a decisão final sob o arbítrio de seu médico ${ }^{56}$.

"O médico tem que passar uma confiança."

"Eu acho que tem que haver uma relação de confiança também, que não precisa ficar explicando demais."

\subsubsection{Entendimento do significado do placebo}

Com relação ao placebo os dados obtidos no grupo focal corroboram os dados já apresentados e são congruentes com os de outras pesquisas, demonstrando que muitas pessoas que participam de estudos com placebo não entendem o seu significado, acreditando tomar um medicamento verdadeiro ou nutrindo crenças diversas a respeito do mesmo.

Alguns pacientes, mesmo tendo consciência de que havia a possibilidade de tomar placebo, comunicaram melhora do quadro clínico. Por isso, o tratamento com placebo não deve ser considerado ausência de um tratamento, mas apenas ausência de um tratamento especificamente ativo ${ }^{12}$.

Como sabido, há evidências na literatura sugerindo que o efeito placebo está determinado também pela expectativa do benefício (melhora). Portanto, o efeito placebo pode ser produzido sem propriamente 
necessidade da administração do placebo, pois tudo depende do quanto o paciente está convencido de que vai melhorar com o tratamento em questão, seja placebo ou tratamento ativo ${ }^{140}$.

Nas doenças cardiovasculares o efeito placebo tem sido descrito em diversas situações. Nos quadros de angina crônica estável estima-se que a melhora dos sintomas com placebo pode ser atingida em $30 \%$ a $80 \%$ dos $\operatorname{casos}^{141}$

"Ao contrário dele entendi que era medicamento."

"Eu tomava ele crente que estava tomando um medicamento bom."

"...pode ter $70 \%$ disso, pode ter menos, ou pode não ser nada, só farinha de trigo."

"É um comprimido inócuo."

"Eu tomei o remédio que ele mandou, caminhei na esteira e melhorei." 
1 


\section{COMENTÁRIOS E PERSPECTIVAS}

Embora estes resultados sugiram a necessidade de instituir mudanças no formulário de consentimento informado, eles também apontam para a complexidade do processo, que perpassa pelo aspecto moral da relação médico-paciente, evidenciando que apenas as normas legais de um país, por melhor que sejam, nunca serão suficientes para assegurar os aspectos éticos de uma pesquisa que depende da postura ética e dos valores de um profissional.

Isto levanta questionamentos sobre o TCLE e o quanto é importante a palavra do profissional que aborda o paciente neste processo de tomada de decisão, especialmente quando os sujeitos são pouco letrados e dependem do atendimento em um hospital público. Nestas circunstâncias, o sujeito acaba sendo muitas vezes refém de uma situação na qual deve seguir à risca o que Ihe dizem pouco compreendendo da mesma, apesar da vontade de desistir da participação, como aponta este estudo.

Sem dúvida devemos rever a postura, quanto ao teor dos resultados encontrados, dos profissionais envolvidos com a pesquisa (pelo menos em nossa instituição), bem como ser proposta uma rediscussão sobre o que 
deve ser o TCLE e como aplicá-lo, levando em conta a responsabilidade institucional neste processo.

Neste contexto, é importante destacar o quanto a instituição é fundamental na vida destas pessoas e o quanto se orgulham do status pacientes e sujeitos da pesquisa, surgindo daí o grande respeito que mostram pela mesma e pelos seus profissionais.

É importante destacar ainda que a participação do sujeito em um ensaio clínico também tem aspectos positivos, uma vez que favorece sua adesão ao tratamento em virtude do acompanhamento ser mais rigoroso e os retornos mais freqüentes, contribuindo com isso para a orientação minuciosa. Isto também deve ser considerado, pela instituição, na decisão de participar e desenvolver este tipo de pesquisa.

Outro aspecto a ser pontuado nesta pesquisa refere-se ao viés de lembrança da informação num estudo retrospectivo, mesmo tendo sido critério de exclusão dos participantes. É provável que, num estudo prospectivo com aplicação deste questionário ao final da participação no ensaio clínico ou após aplicação do TCLE, alguns dados pudessem ser diferentes, embora na realização do grupo focal isso não tenha sido evidenciado.

Consideramos que os resultados desta pesquisa apontam que o estudo da ética em investigação clínica faz parte da construção do conhecimento, em uma área de atuação relativamente nova no país. 
Cabe aos órgãos oficiais estimular estudos, uma vez que o rigor burocrático atrelado ao TCLE e aos centros de pesquisa não assegura a efetividade de um processo que tem como linha final o sujeito da pesquisa. 
1 


\section{CONCLUSÕES}

- O Termo de Consentimento Livre e Esclarecido é pouco compreendido pelos sujeitos e para alguns a confiança no seu médico é crucial para a decisão em participar de um ensaio clínico com fármacos;

- Evidenciou-se também influência do nível de instrução dos sujeitos no entendimento do termo placebo, mas que é melhor compreendido pelos sujeitos analfabetos/fundamental incompleto quando se muda a abordagem da pergunta, sugerindo fortemente que os Termos de Consentimento Livre e Esclarecido são ainda muito complexos e não exercem a função que de fato deveriam desempenhar;

- Não houve repercussão na vida dos sujeitos da pesquisa que participaram de ensaios clínicos com ou sem placebo, uma vez que a participação é motivada, na sua grande maioria, pela expectativa do benefício terapêutico. 


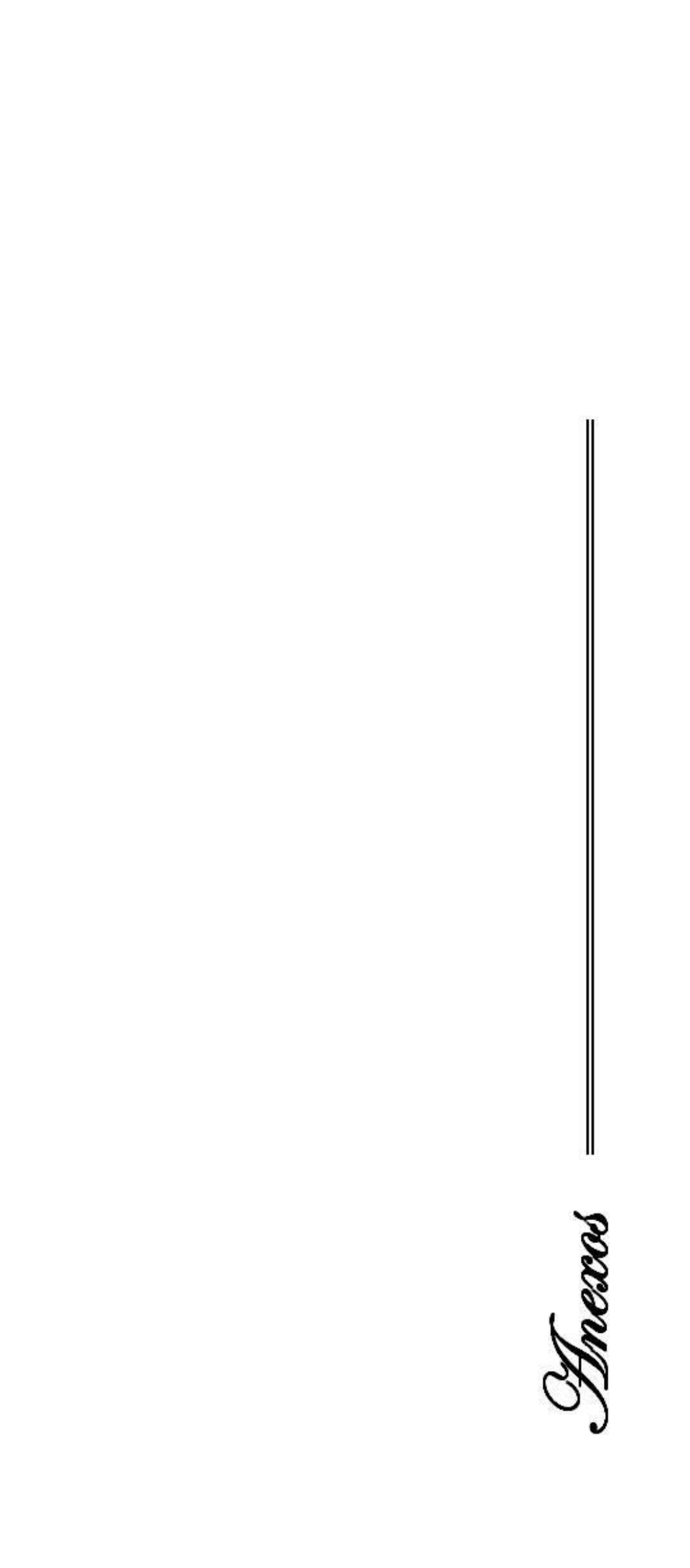




\section{ANEXOS}

\subsection{Instrumento para Coleta de dados}

Data:<smiles>CCCC</smiles>

Grupo:

Número no banco de dados:

\section{I - Dados de Identificação}

1 - Nome:

2 - RG: 3 - Idade: 4 - Sexo: $\square \mathrm{M} \square \mathrm{F}$

5 - Escolaridade:

- Fundamental: $\square$ completo $\square$ incompleto

- Médio: $\square$ completo

$\square$ incompleto

- Superior : $\square$ completo

$\square$ incompleto

6 - Estado civil:

7 - Profissão:

8 - De qual pesquisa participou?

9 - Participou do estudo até o final? $\square$ Sim $\square$ Não

10 - Há quanto tempo é paciente desta instituição?

11 - Qual o ano de início da participação?

\section{II - Informações acerca da participação na pesquisa}

12 - Quem o convidou para participar da pesquisa?
- Pesquisador
$\square$ Outro paciente $\square$ Enfermeira
$\square$ Secretária
口 Outros

13 - Foi importante para o(a) Sr(a). quem o convidou para participar da pesquisa?
口 Sim
Não

14 - Como foi feito o contato para o(a) Sr(a). vir para o hospital participar da pesquisa?
$\square$ Telefone
口 Pessoal
$\square$ Outros

15 - Foi dito que era para participar de uma pesquisa?
$\square$ Sim
○ão

16 - Por que aceitou participar da pesquisa?

- Para o bem da ciência

Em benefício próprio

- Porque o médico que o atendeu pediu 
- Porque o médico que o atendeu disse que era bom para o(a) $\operatorname{Sr}(a)$.

- Por medo de não ter atendimento ou perder a vez

- Porque é um hospital público

Outros:

17 - Foi informado:

A - Da importância da pesquisa?
口 Sim
Não

B - Dos possíveis riscos e incômodos que poderiam ocorrer em função da pesquisa?
口 Sim
口 Não

C - Da existência de outros tratamentos diferentes dos da pesquisa?
$\square$ Sim
口 Não

D - Da garantia de sigilo, isto é, nenhuma informação que possa identificá-lo? - Sim

Não

E - Das formas de ressarcimento das despesas que o(a) $\operatorname{Sr}(a)$. teria pela participação na pesquisa?
$\square$ Sim
- Não

F - As formas de reparação diante de eventuais danos ou problemas que poderia ter pela participação na pesquisa?
口 Sim
口 Não

G - Que poderia desistir a qualquer momento sem prejudicar seu tratamento na Instituição?
口 Sim
口 Não

18 - Quando o(a) Sr(a). decidiu participar da pesquisa assinou um documento?
$\square$ Sim
○ão

19 - O(a) $\operatorname{Sr}(a)$. leu o documento antes de assinar?
口 Sim
口 Não
○ão sei

20 - O(a) Sr(a). conversou sobre o TCLE com o pesquisador?

口 Sim

口 Não

21- Ao assinar estava certo de ter entendido o que o termo de consentimento explicava?
$\square$ Sim
口 Não

22 - Se não estava, o que fez?

- Assinou mesmo sem entender

- Pediu nova explicação ao pesquisador

O Outro:

23 - Foi entregue a(o) Sr(a). uma cópia do documento?

- Sim

口 Não 
24 - O(a) $\operatorname{Sr}(a)$. entendeu o que significava placebo?

$\square \operatorname{Sim}$

Não

E o que o(a) $\operatorname{Sr}(a)$. entendeu (ou não)?

25 - O(a) Sr(a). sabia que poderia tomar um comprimido sem nenhum efeito durante alguns meses? (Aplicável aos pacientes do grupo I)
口 Sim
Não

26 - Se convidado, participaria de outra pesquisa semelhante?
口 Sim
○ão

27 - Pensou em abandonar a pesquisa?

$\square \operatorname{Sim}$

Não

Se sim, por que não informou?

28 - Foi importante para o(a) $\operatorname{Sr}(a)$. ter participado de uma pesquisa?

- Sim

Não

Por quê?

29 - O(a) Sr(a). aconselharia um amigo ou parente a participar de uma pesquisa clínica?

口 Sim

口 Não

Por quê? 
8.2. Aprovação do projeto de pesquisa pela Comissão de Ética para Análise de Projetos de Pesquisa - CAPPesq

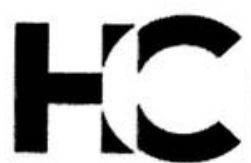

\section{APROVACÃO}

A Comissão de Ética para Análise de Projetos de Pesquisa - CAPPesq da Diretoria Clínica do Hospital das Clínicas e da Faculdade de Medicina da Universidade de São Paulo, em sessão de 26.01.06, APROVOU o Protocoio de Pesquisa $n^{\circ} 1223 / 05$, intitulado: "Avaliação de como os sujeitos de pesquisa entendem sua participação em estudos clínicos num hospital terciário." apresentado pela COMISSÃO CIENTÍFICA DO INSTITUTO DO CORAÇÃO, inclusive O Termo de Consentimento Livre e Esclarecido.

Cabe ao pesquisador elaborar e apresentar à CAPPesq, os relatórios parciais e final sobre a pesquisa (Resolução do Conselho Nacional de Saúde $n^{\circ} 196$, de 10.10.1996, inciso IX. 2, letra "c")

Pesquisador(a) Responsável: Prof. Dr. Luiz Antônio Machado César Pesquisador (a) Executante: Dr. Silmara Meneguin

CAPPesq, 26 de Janeiro de 2006.

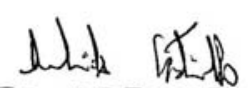

PROF. DR. EUCLIDES AYRES DE CASTILHO Presidente da Comissão de Ética para Análise de Projetos de Pesquisa

\footnotetext{
Comissão de Ética para Análise de Projetos de Pesquisa do HCFMUSP e da FMUSP Diretoria Clínica do Hospital das Clínicas da Faculdade de Medicina da Universidade de São Paulo Rua Ovídio Pires de Campos. 225, $5^{\circ}$ andar - CEP 05403010 - São Paulo - SP

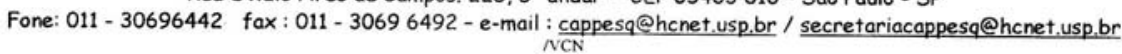




\subsection{Termo de Consentimento Livre e Esclarecido}

HOSPITAL DAS CLÍNICAS

DA

FACULDADE DE MEDICINA DA UNIVERSIDADE DE SÃO PAULO

TERMO DE CONSENTIMENTO LIVRE E ESCLARECIDO

(Instruções para preenchimento no verso)

\section{I - DADOS DE IDENTIFICAÇÃO DO SUJEITO DA PESQUISA OU RESPONSÁVEL LEGAL}

1. NOME DO PACIENTE

DOCUMENTO DE IDENTIDADE N ${ }^{\circ}$ :

SEXO:.$M \quad F$

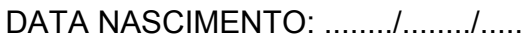

ENDEREÇO

BAIRRO:

CEP:.

TELEFONE: DDD

$\mathrm{N}^{\circ}$ CIDADE

2.RESPONSÁVEL LEGAL

NATUREZA (grau de parentesco, tutor, curador etc.)

DOCUMENTO DE IDENTIDADE :

SEXO: $M \quad F$

DATA NASCIMENTO.: .....................

ENDEREÇO:

No …........APTO:

BAIRRO:

CEP:

TELEFONE: DDD (

CIDADE

APTO:

.

Anexo D 


\section{III - REGISTRO DAS EXPLICAÇÕES DO PESQUISADOR AO PACIENTE OU} SEU REPRESENTANTE LEGAL SOBRE A PESQUISA, CONSIGNANDO:

Conforme já Ihe foi explicado pelo telefone, você está sendo convidado(a) para participar de uma pesquisa cujo objetivo é saber como foi sua participação numa outra pesquisa. Para tanto, você vai responder, sozinho, a um questionário com várias opções e depois será feita uma entrevista com outras perguntas para o Sr(a) responder também. As perguntas serão a respeito de sua participação em um estudo aqui neste hospital há algum tempo atrás. O tempo estimado de sua permanência no hospital para estas pereguntas é de menos de duas horas.

Após o término deste questionário termina sua participação, e você está dispensado(a) para retornar a sua residência. Conforme foi informado durante o contato telefônico, suas despesas de transporte serão pagas.

\section{IV - ESCLARECIMENTOS DADOS PELO PESQUISADOR SOBRE GARANTIAS DO SUJEITO DA PESQUISA:}

Esta pesquisa não trará nenhum risco a sua saúde. Não há previsão de qualquer reembolso exceto os da sua despeza de transporte, como já explicado.

A sua identidade não será tornada pública, mas os resultados desta pesquisa serão tornados públicos, com os cuidados de privacidade conforme a legislação vigente no nosso país.

\section{INFORMAÇÕES DE NOMES, ENDEREÇOS E TELEFONES DOS RESPONSÁVEIS PELO ACOMPANHAMENTO DA PESQUISA, PARA CONTATO EM CASO DE INTERCORRÊNCIAS CLÍNICAS E REAÇÕES ADVERSAS.}

Enfermeira Silmara Meneguin

Av. Dr. Enéas de Carvalho Aguiar n 44 - Cerqueira César - CEP: 05403-000

São Paulo - SP

Tel. (011) 3069-5239

VI. OBSERVAÇÕES COMPLEMENTARES: 


\section{VII - CONSENTIMENTO PÓS-ESCLARECIDO}

Declaro que, após convenientemente esclarecido pelo pesquisador e ter entendido o que me foi explicado, consinto em participar do presente Protocolo de Pesquisa

São Paulo,

de

de 200

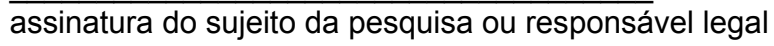

assinatura do pesquisador (carimbo ou nome Legível) 


\subsection{Transcrição da Gravação do Grupo Focal - Grupo I}

\section{Data:16/10/2007}

Início: $14 \mathrm{~h} 10$

Término: $15 \mathrm{~h}$

Convidados: 12 sujeitos da pesquisa

Presentes: 08 sujeitos da pesquisa

Intercorrências: 02 sujeitos chegaram atrasados

Técnicos: 01 moderador e 01 Observador

Local: Sala de Reuniões - $4^{\circ}$ Andar - Bloco I - Instituto do Coração - HCFMUSP

Moderador- E por que conversar? Ela terminou o levantamento dela e os questionários que vocês responderam têm alguns pontos que nós gostaríamos de conversar mais. Aí no lugar de estar fazendo um outro questionário, preenchendo um outro questionário a gente entendeu que a conversa era a melhor opção. $E$ assim, a gente pode estar trocando idéias. A conversa propicia que a gente troque idéias. E para qualquer dúvida nada melhor do que perguntar, não é? Então pergunta responde, responde pergunta, e é um caminho de duas vias. Vocês perguntam e a gente responde e a gente pergunta e vocês respondem. Também entre a gente e também entre vocês, certo? Então a primeira questão que fica assim no ar é se todo mundo entendeu o que é era uma pesquisa, todo mundo entendeu o que era uma pesquisa? Ficou claro?

JC- Sim, não ficou nenhuma dúvida.

Moderador-Para todos? O que era uma pesquisa... ficou claro para a senhora?

A- Eu queria uma resposta, com certeza, né Silmara?

Moderador- Você queria uma resposta?

$\underline{A}$ - Eu queria uma resposta, saber o que eu tomei na pesquisa, né? Depois se você passasse mal eu ia ter uma resposta. Mas e aí qual resposta que vai dar certo, que vai funcionar para as outras pessoas e tal, isso não pode falar...

Moderador- Toda pesquisa ela tem um segredo, né? Que às vezes nem o próprio pesquisador que tá fazendo conhece.

JC- Vai ser usado os dados de outros pesquisados e nem um deles vai saber, só quem tiver coordenando lá na frente quando chegar todo mundo junto, aí que ele vai ter uma resposta, pode até nem ter.

Moderador- Pode até não ter. Tem que fazer uma nova pesquisa para conseguir. A ciência é assim, né? É assim que ela caminha.

JC-É longo, né? 
A- É longo, o processo é...

Moderador-Eu não vou estar falando o nome de vocês e nem a Silmara, porque para poder ter memória depois a gente está gravando, certo? Então para poder ficar absolutamente tranqüila eu não vou estar chamando vocês pelo nome. Fiquem a vontade pra falar meu nome, e o nome da Silmara, não tem problema nenhum. É só o de vocês porque fica mais tranqüilo, mais fácil da gente falar, pelo menos na gravação a gente não está identificando. Então vocês estão me dizendo que sabiam que era uma pesquisa, ficou claro?

JC- Ficou, sim senhora.

MD- Não tem nenhuma dúvida?

$\underline{J R-S e m}$ nenhuma dúvida.

Moderador- $O$ termo de consentimento que é aquele papel que vocês assinaram, ele é que deixou isso claro?Foi ele?

G- Eu já respondi isso pra Silmara daquela vez.

Moderador- Todas palavras que estavam nele, ficaram tranqüilas no entendimento? Para senhora também?Também?

Moderador- Vocês conhecem alguém que participou de pesquisa, que não sabia ler e que comentou depois que teve alguma dificuldade ou que teve dificuldade com isso?

JR- Não.

G- Não

Moderador- E como que foi a relação do médico que pediu pra assinar o termo, ele foi claro? Ele explicou todos os pontos, eles permitiu um diálogo, como é que vocês sentiram no relacionamento.

JC- Bom eu... da minha parte não tive muitos problemas, porque eu que cuidei da minha esposa e era eu que anotava e que fazia tudo porque ela estava muito doente. Então eu já tinha mais ou menos uma noção do que é uma pesquisa. Não tive problemas, sem contar que a Silmara na época e o Dr. Marcos foram muito claros, não deu problema nenhum.

J- Ficou bem explicado pra gente, né Silmara? No meu entender nem ela sabia o que a gente tava tomando, que remédio que tava tomando se era fórmula, farinha e se fazia mal, né Silmara?

$\underline{J V}$ - Inclusive no medicamento que nós tava tomando tinha que anotar no papel o que estava tomando.

A- Só mais uma pergunta, todo mundo esteve com o mesmo médico?

G- Eu não, no meu caso foi com o Dr. Sérgio.

A- O meu foi o Dr. Marcos e a Cristina, vocês são de outra pesquisa?

MG- Eu com o Dr. Marcos e a Silmara. 
MG- O meu também.

$\underline{J C-}$ Veio a Silmara, a Cristina e depois a Vera.

JR- O meu era com o Dr. Reinaldo e o Dr. Marcos também.

J- O meu com o Dr. Marcos e a Silmara também.

$\underline{R-}$ O Dr. Marcos e a Silmara também.

Moderador- Vocês teriam...qual sugestão vocês dariam para que fosse colocado no termo de consentimento, porque ele é grande, né? Vocês teriam alguma sugestão para dar para que ele ficasse mais acessível na compreensão, na leitura, para que os profissionais ficassem mais dinâmicos, né? Que vocês pudessem pegar e ler sem problemas. Teriam alguma sugestão?

JC- Eu acho que não, poderia simplificar mais, aquilo que está lá mesmo, de um modo mais simples, porque acho que nem todos conseguem entender.

G- Eu como sou analfabeto às vezes tem palavra que ta lá e eu não sei o que é, o significado. Eu li a palavra, mas não entendi o que era.

$\underline{J C-E u}$ quero entender o que é pesquisa. Mas eu não fico me aprofundando. Eu acho que tem que aí tem que haver uma relação de confiança também, que não precisa ficar explicando demais tem que confiar no que ele tá fazendo.

A- Pelo menos o Dr. Marcos me explicou muito bem, né? Passou muito bem a pesquisa, ele falando, ele explicando, passou muito bem.

Moderador- Tá certo. Então, o que ajudou foi o fato ou da Silmara ou do médico estarem junto explicando, porque se fosse só o papel vocês teriam dificuldade?

$\underline{J C-}$ - Aqui pra nós, usa muito termo que pra nós é um palavrão às vezes.

JC- Eu como já disse, já acompanhei muito minha mulher pro outro lado. O lado de lá já estava habituado. A pesquisa de uma forma geral é uma forma de pesquisar uma coisa diferente, não muda muito.

Moderador- A gente agora tá fazendo uma pesquisa de opinião. Estou perguntando a opinião de vocês a respeito do preenchimento do termo de consentimento. $E$ vocês estão me dando uma resposta que é importante, muito, porque no dia-a-dia a gente constrói a frase e às vezes não percebe que está utilizando uma linguagem uma palavra que fora da instituição as pessoas, a grande maioria, não usa e na verdade as pessoas que participam são da instituição. Quem vai participar da pesquisa e quem vai ler, somos nós, certo? Então esta é a contribuição, e este é um dos motivos que a gente está aqui. É uma contribuição importante. É uma opinião importante de vocês porque a pesquisa como um todo também tem como objetivo modificar este contrato esta forma de contrato porque isso é um contrato. A pesquisa é um contrato de saúde de vocês, das duas partes. Vocês que contratam aceitam participar e nós que solicitamos que vocês assinam o contrato nos comprometemos a efetuar a pesquisa, né? A trabalhar com a pesquisa, a desenvolver e principalmente devolver os resultados que também é importante.

A- Porque eu acho que é assim, porque eu acho que quando a gente aceita a pesquisa, no meu caso, eu tava assim, tão, tava no começo. Ah! quer entrar? é 
assim. Ah, eu entro em qualquer coisa desde que tenha uma atenção. Acho que é carência. Tenha uma atenção. Mas se for só para colaborar não tem nada que você vai sarar. Claro, mas eu entro sim, eu sou extremamente curiosa, e tal. Eu acho que é pela atenção que a gente tem também, em saber aquilo lá porque você sabe que não vai melhorar nada, né?

JC- Tem duas coisas, né? Você vai entrar pra colaborar e tem um pouquinho do que falei para a Sra., do lado egoísta. Se aquilo lá for muito bom você é um dos primeiros a sarar. (risos)

MG- Eu estava muito mal quando entrei na pesquisa. Não podia fazer nada. Agora vou levar lixo, só não posso andar depressa. Nossa, do jeito que eu estava melhorei muito.

Moderador- E porque a senhora entrou nessa pesquisa?

MG- Eu passei no pronto socorro. Aí cheguei no pronto socorro, nossa eles me atenderam muito bem. Fiquei internada, fiz cateterismo. E aí quando estava fazendo a esteira, no mesmo dia, chegou um médico, que não me lembro o nome e perguntou se eu gostaria de participar. Ô se eu gostaria!

Moderador- E porque a senhora queria tanto?

MG- Ah! eu queria tanto porque eu queria ajudar e melhorar.

$\underline{A}$ - Então a senhora acha que o remédio melhorou a senhora, este remédio que a senhora tomou?

MG- Ah, eu tomei o remédio que ele mandou, caminhei na esteira e melhorei.

J- Eu também melhorei.

$\underline{J}$ - Eu não sarei do que era eu melhorei.

Moderador- E porque o senhor aceitou participar?

J- Aceitei porque a Silmara me convidou, né Silmara? Eu aceitei e tive vontade pra melhorar mais, e melhorei graças à Deus.

Moderador- E a senhora, porque aceitou?

$M D$ - Ah, eu aceitei porque fui convidada. Foi interessante porque aí entrou uma moça morena e aí me convidaram para uma pesquisa e aí veio a Silmara e o Dr. Marcos também. Eu aceitei porque acho que dentro da ciência você tem que aceitar porque é bom pra gente, bom pra eles que estão precisando porque vão descobrir outras coisas mesmo sendo uma cobaia, né? Porque nós fomos praticamente, fomos mesmo cobaia deles, então eu acho que foi interessante.

Moderador- E o que é ser cobaia?

MD- Então é o que eu penso, né? Ser cobaia é você dar tudo de si. Eu acho que é ser mesmo uma cobainha porque ia tomar o remédio e podia não servir para nada.

J- Não... eu tô entendo o que ela quer dizer. Só que eu acho que ser cobaia é o que injeta lá ... que nem antigamente é cobaia. Não é o caso da gente. 
MD- A última vez que vim aqui a Doutora Eva me chamou pra eu participar, fazer uma pesquisa com ela, cheia de aparelhos. No telefone ela falou para mim que não ia fazer nada, não ia sentir dor, não ia fazer nada, só uns exames.

MD- Eu acho que é isso. No fundo a gente também foi uma cobainha porque além de tomar o remédio que podia servir como não servir para nada. Como o $\mathrm{Dr}$. Marcos disse pode ter 70 por cento disso, pode ter menos, ou pode não ser nada, só farinha de trigo. Então a gente provou de tudo. Eu pelo menos não senti nenhuma evolução, mas não senti nada contra. Não melhorou. mas também não piorou. Foi Deus, né? Mas eu gostei de ter feito a pesquisa.

Moderador- E você porque aceitou participar?

G- Porque recebi o convite da Silmara, que é uma pessoa muito ótima. Também resolvi participar dessa pesquisa para ver se essa pesquisa tinha algum fundamento. Tomei remédio. Se melhorei ou não gostei de participar.

Moderador- E a Senhora?

$\underline{R-\text { Retribuição }}$

Moderador- Retribuição a que?

$\underline{R}$ - Foi uma maneira que achei também para retribuir para as pessoas, não só para mim.

\section{Moderador- E o Senhor?}

JR- Eu também, pra melhorar a saúde. Eu já tava, já tava aqui alguns anos e a Silmara me convidou e eu aceitei. Pra melhorar, né? E eu acho também que eu melhorei. Não sei se foi por causa do remédio da pesquisa ou do outro que até hoje eu tomo ele. Então ta aí... Com vontade de melhorar e de viver mais.

$\underline{J-}$ De viver mais.

JR- Eu tenho problema até cirúrgico. Então vamos ver se com o remédio melhora pra não precisar de operar. Era isso que eu queria, então é isso aí vamos ver se vai melhorar sem precisar de cirurgia.

Moderador- Pesquisa é tratamento?

JC- Tratamento é tratamento. Aí é um desenvolvimento do medicamento.

Moderador- Pesquisa é um tratamento? O tratamento é tratamento?

JC- É uma pesquisa do medicamento que vai proporcionar o tratamento diferente, mais moderno, mais sofisticado, sei lá. Mas é uma pesquisa, porque nem sabe se vai dar certo ou não.

Moderador- Então tem uma diferença?Tratamento e pesquisa, vocês concordam?

JR- Eu concordo também.

A- Eu concordo.

Moderador- Que tem uma diferença?

A- Tem uma diferença. 
$\underline{J C-E u}$ quando entro nessas pesquisas já tive mais ruim.

JC- A primeira não tive diferença nenhuma. Já na segunda na primeira semana eu falei pro Dr. Reinaldo que achava que era o medicamento e que não tinha nada de placebo porque eu senti a diferença. No entanto, eu tô aqui até hoje, melhorou e continuo aqui.

G- Eu vou complementar o que ele ta falando. Hoje eu tomei o remédio, e também acho que me senti melhor, porque veja só .. agora mesmo eu tô sentindo mais cansaço com o outro remédio, que pego aqui pelo hospital... Eu hoje me sinto mais cansado, em andar, subir escada. Inclusive agora em fevereiro fui passear no nordeste na casa de uma colega minha, e fazia muito tempão que não viajava para o nordeste, cheguei lá e passei mal tomando remédio. Aí fiz cateterismo semana passada e estou aguardando a Dra. Ângela me chamar para dar o resultado e ver se vai fazer safena ou vai botar uma válvula. E aí me chamaram pra essa pesquisa hoje e eu vim pra ver, pra ficar mais por dentro do assunto.

Moderador- Tá certo. E para a senhora, pesquisa é tratamento?

$M D$ - Acho que não.

Moderador- Não, são coisas diferentes?

Moderador- Então o que vocês estão me dizendo tava claro na hora que vocês assinaram, que vocês não corriam nenhum risco em relação a opção que vocês estavam fazendo. Se houvesse algum problema o médico estaria atento para imediatamente tomar uma posição. Tudo tava claro? Pesquisa é pesquisa e tratamento é tratamento.

JC- Pode ser tratamento, mas não é cientificamente um tratamento. Pode ser, pode não ser. Até hoje, eu não voltei a me sentir mal como me sentia antes.

$\underline{A-M a s}$ nesse tempo o senhor estava tomando a outra medicação também?

JC- Outra medicação. Mas foi mudado, para menos. Só que entrou outro que diminuí a freqüência cardíaca.

A- Mas não da pesquisa o outro normal ?

JC- Não, da pesquisa. O da pesquisa, saiu o normal e entrou um outro da pesquisa, mais fraco e entrou um outro. Esse outro que era placebo, a farinha, mas que não era porque eu senti a diferença. Estou sentindo até hoje, melhorou.

JC- Ainda tem a minha subida lá que é o meu termômetro.

JC- Ando rápido lá e não sinto mais nada, a não ser quando estou muito cansado.

A- Então pra mim foi o contrário. Eu continuo tomando a mesma medicação que eu já estava, mas aquele lá. E nos primeiros meses eu colocava aquele embaixo da língua e continuei colocando normal. E aí é difícil falar porque já estava com outra medicação.

Moderador- E quem é que tomou só o da pesquisa? Só o da pesquisa.

G- Eu tomei. 
Moderador- O importante é que vocês estão dando para mim. Primeiro o termo, as palavras do termo de consentimento precisam ser mais claras, menos científicas.

JC- Uma linguagem popular, né?

Moderador- Eu acho que é a opinião do grupo, você escolhe o porta voz do grupo que todo mundo coloca com a cabeça que era isso mesmo. Vocês estão me dizendo que a pesquisa não é tratamento, né? Isso significa que estava claro que vocês estavam participando de uma pesquisa. Isso também é muito importante pra gente saber e que num determinado momento das dúvidas, das respostas ficou essa dúvidas e por isso que a gente ta perguntando hoje. Vocês estão dizendo que a pesquisa tem dois lados: tem um lado afetivo que permite participar porque vocês se sentem mais acolhidos e também tem o lado da contribuição, se eu tiver falando alguma coisa que vocês não disseram interrompam dizendo, não é bem assim, por favor,... certo? E que tem o lado afetivo e tem o lado da contribuição para ciência, que de alguma forma metade do grupo veio pela pesquisa e pela contribuição, um pouco do grupo veio pela contribuição e depois acabou ganhando o afetivo pela confiança.

A- É porque é um trabalho no INCOR. Você falou em INCOR todo mundo participa.

Moderador- Passou alguma dúvida durante a pesquisa que vocês tiveram dificuldade de perguntar ou todas as dúvidas que surgiram foram esclarecidas? A equipe estava aberta para esclarecer?

JC- Não, qualquer coisinha que surgisse eu escrevia no caderninho do médico.

Moderador-A equipe estava bem aberta para explicar?

J- Tava.

MG- Sim, com a Silmara, o Dr. Marcos, Dr. Reinaldo, todo mundo, qualquer coisa .A gente tinha o telefone da Silmara.

MD- Não tive dúvida nenhuma.

J- Pra mim também, não tive dúvida nenhuma. Tudo marcadinho, o medicamento que agente tomava marcava o dia, a hora e quando sentia dor no peito marcava. Se colocava o remédio embaixo da língua marcava no papel, tudo diretinho.

Moderador- O Senhor sentiu que por parte da equipe se tivesse alguma dúvida, ela tava pronta pra responder?

J- Exatamente, tava sim.

Moderador- Querem saber porque eu tô perguntando? Porque esse também foi um dado que nos resultados nós tivemos dúvidas. Se as pessoas tinham encontrado na equipe apoio suficiente para poder estar esclarecendo, né? $\mathrm{E}$ aí, eu posso confirmar que vocês encontraram?

J-Encontramos, da Silmara, do Dr. Marcos.

JC- Não tive esse problema nem com o Dr.Marcos e nem com o Dr. Reinaldo.

$\underline{M D}$ - Não é bem assim. É que eu estava com muita dor na coluna e queria tomar um remédio pra coluna e eu liguei pro o Dr. Marcos e ele disse que eu não podia tomar. 
$\underline{A-E s s a}$ atenção pra gente foi muito importante, pela confiança.

$\underline{M D}$ - Ela mandou ligar. Não tome este, mas tome este. Eu queria tomar o voltarem e ele disse que não podia tomar o voltarem, mas podia tomar o paracetamol.

Moderador- Alguém sentiu vontade de sair da pesquisa?

J- Eu não.

MG- Pena que acabou a pesquisa, eu pensei que fosse mais comprida.

JR-Eu vim hoje pensando que ia continuar.

JC- Já perguntei pra enfermeira se não vai me chamar mais.

A- Quando ela me ligou estava travada da coluna, mas disse se não for pra fazer esteira conta comigo porque não dá. Já me encaminharam pro ortopedista.

Moderador- Então ninguém teve vontade de sair?

J- De jeito nenhum.

JR- Não, não. (Risos)

Moderador- Eu chamei para tirar as dívidas que restavam. Vocês estão dando informação importante. (risos)

G- E quando vocês estão aí melhora mais o atendimento.

Moderador- Somos todos funcionários da casa e a instituição de alguma forma tem esse papel, de tentar vincular um hospital escola ...que faz parte de um complexo de estudos de atendimento terciário. A gente agradece a colaboração de vocês, de estarem sempre prontos para poderem estar contribuindo.

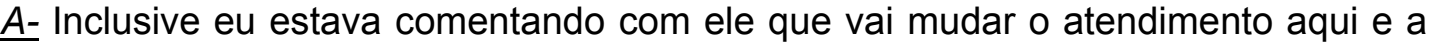
gente está com medo.

Moderador- Essa é uma informação que eu não tenho. Vamos esperar a Silmara voltar. A pesquisa quem está a frente da pesquisa é a Silmara e eu entro como um elemento externo. O pesquisador sempre pergunta e entende aquilo que às vezes por causa do afeto, do carinho acaba esquecendo de perguntar alguma coisa que pode ser o contrário. Então, a gente sempre faz o grupo com um outro pesquisador. A minha área de pesquisa é outra. Então quando o grupo é na minha área é a Silmara que às vezes vai coordenar, que vai participar, a gente vai trocando. Então esta resposta eu não sei dar quando ela voltar com certeza.

$\underline{J C-}$ - Muita gente tá caindo tudo aqui e aí afoga, sufoca aqui.

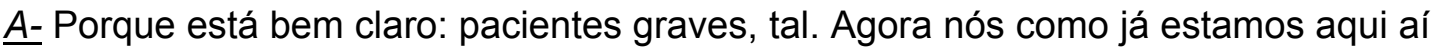
a gente tem está dúvida.

Moderador- Quem já está tratando enquanto não tiver alta continua tratando. Agora que entendi, não é em relação a esse tratamento, mas mudança na instituição como um todo, no Hospital das Clínicas.

$\underline{A}$ - Mas se eles me cortam eu perco a oportunidade de participar da pesquisa. 
JC- Não perde não, já está cadastrada aqui pra pesquisa. Isso é pra pacientes novos, e acaba sufocando o serviço porque não dá pra atender todo mundo.

G- Com o que a instituição tem não. Como já faço tratamento desde 2002 quando cheguei em Natal fui melhor atendido quando falei que era paciente daqui. Parece que estava adivinhando que ia acontecer, levei toda papelada minha do Instituto do Coração, a receita tudo. Fui muito bem atendido.

Moderador- Se o Senhor quiser trocar de cadeira aqui tem uma que talvés fique mais confortável. Fique à vontade, certo?

Moderador- A Outra questão que a gente está querendo conversar aqui, é o que vocês fariam com relação à mudança do termo? Que não houve dificuldade para entender porque o médico ou a Silmara foram explicando porque se fosse só a questão da escrita ele tem palavras que fogem. É que nem receita de bolo quem sabe fazer bolo pega a receita bate o olho vai lá e faz direitinho. Quem não sabe, pode ser. Se mudar uma colherzinha, pegar a colher de sopa no lugar da de chá, não é isso? E fazer confusão pronto. Estava escrito colher de chá. Pra quem não sabe, certo? E agora eu queria saber, uns disseram que tomaram placebo, outros disseram que tomaram comprimido de farinha, o que é placebo?

JC-É um comprido inócuo, é farinha. Não faz nem bem nem mal.

Moderador- É um medicamento?

JC- Não é um medicamento, ele é inócuo, não faz nada . Então aquele paciente vai ser estudado sem o remédio, tudo que aconteceu com ele sem o remédio. Aquele que tomou o remédio vai ser comparado com aquele com o que sentiu com o remédio.

Moderador- $O$ que você entende?

G- Eu ao contrário dele eu entendi que era um medicamento.

A- Eu também.

G- Entendi que era um medicamento. Porque desde quando ele veio para gente pra fazer o teste do remédio, ele vem como medicamento, pra gente tomar e dar a resposta pra saber se deu resultado.

Moderador- Ele foi entregue como medicamento, com o nome de placebo?

G- Com o nome de placebo, exatamente.

$\underline{J C-}$ Eu não vi nada disso. Era igual pra todo mundo. Ninguém sabia o que era.

G- O que eu lembro no momento não era não, mas o Dr. Jallad e a Silmara passaram bem para mim como medicamento.

Moderador- Para o senhor é um medicamento. E para a senhora?

$\underline{A}$ - É uma coisa que você vai ter. Deve ter alguma coisa a ver. Como ele falou podia ser farinha, mas podia não ser. Deve ser uma coisa que é um teste, acho que é uma medicação. 
G- Porque no meu entendimento às vezes, por exemplo, acontece de um paciente ter um outro tipo de patologia e às vezes toma medicação errada. Tomou o remédio errado. Quer dizer era um medicamento.

Moderador- Dentro do tratamento, e não dentro da pesquisa?

G- Dentro do tratamento, ficou claro?

Moderador- Dentro do tratamento pode ser que tenha uma medicação que é prescrita, que é dada contrária aquilo que o paciente precise, fora de uma da pesquisa?

Moderador- E na pesquisa você entende que o placebo é um medicamento que é dado?

\section{Moderador- E o senhor?}

JR- Eu também acho que é como um medicamento. Eu acho que serve como um medicamento. Eu tomava ele é crente que eu tava tomando um medicamento bom. Podia se de farinha o que fosse, mas eu tava tomando ele na fé, eu tava tomando ele como se fosse um medicamento original, entendeu?

JC- Eu tomava ele porque eu tava consciente de que eu tava em uma pesquisa. Porque eu tomava o placebo porque eu acho que não era medicamento, achava que era só farinha. O meu resultado ia ser comparado com o outro, que eles sabem o que é placebo e o que não é. Porque eu acho que nem vocês aqui, né?... Só o laboratório é que sabe. Então o meu vai ser comparado com o seu. Não sei se você toma farinha ou remédio. O nosso vai ser comparado e ele sabe. Resultado positivo para quem toma ou não. É uma pesquisa, né?

Moderador- A senhora tá concordando ou discordando? Ora faz assim, assim.

MD- Eu acho que é um medicamento, é tomado como um medicamento, ele pode não servir ou não servir, mas que ele foi dado como um medicamento ele foi. Pra mim é um medicamento.

Moderador- Apesar de vocês terem dito que pesquisa não é um tratamento?

$\underline{M D}$ - Não é um tratamento, mas o remédio, o comprimido que a gente tomou era um medicamento.

J-Eu também concordo porque tirou o outro que a gente tomava e a gente não passou mal tomando o comprimido.

Moderador- A gente não consegue pegar as frases..

MG- Eu fiz esteira, na esteira e ele falava pra mim que eu estava andando mais um pouquinho porque comecei não andando nada. Então, quer dizer que fiz exames de sangue, eco, fazia eletro toda vez que eu vinha. Então foi um tratamento muito bom onde eu ia arrumar para fazer todos os exames.

Moderador- Os exames eram o tratamento e o remédio?

MG-Também. 
Moderador- Como é para a Senhora? A Senhora está tão quietinha todo mundo está querendo escutar.

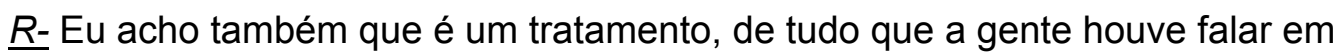
pesquisa.

Moderador- É um tratamento mesmo, sabendo que o que vocês tomaram podia ser um comprimido de farinha. Então, na opinião dele é um comprimido de farinha, que na constituição, pela opinião da equipe, ninguém sabe se é um comprimido verdadeiro ou de farinha, se é um comprimido inócuo. Foi isso que ele falou. Acho que só o Senhor está pensando assim. É um medicamento para a maioria. Toma como medicamento, é isso?

G- No meu caso os remédios foram afastados e eu fiquei só com ele.

MD- Eu também.

G-Porque aquele comprimido debaixo da língua sempre que usava via fazendo efeito.

$\underline{J C-}$ - Mas aquele não é da pesquisa.

$\underline{J R-}$ - Aquele numca precisei.

Moderador- Foi receitado, já comprei, mas nunca precisou?

$\underline{M D}$ - O meu foi receitado fora da pesquisa.

Moderador- E a Sra. usou.

MD- Passei mal dentro do metrô.

Moderador- Mas porque usou ou não?

MD- Porque usei, mas depois nunca mais usei.

$\underline{J-}$ Eu uso quando ando muito

$\underline{J C-}$ Eu usei só três vezes

Moderador- A Senhora usou?

MG- Não.

Moderador- Então eu vou recapitular as informações que vocês já disseram e vocês me corrigem que se eu estiver errada. O termo de consentimento é claro porque a equipe explica, não porque ele tá claro da forma que como ele tá escrito. É isso?

G- Exatamente.

Moderador- Às vezes complica as palavras. Complica um pouco, não todas.

Moderador- Precisa mudar a forma como deve ser feito. Está todo mundo de acordo?A outra informação que vocês deram é que aceitar participar da pesquisa é bom porque vocês se sentem mais atendidos, existe mais atenção da equipe, mais protegidos. É isso? 
JC- Eu não vi muita diferença de antes da pesquisa. Houve uma convivência maior, que é lógico cria-se um vínculo de amizade por causa da pesquisa.

Moderador- Mas e a confiança?

J-Eu vinha toda semana agora de ano em ano.

$\underline{J R}$ - Eu acho que melhorou por causa de mais exames. Tinha vezes que eu vinha duas vezes por semana aqui e agora uma vez por ano.

G- Marcaram meu retorno para vinte de outubro de 2008, mas se Deus quiser já fui para o nordeste.

Moderador- Este também é o motivo que faz com que vocês aceitem participar da pesquisa?

$M D$ - Acho que sim, porque na pesquisa tem uma aproximação maior com o médico. Eu vejo minha cardiologista de ano em ano. Os exames são de ano em ano.Vou fazer exame em janeiro e a consultar em fevereiro.

Moderador- Vocês deram mais um motivo da minha retomada.Tem o vínculo afetivo, tem a relação de confiança, que aumenta, tem o benefício da quantidade de exames que fazem que vocês acham que é melhor do que quando só está com o tratamento, é isso? Se eu tiver usando alguma palavra que não foi dita falem, por favor.

G- Tá certinho, pode continuar.

Moderador- A contribuição com a questão da ciência que vocês acham importante. O fato de que o placebo, e aí estamos com o grupo dividido, é um comprimido de farinha que não é medicamento, e só é tomado como um medicamento e que placebo ou comprimido de farinha é um medicamento. Que pesquisa é pesquisa, e tratamento é tratamento. É isso?

A- Certo?

Moderador- Que mais que saiu nesta história toda e que vocês fariam diferente, ou estariam sugerindo que é diferente? Todos disseram que estão prontos para a próxima pesquisa. Inclusive surgiu uma duvida com relação à mudança institucional dos casos novos no atendimento regionalizados e no atendimento das grande emergências para hospital terciário. A dúvida é se eles estariam recebendo alta ou seriam cortados da pesquisa em função desta determinação.

JC- Acho que aqui não tem ninguém pra receber alta. Pode determinar uma vez por ano, duas vezes por ano, mas alta acho que não vai ter.

A- Eu fiquei com medo

JC- O Incor perto da minha casa é uma desgraça. Não o pessoal clínico porque eu já fiz fisioterapia lá é uma beleza, mas até chegar lá é uma desgraça. Você vai trabalhar com ajudante do vereador tal e tal.

J-Eles não vão dar alta pra gente. Não tem problema nenhum pra gente.

JC- A maioria aqui tem uma patologia crônica. 
Moderador- Se no termo de consentimento no lugar de colocar patologia a gente colocasse doença crônica, fica mais claro?

A- Fica mais claro.

J- Claro.

Moderador- Agora eu e a Silmara somos as pacientes do hospital e vocês são os pesquisadores. Cada um vai convidar a gente para participar de uma pesquisa.

Pode começar, a gente vai ouvir. Como vocês fariam?

G-É melhor a Sra. fazer a pergunta e a gente responde. (Risos)

Moderador- Não é questionar, é convidar.

G- Não sei convidar não.

$\underline{R}$ - Acho que fica estranho chegar e convidar pra fazer uma pesquisa e dizer que tem ela uma doença crônica, acho que é mais bonitinho colocar lá patologia. Fica bem mais bonitinho.

A- Era isso que era queria ouvir, né?

Moderador- É mesmo, você acha?

Moderador- Você prefere patologia do que doença?

$\underline{R}$-É, todo mundo sei lá eu acho.

$\underline{J R-E u ~ n a ̃ o ~ c o n c o r d o ~ c o m ~ e s s e ~ n e g o ́ c i o ~ d e ~ p a t o l o g i a . ~}$

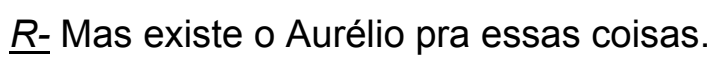

$\underline{J C-}$ Faz seis anos que não pego aquilo na mão, quando preciso ele nunca está por perto, é muito pesado.

Moderador- Para a Senhora é importante o termo científico dentro no termo de consentimento?

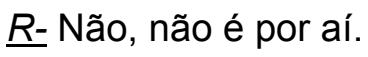

Moderador- Diga, nos estamos aqui para conversar, pra entender mesmo.

$\underline{R}$ - Não, eu tenho essa mania. Se eu vejo uma palavra que eu não sei o que é, que eu não entendo eu procuro mesmo. Até peço pro meu filho ir comigo na internet para ver.

G- Eu pelo menos essa palavra patologia vim descobrir de um ano pra cá porque pedi um laudo médico pra fazer uma perícia e na hora lá a Doutora falou pra mim que minha patologia.... e eu perguntei o que era patologia... pra tirar a dúvida?

Moderador- Por patologia ou por doença eu queria ser convidada pra participar de uma pesquisa. Silmara, você não queria? Pra gente poder entender.

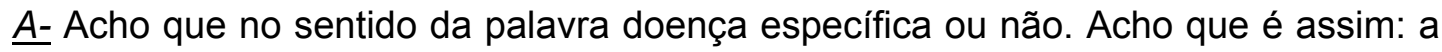
pessoa chegar pro outro e fala assim: você tem HIV positivo. Acho que não é o termo que você usa que vai chocar, mas é o como que você vai passa aquilo lá. Eu 
poderia falar: olha você vai participar de uma pesquisa porque você está com uma doença ... sei lá qualquer tipo de doença no caso.

Moderador - Infecto-contagiosa.

A- Uma doença grave, por exemplo, se fosse, sei lá. Então já ia ter que explicar tudo e você já tem o problema, a doença. Então acho que não é como você fala, mas como você passa aquela situação. Saber conversar com a pessoa pra receber sem se chocar..Quando ela falou patologia, o que é isso? Você já ficou assim.

$\underline{A-E l e ~ f a l o u ~ s e r a ́ ~ q u e ~ t e n h o ~ m a i s ~ u m a ~ d o e n c ̧ a ? ~}$

JR-Mas pra ele foi bom.

G- Para mim toda vez que uma pessoa falar patologia já sei o que é.

Moderador- Eu consegui recuperar todas as coisas que nós falamos? Faltou alguma? Faltou o convite.

$\underline{J R-E ́ ~ m e l h o r ~ e s c u t a r ~ a ~ s e n h o r a ~ f a l a r . ~}$

J- Pesquisa, nós pouco sabemos dessa que nós fizemos. Como que nós vamos convidar a senhora?

Moderador- Convida pra uma pesquisa de bolo, uma pesquisa de passeio.

G- Uma viagem pro nordeste.

Moderador- Não precisa ser pesquisa para tratamento. É uma pesquisa. Só não pode ser pesquisa política, o resto.

$\underline{A-}$ Acho que uma pesquisa, no caso da gente, é um teste. Você está com alergia. Aí eu falo pra você levar assim essa pomada aqui que é ótima. E aí você fala pra mim: e se eu passar e ficar pior? Então você volta amanhã e te vendo outra. Eu sou da farmácia. Aí você fala tem certeza? Eu vou falar pra você é um teste. Pra mim a pesquisa é isso.

Quando eu perguntei pro médico e aí agora quero saber o resultado. Eu fiz o teste e quero saber o resultado. Ele disse: não tem. Como não tem se eu fiz o teste eu quero saber o resultado. Mas eu falei brincando. Depois só eles que vão saber lá.

G-É isso que nós estamos perguntando para Silmara.

Moderador- Eles disseram que vieram porque tinham certeza que a pesquisa ia continuar.

$\underline{A-E l e s ~ e s t a ̃ o ~ c a r e n t e s . ~}$

A- Uma consulta de ano em ano é bom? É bom de mais.

Moderador- Ele está falando que fora de pesquisa a consulta é de ano em ano, mas se sentir qualquer coisa é pra vir direto pra cá. É um de ano em ano, mas de portas abertas. Vocês se sentem tranqüilos com isso?

$\underline{A-V o c e ̂ ~ c o n f i a ~ e ~ s a b e ~ q u e ~ t e m ~ p r a ~ o n d e ~ c o r r e r . ~}$ 
J- Se é de ano em ano é porque não é grave, né Silmara? Inclusive essa segunda pesquisa eu não participei porque a dor tinha um nível que acho que era setenta. Não sei o que é, mas o meu não atingiu porque estava bem melhor.

Moderador -Tinha um limite pra poder participar e o Senhor não ficou triste com isto?

J- De jeito nenhum, fiquei alegre. E tô melhorando, né Silmara?

Moderador- Alguma outra pergunta? Ou alguma pergunta já que todas quem fez foi eu.

Moderador- Nós gostaríamos de agradecer a todos que participaram 


\subsection{Transcrição da Gravação do Grupo Focal - Grupo II}

Data:19/10/2007

Início: 9h20

Término: $10 \mathrm{~h} 20$

Convidados: 12 sujeitos da pesquisa

Presentes:11 sujeitos da pesquisa

Técnicos: 01 moderador e 01 Observador

Local: Sala 2 - $2^{\circ}$ Andar - Bloco I - Instituto do Coração - HCFMUSP

Moderador- $O$ resultado dela ficou um pouco dividido com algumas respostas. Alguns acham por um lado e alguns acham por outro, então nós resolvemos fazer atividade de grupo para tirar essas dúvidas. Então hoje na verdade o que a gente vai fazer é um diálogo em cima destas duas dúvidas que surgiram e ninguém melhor do que as pessoas que responderam para fazer este diálogo com a gente do que outra pessoa, $50 \%$ deu x e $50 \%$ deu y. O melhor neste momento é fazer o grupo. Então para fins de memória está sendo gravando. Então para que as pessoas fiquem absolutamente à vontade na gravação eu não vou dizer o nome de ninguém, no máximo o Sr. e a Sra. E assim, as pessoas fiquem despreocupados com a gravação, como minha voz vai ficar, como que é, etc. Deixa ele no lugar porque depois a memória fica e continua com os pontos. Então, um dos primeiros pontos da minha dúvida é o que vocês entendem por pesquisa? O que é pesquisa?

$\underline{R R-E ́}$ um trabalho, pra desenvolver novos medicamentos, ou talvez até pra testar um novo tipo medicamento principalmente neste aspecto.

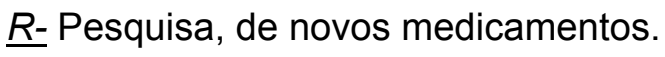

A-É para descobrir novas fórmulas.

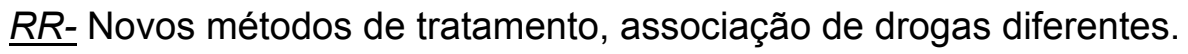

Moderador- Você gostaria de falar?

ME- Não.Pesquisa, não vou ficar aqui falando. O que a gente entende é isso, né? É um medicamento concordo com ele.

A- Eu fiz uma pesquisa aí por causa daquele Aradois, né? E deu certo pra mim, agora esse ano já mudou porque tava com um tipo de diabete, tava inchada inclusive.

Moderador- Pesquisa é tratamento?

$\underline{R-}$ Eu acho que é tratamento.

$\underline{R R}$ - Eu acho que não é o foco do tratamento.

Z-É uma descoberta. 
$\underline{R}$ - Mas de repente no tratamento tá tomando um medicamento que ela falou, o Aradois, né? $O$ que aconteceu é que se não tiver fazendo efeito a pesquisa, tá fazendo um tratamento.

$\underline{R R}$ - Eu acho que não é o tratamento, você participando de um trabalho de pesquisa você pode não necessariamente tá tomando uma droga, tá tomando remédio nenhum. Você pode participar destas pesquisas, é... tomando medicamento que não tem efeito sobre nenhum.

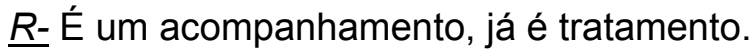

C- Eu acho que a pesquisa não é o tratamento, ela não é o tratamento, entendeu? É uma forma de você, uma formula de saber se aquela droga vai dar certo, se não der essa para, entendeu?

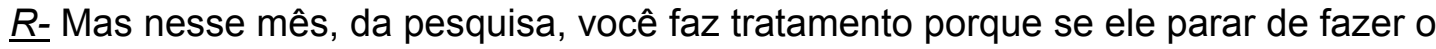
tratamento?

$\underline{C}$ - Não, tá certo porque ele não toma aquele medicamento toma outro, se der certo, né? Se der certo a pesquisa funciona, se não der ele para.

R- Ou muda o tratamento.

$\underline{R-E u}$ acho que a pesquisa é uma forma diferente de tratamento.

$\mathrm{MH}$ - A pesquisa que eu continuei fazendo, eu me senti muito bem, eu não senti nada, apesar que depois que eu parei eu me senti um pouco diferente, senti um pouco mais de fraqueza, falta de ar, eu não sentia falta de ar quando tava tomando o remédio. Aí depois eu fui no médico lá perto, foi depois que mudou o meu medicamento, minha pressão. Eu tomo remédio pra pressão alta, eu tomava remédio pra pressão alta, minha pressão tava normal depois que eu parei de tomar ele que eu comecei outro remédio minha pressão mudou, eu tomava remédio minha pressão tava $19 \times 8$. É isso aí que eu tô, é que o medicamento que eu tomava é melhor que os medicamentos que eu tomo.

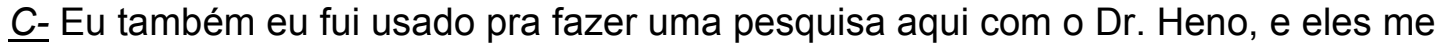
deram um potão assim do remédio lá, pra pressão, minha pressão ficou legal, ficou $12 \times 8$, entrava num baldinho com água, tal, legal, entendeu? Quando terminou, eu fiquei com saudades. Hoje eu estou tomando três tipos de remédios pra pressão e ela oscila, e na época não.

$\underline{R-}$ - Por isso é um tratamento. O tratamento também é psicológico, entendeu?

C- Parou! E eu fiquei com saudades do remédio.

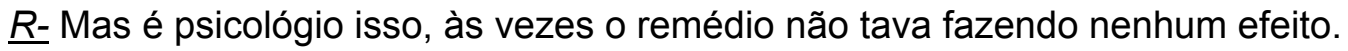

ME-Tem alguém aí. Tem alguém batendo.

$\underline{R R}$ - Eu acho que se fosse chamado de tratamento, o remédio que nós tivemos teria acompanhamento médico.

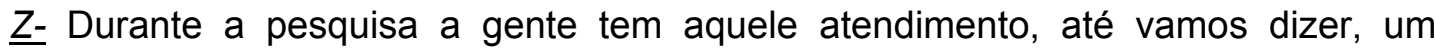
atendimento vip porque tanto pode dar certo, fazendo bem pro problema da gente, como também pode ser que dá errado. Então é um termo assim, de 
responsabilidade que a gente até assina no início da pesquisa. Ah! não é tratamento, é uma pesquisa pra ver se aquela medicação com o tempo pode ser lançada no mercado e que vai fazer bem pra várias outras pessoas através de nós que participamos e vai trazer benefício para muitas pessoas... que estão aqui no Incor, todo mundo. Mas é uma descoberta.

$\mathrm{R}$-Se iniciou o tratamento,e depois se aprovado esse remédio, esse remédio vai ser usado como um tratamento.

Z- Más só após a pesquisa que ele vai fazer um tratamento com ele, porque enquanto ele não for comprovado durante a pesquisa, ele não tá no mercado ainda pra ser vendido.

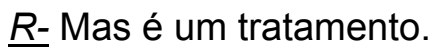

Z- Então, é uma forma de fazer pesquisa. Nós vamos ser o tipo do cobaia, é tipo de uma cobaia. Nós estamos participando pra ver se a medicação vai ser boa se não for boa a gente tem até um termo de responsabilidade que assina, do Incor, certo? Então se for um tratamento a gente não tinha que assinar.

$\underline{M H-O}$ que você vai fazer num jogo é jogar, né?

Z- Não, eu não concordo que é tratamento. Eu acho que é uma pesquisa pra melhoria nossa e do pessoal que vem aí, que tem problema quanto como a gente.

$\underline{\mathrm{MH}}$ - Na pesquisa a pessoa pode ganhar se o remédio der certo e pode perder, é tipo um jogo. A pessoa fala assim: eu vou jogar, eu vou ganhar. Sabe que pode perder, a gente tem que ter fé que vai dar certo

J-Bom dia, meu nome é J., então eu no caso da pesquisa eu fui tomar um remédio. Agora também na questão de fazer bem ou mal, também pra mim fez mal, né? $\mathrm{E}$ também eu tinha pressão alta eu não sentia nada, depois que eu comecei a tomar o remédio, deu falta de ar...

Moderador- A pergunta que fica no ar é Pesquisa? É tratamento? Ou pesquisa é pesquisa? E tratamento é tratamento?

J-É um teste da medicação.

Moderador- Mas é tratamento ou não é tratamento?

$\underline{A-}$ Eu acho que uma espécie de tratamento, porque continua, né?

A- É um teste.

A- Vamos ver se este medicamento, vamos investigar, vamos estudar este medicamento, e vamos investigar pra ver se este medicamento é bom pra você.

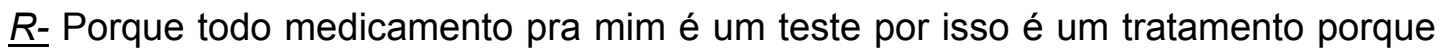
tem remédio de pressão que eu não posso tomar. Se eu tomar o coração entope, então aí eu tenho que voltar lá no médico pra ele me dá outro. Ele não fez a pesquisa ele tá fazendo um tratamento, é um tratamento.

$\underline{A-E ́}$ um tratamento. Se der certo você vai continuar se não, não vai. 
$\underline{R}$ - Então todo médico que você vai no consultório, então ele não tá fazendo um tratamento, tá fazendo uma pesquisa com você. Então eu acho que é um tratamento. Muito medicamento que o médico receita pra você não faz efeito, aí você volta naquele médico, e dentro do hospital também.

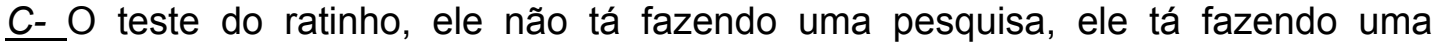
descrição do que vai acontecer com a gente

$\underline{A-M a s}$ uma coisa que ele estava comentando.

Moderador- Vamos tentar falar um por vez se não depois nossa memória lá fica toda bagunçada.

(Risos)

Moderador- Desculpe ele tava falando do ratinho e a gente já passa pra Sra..

Moderador- O Sr. tava falando do ratinho, né?

C- A pesquisa foi no ratinho.

C- Então ele tá tratando do ratinho? Não, ele está pesquisando. Então, não é um tratamento. Está pesquisando se o tratamento vai dar certo no paciente.

$\underline{R-}$ - Até eu concordo, o rato é uma pesquisa, mas com ser humano ele já faz tratamento, ele não vai colocar e igualar o rato com o ser humano.

$\underline{C}$ - Eu fui usado como uma cobaia, pra poder ver minha pressão que tava $17 \times 10$, vai. E ela baixou e ela ficou tranqüila, porque passei três meses aqui. Só que depois parou, e eu queria que continuasse, eu voltei de novo, né? Eu pego o remédio aqui pelo Incor e voltei de novo com a medicação do meu médico. Três remedinhos de manhã, três à noite, três de manhã, três à noite.

$\underline{A-}$ Aquele outro que o senhor tava tomando acho que já tinha sarado.

ME- Não tem cura. Ela tem controle. Fiz dieta, emagreci 22 Kilos e eu não tomei remédio pra pressão. Eu vou medindo assim duas três vezes no posto pra ver como está indo e não estou tomando não porque se eu tomar eu passo mal, minha pressão tá dando $9 \times 6$.

\section{$\underline{R-A i ́ ~ a b a i x a ~ m u i t o ~}$}

MH- Então, você tem que ver, sabe o que acontece? As pessoas toma remédio pra pressão alta. Eu conheço gente que toma remédio pra pressão alta e come é feijoada, toucinho, carne de porco, é muito sal na comida. Eu conheço umas pessoas que tomam remédio. Era melhor não tomar aquele remédio ou não comer o sal porque se a pessoa toma um monte de remédio pra baixar a pressão e come bastante sal, só sal, pega a salada e taca sal, é feijão salgado. Eu olho assim tá cheia de óleo em cima, de tanto óleo que tem no feijão. Eu conheço gente que faz isso, que fala que o remédio não presta. Às vezes o remédio pra ela é bom, o remédio. Mas tem gente que fala que o remédio não presta, porque a pessoa tá comendo sal, tá gorda, e o remédio vai abaixar a pressão, como? Não tem condições não.

ME- Tem que ver a dieta, a sua alimentação no dia -a- dia. 
$\underline{M H}$ - Às vezes a pessoa come o dia todo, tá gorda e não emagrece.

ME- Se você não fizer caminhada!

$\underline{\mathrm{MH}}$ - Meu colesterol tava muito alto, eu vim aqui o médico falou que meu colesterol tava alto, sabe o que eu fiz?

$\underline{M H-}$ Tirei todo óleo.

$\underline{C}$ - Olha a discussão aí, nós estamos fugindo da pergunta lá. Nós estamos falando de pesquisa e não de feijoada. (risos)

$\underline{R R-}$ Eu acho assim, eu acho que pesquisa e tratamento são coisas distintas. A partir da pesquisa pode surgir um tratamento diferente pra cada tipo de doença.

$\underline{C}$ - Você não é pesquisa, e eu também não sou...

Z- Eu acho que a pesquisa não é tratamento.

$\underline{C-N a ̃ o ~ e ́ ~ t r a t a m e n t o . ~ O s ~ d o i s ~ a c h a m ~ q u e ~ e ́ . ~}$

Z- Eu já estava me tratando no Incor, quando eu fui convidada a participar de uma pesquisa, quer dizer, eu já estava em tratamento aí. Eu tive um acompanhamento melhor, tipo um atendimento vip. fazia exame... Aqui você faz exame uma vez por ano, quando eu tava na pesquisa eu fazia diretamente, porque? Eu tava com uma medicação nova que o Incor tava testando.Pra mim é ótima porque se deu certo pra mim vai dar certo pra várias pessoas. Eu vou ficar feliz porque não vou estar pensando só em mim, eu quero o bem de todo mundo. Mas não é tratamento, eu acho que é pesquisa.

$\underline{R-}$ - Agora eu vou mudar a pergunta, aí o tratamento deu certo?

Z- Mas eu não continuei com o remédio da pesquisa, ficou na pesquisa, eu voltei pra minha medicação do tratamento.

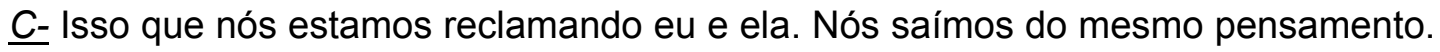
Então, só que pra mim também foi ótimo. Só que não continuou, e eu fiquei com saudades daquele medicamento porque ele não fez só comigo.

Moderador- Não, nós temos o grupo de vocês. É um grupo que participou de diferentes pesquisas, certo? Todas de medicamento, diferentes tipos. Então, quem continuou era porque a pesquisa era pra uma finalidade, quem não continua porque a pesquisa tinha outra finalidade, os detalhes das pesquisas eu não conheço e exatamente porque eu não conheço é que sou que estou coordenando esta atividade. Eu não sei quais foram as pesquisas que vocês participaram, quem eram do grupo de quem, o que era o objetivo da pesquisa. Eu só vim tirar a dúvida. Esse é o segundo grupo que a gente tá fazendo. A dúvida aparece e que o resultado que a gente encontrou ele é claro. A gente tinha uma dúvida de entendimento. As pessoas não tinham entendido o que a gente tinha perguntado, mas parece que é claro. Para alguns a pesquisa é tratamento, para outros a pesquisa não é tratamento, isso tá claro. Todo mundo concorda com as duas respostas?

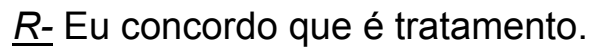


Moderador- A outra dúvida é: porque sendo tratamento, ou não sendo tratamento a pesquisa vocês aceitam participar? Por que a senhora aceita participar, porque a senhora aceitou participar da pesquisa?

$\underline{A-}$ Porque eu achava que eu tava cooperando com a melhoria não só da minha saúde, mas de outras pessoas também. Fui convidada, achei que seria bom pra mim e pra outras pessoas que tivesse o mesmo tipo de problema pra resolver. Pra mim na busca de uma solução, de um problema meu. Cada um ter uma resolução para seu caso como um todo, né?

$\underline{R R}$ - Eu concordo com ela, também acho que de certa forma vai contribuir pra com um resultado satisfatório pra mais pessoas e também eu acho que eu já imaginei, como aquela senhora disse. que a gente tem um tratamento vip mesmo, tem uma série de exames extras. Então também tem um lado positivo, com uma avaliação mais criteriosa, o médico começa uma avaliação mais periódica. Se a gente tivesse um problema mais sério nós seríamos informados, eu sairia do grupo de pesquisa porque de alguma forma a gente seria informado. Então, eu acho que principalmente pode contribuir para uma satisfação pessoal também.

Moderador- A senhora?

Z- Eu também concordo que estando participando, vai ser bom pra mim, e pra todas aqueles outros que tiverem um problema igual ao meu. Uma descoberta de uma nova fórmula, prá tratamento que é uma coisa tão... coração, né? Pressão alta... Então, é bom pra mim, é bom prá várias pessoas. Eu quero mais é contribuir, não só pensando em mim, mas em toda a população que tenha um problema desses.

Moderador- E o senhor?

O- É o meu também o que ela disse é a mesma coisa, é um... o tratamento é a continuação do tratamento que a gente tava fazendo antes, então pra mim foi uma beleza, foi bom.

Moderador- E por isso os senhores aceitam participar?

$\underline{\mathrm{MH}}$ - Eu acho a pesquisa muito boa, porque se não fosse a pesquisa como seria esse povo no mundo sem uma pesquisa pra tomar um remédio? Então, de todo jeito tem que ter pesquisa pra tomar o remédio prá a humanidade, não é só pra mim é prá todos.

$\underline{C}$ - Eu concordo com ela também é o que eu falei no primeiro item lá, até fiquei com saudades do remédio porque controlou minha pressão e depois tive que voltar de novo pros outros remédios que eu tava tomando. Inclusive, continuo tomando eles até hoje. Então, concordo com ela.

$\underline{\mathrm{MH}}$ - As pessoas vivem tomando tipo uma benzetacil, ficam tão bem tomando benzetacil. Eu mesma não posso tomar benzetacil, a outra pessoa pode tomar eu não posso. É igual pesquisa, a pessoa fala assim. É, nós somos ser humano, a pesquisa tem que tá ali para ajudar a pessoa. não pode ter medo de pesquisa. É igual o negócio do HIV, tanta pesquisa que tem aí ainda não foi descoberto, mas vão descobrir ainda um remédio, mas tem que ter vontade de pesquisar, não pode ter medo. 


\section{Moderador- E a senhora?}

$\underline{A}$ - Eu também concordo, porque eu fiz a pesquisa e continuei tomando o remédio da pesquisa que ele fez. Quer dizer, o que eu deixei porque mudaram a medicação. Quando for agora eu continuei tomando mais o losartam, né? E eu concordo porque o que eu não tô tomando, mas ela pelo jeito já tá, serve pra outro.

Moderador- A Sra. compreende a pesquisa como uma contribuição?

$\underline{Z}$ - É, também como uma contribuição, pra mim e pra outras pessoas.

JV- Eu também tava passando com o Desidério Favarato e chegou uma médica lá e olhou meu fichário naquela época. Aí falou com o Dr. Sérgio também ....Eu entrei, me dei muito bem, que nem o senhor falou, um tratamento vip. Não só por isso, mas me dei bem, e voltei a tomar os outros remédios que eu tomava e continua a mesma coisa. Então, pra mim, aquilo não foi uma pesquisa foi um tratamento porque o remédio me deu bem.

$\underline{R R}$ - Continua tomando?

$\underline{J V-T}$ omo, continuo tomando o que o Desidério Favarato passou.

$\underline{R-} \mathrm{O}$ da pesquisa?

$\underline{J V}$ - $\mathrm{O}$ da pesquisa não estou tomando. Não veio nenhum remédio diferente... a menos que tenha outro nome aí que eu não saiba.

J- Agora a questão de continuar o tratamento. Na hora que fui fazer a pesquisa o médico falou: este remédio é super caro. Acho que custa $R \$ 90$ reais, o que eu estou tomando hoje a cartela é de $\mathrm{R} \$ 5.00$.

Moderador- Então tem pouco tempo, eu acho que a gente pode fechar. É que alguns entram na pesquisa como uma contribuição para a ciência e alguns pensam também que durante a pesquisa o fato da quantidade de exames ou do tempo, do período de exame ser menor isso dá mais garantia para descoberta de outras doenças que naquele momento vocês poderiam ter desenvolvido, é isso?

Z- Eu descobri que eu tava com tiróide na pesquisa, falei até com o Dr... não é Dr. Sérgio, era um outro. Ele falou que eu tava com os olhos muito inchados e falou que eu tava com diabetes. Falei não! Diabete não! Tiróide. Falei não, não tenho. Eu fiz exames.Tinha feito há dois meses, há um mês... Ele falou: vai colher sangue, foi com você, né?

Moderador- Tá certo, então, aí ele usou um protocolo. Na época se falava que era protocolo. Pesquisa é protocolo. Aproveitando a deixa do termo, da palavra, como que é assinar um termo de consentimento? Você assina um termo de consentimento pro Incor. Como que é assinar isso? Se a gente pegar um termo de consentimento e ler sozinho ele é claro pra todo mundo?

$\underline{M E-}$ Ele é claro. Aceitava se quisesse. Se não quisesse o tratamento seria 0 mesmo.

Moderador- Mas isso porque o médico tava junto explicando ou porque tava lendo o termo? 
A- Eu tava lendo.

Moderador- A senhora estava lendo?

C- Como sou curioso...

J- Fiquei em dúvida em relação aos riscos.

$\underline{\text { C- }}$ Como eu como sou curioso algumas palavras que eu não entendia eu perguntava pra ele, e ele me explicava. Só que no final eu tava consciente do que eu tava fazendo então...

Moderador- Pra todo mundo o termo ficava claro?

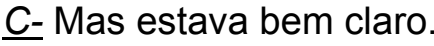

ME- Bastante claro.

C- Muito claro...

ME- Ele falou que não era obrigada a participar, explicou direitinho.

J-Apesar dele explicar todos os riscos ... fiquei com dúvida.

Z- Mas no termo tava escrito tudo, os riscos. Apesar que você tinha que ler bem e ver se você queria participar porque ali tava escrito tudo.

J- Mas na prática olha o que ele fala. Na última pesquisa durante o tratamento fez mal para cinco de seis pessoas.

J- Mas aí já era mais específico. Olha, se era médio, alto risco ou de grande risco. Tava bem específica. Tem o tratamento de baixo risco, tem o tratamento de alto risco. É, mas mesmo o de baixo risco tem risco.

Moderador- A questão não é se durante a pesquisa tem risco ou não. A questão é se o termo estava claro.

J- Estava claro.

Moderador- Pra vocês só não ficou claro qual era o tamanho do risco, mesmo que pequeno, o que é pequeno? É isso o que vocês queriam saber. Pequeno qual é a proporção que tem? Certo, no seu caso? Vocês estavam dizendo que se quisessem sair da pesquisa podia. Alguém teve vontade de sair?

Z- Eu não tive.

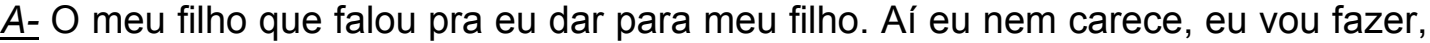
que seja feita a vontade de Deus. Se você for pensar até o medicamento que você vai tomar, que vem da pesquisa, você faz tratamento com o médico porque qualquer problema você vai lá e você passa no médico. Ele fala olha pode dar isso, isso e isso. Você vai desistir e não vai tomar o remédio? Você tem que ficar.

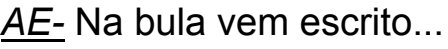

A- Claro! Efeitos colaterais.

$\underline{A E-}$ Eu nem leio a bula porque se você for ler você nem toma nenhuma medicação. 
$\underline{M H-}$ Quase todos os remédios têm efeitos colaterais.

JV- Quando falaram pra mim levei para casa e minha esposa leu. A melhor coisa que tem é você ser cobaia. (risos...). O médico pode passar um remédio errado, agora por causa de uma pesquisa isso vai acontecer?!

ME- Não é só em pesquisa não, os remédios que usei não funcionou.

JV- Por vezes sempre que eu passava em consulta, com a Silmara acompanhando, né Silmara? Pelo menos o médico nunca falou este remédio já fez mal? Pra mim deu ta tudo normal.

Moderador- E o que é melhor ler o documento ou ter uma conversa com o médico?

C- Ter uma conversa com o médico.

$\underline{R-}$ - Concordo, conversa.

C- Olho no olho.

Moderador-Tá, prá poder saber, mas não para poder ser a verdade. Mas poder saber e ter segurança e confiança na pessoa do médico.

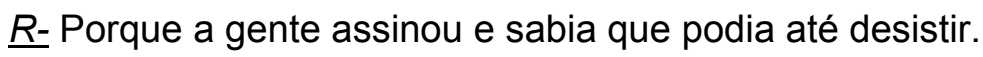

$\underline{M H-}$ - Tem médico que não mede minha pressão não. Você vai embora para casa sem medir a pressão.

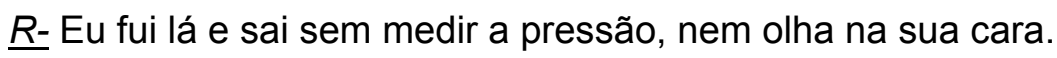

Moderador- Todo mundo concorda que são as duas coisas, ou não?

$\underline{R R}$ - Tem que ter o documento e confiança no médico.

$\underline{R-}$ O médico tem que passar uma confiança.

ME- Tem que passar confiança.

Z- Primeiro lugar eu fui ver e tava assinado pelo médico, no começo foi a doutora Everli. Então, a partir daí que ela assinou eu li com bastante atenção, mas não adiantou muito porque tinha primeiro a assinatura da médica... dizendo tudo em um papel.

Moderador- Então, passa pela confiança? Se não confiar no médico mesmo entendendo o termo, sabendo que é importante?

$\mathrm{MH}$ - Muitas vezes você vai confiar no médico. Não é que eu vou falar assim que todos os médicos são errados. Tem médico aí que às vezes, tem médico aí que nem médico é (risos) que fica falando que é médico pra você entrar na pesquisa dele, e aí se ferrra e aí aonde a pressão vai chegar? (risos)

JV- Porque você tem que confiar no médico, se estiver errado não vai lá para resolver o seu problema?

$\underline{M H}$ - Acho que passa pela confiança, mas se ele não confia em você como vai ser essa pesquisa.

ME- Se não confiar no médico vai confiar em quem? 
ME- Você tem que confiar.

JV- Eu consultava com o Desidério Favarato, mas muitas vezes quando eu vim aí foi o Dr. Sérgio que me atendeu na pesquisa.

ME- $O$ atendimento no grupo que nós entramos foi sempre com a mesma pessoa.

Moderador- Para vocês os termos, as palavras dos termos de consentimento eram claras?

ME- Pra mim eram.

Moderador- Permitiram que vocês entendessem o que tava lá colocado?

Moderador- Ninguém teve vontade de sair? Conheceram alguém que teve vontade de sair e não saiu por medo...

ME- Não, não...

JV- Eu não ouvi comentário nenhum.

ME- Como ele falou assim, quando saiu ninguém queria era sair.

$\underline{C}$ - $\mathrm{O}$ que estou vendo é que cada um teve uma pesquisa diferente. A minha deu eu fiz com o médico..Eu tive que trazer de volta a caixinha do remédio para contar.

JV-A minha também, trazia o remédio que sobrava.

C- Eu foi assim. Eu tava lá no ambulatório e a enfermeira ligou, e falou assim: seu C., porque eu era um caso especial. Meu problema de pressão era composto por uma depressão. Aí eu fui encaminhado para o Doutor Heno. Então, eu estou sentindo que cada um é um caso.

A- O meu também foi do balde de água.

C- Então, aí eu fiquei com saudades porque a pressão ficou legal. Hoje minha pressão tá lá 12x8, né? Tá baixa, mas quando a depressão vem legal, assim, daí vai lá em cima.

$\underline{C}$ - Quando eu chegava lá em casa, porque eu tenho duas filhas que são técnica, são da área né? Eu chegava em casa e falava que gostava daquele baldinho de água.

$\underline{A-} \mathrm{E}$ não pode continuar usando o balde?

(Risos)

ME- Por que não faz o baldinho em casa? Não era bom?

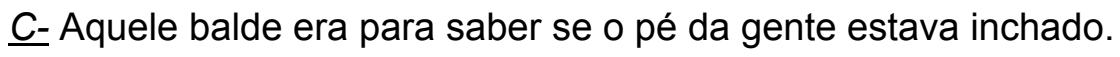

$\underline{C}$ - Todos aqui tem problema de pressão?

MH- Não.

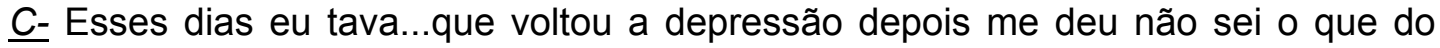
pânico. Eu tava com medo de entrar no metro e aí minha pressão ficou $14 \times 7$. Aí 
peguei o telefone e liguei para o Dr. Heno. Tenho uma fé nele. Só de falar com o camarada. Ele é professor, é um cara legal, educado.

JV-Começando do pessoal da limpeza aqui todo mundo é muito educado. Por ser público é uma atenção especial.

Moderador- Tem autonomia pra ficar dentro ou fora da pesquisa? Tá claro isso?

Moderador- Tá claro?

Moderador- Tá claro?

Moderador- Vocês tinham autonomia pra perguntar o que quiser? Qualquer dúvida, em qualquer tempo? Em nenhum momento se sentiram usados pela pesquisa por não terem informação?

MH- Não.

C- Não.

O- Até pelo contrário.

Moderador- É verdade, tinha mais liberdade?

$\underline{\mathrm{MH}}$ - Durante a pesquisa tinha mais liberdade.

O- A liberdade, o acompanhamento era outro e depois que parou a pesquisa nunca mais eu fiz exame. A coisa foi pedida agora ainda para o ano que vem ainda. Já faz três anos que fiz e antes tinha um acompanhamento mais rigoroso.

C- Também não foi proibido pegar o remédio lá da farmácia normalmente, mas também não poderia misturar o remédio da pesquisa. Não podia usar outro, só o dele.

Moderador- Então voltando a pergunta: seria melhor participar da pesquisa do que entre aspas fazer só o tratamento? Estou colocando entre aspas porque alguns acham que a pesquisa é tratamento e outros acham que não. O que vocês estão dizendo é que o atendimento durante a pesquisa é mais seguro que fora da pesquisa? É isto?

O- $\mathrm{O}$ acompanhamento é mais...

Moderador- A senhora concorda?

O- Mas isso é uma coisa de pouco tempo (...) e eu continuo fazendo todo ano todos os exames, colesterol, todo ano (...) não fez mais né?

$\underline{M H}$ - Não fiz mais desde a pesquisa.

$\underline{R-}$ Por que não fez mais? Não pediram?

O- Não, o médico não pediu.

O- O Dr. Sérgio pedia toda vez que eu vinha.

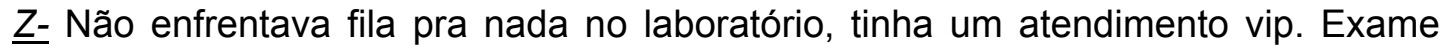
todo mês, não enfrenta fila. 
Moderador- Como que foi? como vocês entenderam essa chamada? Qual era a expectativa que vocês tinham pra essa atividade? Quando a Silmara ligou que expectativa vocês tinham do que ia acontecer hoje?

$\underline{\text { C- }}$ A Silmara ligou.

$\underline{J V}$ - Ela conversou com minha esposa e falou que era um grupo. Eu não estava no fim de semana quando ela ligou e deixou recado com a minha sogra porque agente estava viajando. Quando chegamos a sogra disse que tinham ligado das Clínicas, mas não sabia informar quem era. Aí liguei e conversei com Bete. A gente não consegue falar não para ela.

ME- Pra mim é a segunda vez que ela liga.

$\underline{\text { C- }}$ Para mim também é a segunda vez.

$\underline{R R}$ - Como era objeto da tese da Silmara nessa pesquisa, achei que tinha ficado alguma dúvida.

Moderador- Então por isso que tenho que gravar pra nossa memória ficar registrada de acordo com todo mundo. A gente perguntou o que era pesquisa, metade acha que pesquisa é tratamento, metade acha que pesquisa não é tratamento, certo? Vocês participam da pesquisa quando são convidados porque a pesquisa também é ciência e precisa ser investigado, além disso vocês se sentem melhores do que quando estão fazendo tratamento na casa. A outras coisa é sobre o termo de consentimento, que é absolutamente claro, que é necessário. Pra alguns ele não precisa da assinatura do médico, pra outros ele precisa da assinatura do médico, certo? Não, nós confiamos no médico. Só teve uma pessoa aqui que discordou, a maioria aqui confia no médico.

Moderador- A outra questão que nós falamos a autonomia.Vcs me disseram ter autonomia para permanecer ou não na pesquisa. Então, tá claro? Saindo da pesquisa não seria prejudicado o tratamento.

Moderador- Então mais alguma questão?

Moderador- Nós gostaríamos de agradecer a todos que participaram. 


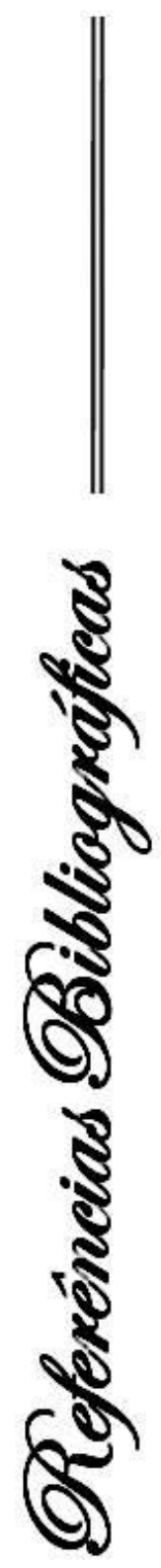




\section{REFERÊNCIAS BIBLIOGRÁFICAS}

1Díaz-Rubio E. La investigación preclínica y clínica de los medicamentos en España. Madrid: Doce Calles; 1994. Cap. 2, p.10-5: La investigación clínica de medicamentos en España.

${ }^{2}$ Alonso FG, Bakke OM. Metodología del ensayo clinico. Barcelona: Doyma; 1991.

${ }^{3}$ International Conference on Harmonisation of Technical Requirements for Registration of Pharmaceuticals for Human Use (ICH). Guideline for good clinical practice [cited 2008 Mar 2]. Available from: www.ich.org/LOB/media/MEDIA482.pdf.

${ }^{4}$ Lousana G, Accetturi C. Pesquisa clínica no Brasil. Rio de Janeiro: Revinter; 2007. Cap 1, p.1-18: Histórico da pesquisa clínica.

${ }^{5}$ Brasil. Ministério da Saúde. Conselho Nacional de Saúde. Resolução No. 251, de 07 de Agosto de 1997 [citado 5 mar 2008]. Disponível em: http://conselho.saude.gov.br/docs/Reso251.doc.

${ }^{6}$ Grady D, Cummings SR, Hulley SB. Delineando um experimento: ensaios clínicos II. In: Hulley SB, Cummings SR, Browner WS, Grady D, Hearst N, Newman TB. Delineando a pesquisa clínica: uma abordagem epidemiológica. $2^{\mathrm{a}}$ ed. Porto Alegre: Artmed; 2003. p.181-201. 
${ }^{7}$ Alonso FG. El placebo en ensayos clínicos com medicamentos. Cuad Programa Reg Bioética.1996;3:29-41.

${ }^{8}$ De Abajo FJ, Gracia DM. Etica del uso de placebo en investigación clínica. Invest Cienc.1997;254:90-9.

${ }^{9}$ Moerman DE. The meaning response: thinking about placebos. Pain Pract. 2006;6(4):233-6.

${ }^{10}$ Olshansky B. Placebo and nocebo in cardiovasacular health. J Am Coll Cardiol. 2007;49(4):415-21.

${ }^{11}$ Benedetti F, Amanzio M. The neurobiology of placebo analgesia: from endogenous opioids to cholecystokinin. Prog Neurobiol. 1997;51:109-25.

${ }^{12}$ Koshi EB, Short CA. Placebo theory and its implications for research and clinical practice: a review of the recent literatura. Pain Pract. 2007;7(1):4-20.

\footnotetext{
${ }^{13}$ Gracia D, Lahuerta J, Carné X, Dal-Ré R. ¿Es ético realizar ensayos clínicos controlados con placebo en el desarrollo de un nuevo fármaco para el transtorno depresivo mayor? (I). Consideraciones sobre el valor intrínseco y validez científica del estudio. Med Clin (Barcelona). 2004;123(14):546-50.
} 
${ }^{14}$ Dal-Ré R. El dictamen único em los ensayos clínicos multicéntricos: la nueva normativa española en el entorno europeo. Med Clin (Barcelona). 2005;124(7):263-5.

${ }^{15}$ Serrano M. Las exigencias de la investigación clínica. ¿Hacia un colapso de los CEICs?, problemas y soluciones. Punto de vista de la administración. ICB Digital. 2004:22:2-6 [citado 5 jan 2008]. Disponível em: http://www.icf.uab.es/icbdigital/archivos/asp/anterior.asp.

${ }^{16}$ Agência Nacional de Vigilância Sanitária (ANVISA). Pesquisa clínica [citado $\quad 5 \quad$ abr 2008]. Disponível em: http://www.anvisa.gov.br/medicamentos/pesquisa/dados/index.htm

${ }^{17}$ Quental C, Sales Filho S. Ensaios clínicos: capacitação nacional para avaliação de medicamentos e vacinas. Rev Bras Epidemiol. 2006;9(4):40824.

${ }^{18}$ Macklin R. Bioethics, vulnerability and protection. Bioethics. 2003;5-6:47286.

${ }^{19}$ Shapiro HT, Meslin EM. Ethical issues in the design and conduct of clinical trials in developing countries. N Engl J Med. 2001;345(2):139-42.

${ }^{20}$ Nuffield Council on Bioethics. The ethics of clinical research in developing countries. London: [ s.n]; 1999. 
${ }^{21}$ Koski G, Nightingale SL. Research involving human subjects in developing countries. N Engl J Med. 2001;345(2):136-8.

${ }^{22}$ Gracia D. Profesión médica, investigación y justicia sanitária. Santa Fe de Bogotá: El Búho; 1998. Cap.4, p.77-110: Investigación clínica.

${ }^{23}$ Greco DB. Poder e injustiça na pesquisa envolvendo seres humanos. In: Garrafa V, Pessini L, organizadores. Bioética: poder e injustiça. São Paulo: Loyola; 2003. p.257-69.

${ }^{24}$ Lolas S F , Quezada S A, editores. Programa regional de bioética: pautas éticas de investigación en sujetos humanos: nuevas perspectivas. Santiago (Chile): OPS/OMS; 2003 [citado 28 set 2008]. Disponível em: www.paho.org/Spanish/BIO/pautas.pdf.

${ }^{25}$ Vollmann J, Winau R. Informed consent in human experimentation before the Nuremberg code. BMJ. 1996;313:1445-7.

${ }^{26}$ Simon P. El consentimiento informado. Madrid: Triacastela; 2000. Cap.1, 25-118: Historia del consentimiento informado.

${ }^{27}$ Lott JP. Module three: vulnerable/special participant populations. Dev World Bioeth. 2005;5(1):30-54.

${ }^{28}$ Ellenberg SS. Informed consent: protection or obstacle? Some emerging issues. Control Clin Trials. 1997;18:628-36. 
${ }^{29}$ Fagot-Largeault A. A experimentação no homem. In: Hottois G, Parizeau MH. Dicionário da bioética. Lisboa: Instituto Piaget; 1993. p.247-55.

${ }^{30}$ Durand G. Introdução geral à bioética. Campanário. São Paulo: Loyola; 2003. Cap. 1, 19-65: Emergência e situação da bioética.

${ }^{31}$ Ayres de Castilho E, kalil J. Ética e pesquisa médica: princípios, diretrizes e regulamentações. Rev Soc Bras Med Trop. 2005;38(4):344-7.

${ }^{32}$ Tealdi JC. Historia y significado de las normas éticas internacionales sobre investigaciones biomédicas. In: Keyeux G, Penchaszadeh V, Saada A, coordinadores. Ética de la investigación en seres humanos y políticas de salud pública. Bogotá: UNESCO; 2006. p 33-62.

${ }^{33}$ Del Rio C. Is ethical research feasible in developed and developing countries. Bioethics. 1998;12(4):328-30.

${ }^{34}$ Zulueta P. Randomised placebo-controlled trials and HIV-infected pregnant women in developing countries. Ethical imperialism or unethical exploitation. Bioethics. 2001;15(5):289-311.

${ }^{35}$ Steinbrook R. Protecting research subjects - the crisis at Johns Hopkins. $N$ Engl J Med. 2002;346(9):716-20. 
${ }^{36}$ Shalala D. Protecting research subjects - what must be done. $N$ Engl $J$ Med. 2000;343(11):808-13.

${ }^{37}$ World Medical Association. Ethics unit. Declaration of Helsinki [cited 2008 Apr 28 ]. Available from: http://www.wma.net/e/ethicsunit/helsinki.htm.

${ }^{38}$ Zion D, Gillan L, Loff B. The Declaration of Helsink, CiOMS, and the ethics of research on vunerable populations. Nat Med. 2000;6(6):1-13.

${ }^{39}$ Abajo FJ. La declaración de Helsinki Vl: uma revisión necessária, pero ¿suficiente? Rev Esp Salud Pública. 2001;75:407-20.

${ }^{40}$ Normas éticas internacionales para las investigaciones biomédicas en sujetos humanos. Cuad Programa Reg Bioética.1996;3: 127-40.

${ }^{41}$ National Institutes of Health. Office of Human Subjects Research. Regulations and Ethical Guidelines. The Belmont Report [cited 2008 Apr 22 ]. Available from: http://ohsr.od.nih.gov/guidelines/belmont.html.

${ }^{42}$ De Abajo FJ. Ética de la investigación epidemiológica. Cuad Programa Reg Bioiética. 1996;3:7-28.

${ }^{43}$ Brasil. Ministério da Saúde. Conselho Nacional de Saúde. Resolução No. 196, de 10 de Outubro de 1996 [citado 22 set 2008]. Disponível em: http://conselho.saude.gov.br/docs/resolucoes/reso196.doc. 
${ }^{44}$ Zoboli ELCP; Massarollo MCKB. Bioética e consentimento: uma reflexão para a prática de enfermagem. Mundo Saúde. 2002;26(1):65-9.

${ }^{45}$ Emanuel EJ, Wendler D, Grady C. What makes clinical research ethical? JAMA. 2000; 283(20):2701-11.

${ }^{46}$ Council for International Organizations of Medical Sciences (CIOMS). International ethical guidelines for biomedical research involving human subjects [cited 2008 Sept 22]. Available from: http://www.cioms.ch/frame_guidelines_nov_2002.htm.

${ }^{47}$ National Institute of Health. Guidelines for the conduct of research involving human subjects. 2004 [cited 2008 Sept 22]. Available from: http://ohsr.od.nih.gov/guidelines/GrayBooklet82404.pdf.

${ }^{48}$ Comissão de Bioética de Castilla y Léon. Guía de consentimiento informado. Junta de Castilla y León: Consejería de Sanidad; [sd].

${ }^{49}$ Lorda PS, Gutiérrez JJ. Consentimiento informado. Méd Clin (Barcelona). 2001;117:99-106.

${ }^{50}$ Gracia D. Fundamentos de bioética. $2^{\mathrm{a}}$ ed. Madrid: Triacastela; 2007. Cap. 2, p.121-97: La tradición jurídica y el criterio de autonomia: los derechos del enfermo. 
${ }^{51}$ Daugherty CK. Impact of therapeutic research on informed consent and the ethics of clinical trials: a medical oncology perspective. J Clin Oncol. 1999;17(5):1601-17.

${ }^{52}$ Beauchamp TL, Childress JF. Princípios de ética biomédica. Barcelona: Masson; 2002. Cap. 3, p.113-78: El respeto a la autonomia.

${ }^{53}$ Simon P, Júdez J. Consentimiento informado. In: Gracia D, Júdez J, editores. Ética en la prática clínica. Madrid: Triacastela; 2004. p.33-54.

${ }^{54}$ Drane JF. Las múltiples caras de la competencia: mayor riesgo, critérios más estrictos. In: Couceiro A, editor. Bioética para clínicos. Madrid: Triacastela; 1999. p.163-76.

${ }^{55}$ Simon P. El consentimiento informado. Madrid: Triacastela; 2000. Cap.2, 119 -206: Fundamentación ética y jurídica.

${ }^{56}$ Doyal I. Informed consent: moral necessity or illusion? Qual Health Care. 2001;10(Suppl I):129-33.

${ }^{57}$ Flory J, Emanuel E. Interventions to improve research participants' understanding in informed consent for research: a systematic review. JAMA. 2004;292(13):1593-601.

${ }^{58}$ Cohn E, Larson E. Improving participant comprehension in the informed consent process. J Nurs Scholarsh. 2007;39(3):273-80. 
${ }^{59}$ Dunn LB, Jeste DV. Enhancing informed consent for research and treatment. Neuropsychopharmacology. 2001;24(6):595-605.

${ }^{60}$ Hossne WS. Poder e injustiça na pesquisa com seres humanos. In: Garrafa V, Pessini L, organizadores. Bioética: poder e injustiça. São Paulo: Loyola; 2003. p.271-86.

${ }^{61}$ Edwards SJF, Lilford RJ, Thornton J, Hewison J. Informed consent for clinical trials: in search of the best method. Soc Sci Med. 1998;47(11):182540.

${ }^{62}$ Sugarman J, McCrory DC, Hubal RC Getting meaningful informed consent from older adults: A structured literature review of empirical research. $J$ Am Geriatr Soc. 1998;46(4):517-24.

${ }^{63}$ Sánches S, Salazar G, Tijero M, Días S. Informed consent procedures: responsabilities of researchers in developing countries. Bioethics. 2001; 15(5/6):398-412.

${ }^{64}$ Angell M. The ethics of clinical research in the third world. N Engl J Med. 1997;337(12):847-8.

${ }^{65}$ Azevedo ES. Ética na pesquisa em genética humana em países em desenvolvimento. In: Garrafa V, Pessini L, organizadores. Bioética: poder e injustiça. São Paulo: Loyola; 2003. p.323-30. 
${ }^{66}$ Vilardaga V. Campos de prova de medicamentos. Pesquisa FAPESP. 2003;83:1-3 [citado 29 set 2008]. Disponível em: http://revistapesquisa.fapesp.br/?art=2037\&bd=1\&pg=1\&ig=.

${ }^{67}$ Duca de Freitas CB. Ética na pesquisa com seres humanos: a experiência brasileira. In: Garrafa V, Pessini L, organizadores. Bioética: poder e injustiça. São Paulo: Loyola; 2003.p.307-14.

${ }^{68}$ Ángeles-Llerenas A, Bello MA, Dirce G, Salinas MA. Argentina, Brasil y México. La investigación biomédica y la defensa de un único estándar de atención en países en desarrollo. Rev Invest Clín. 2004;56(5):675-85.

${ }^{69}$ Glancszpigel D. Clinical trial in latin américa. Applied Clinical Trials [periódico on line]. 2003 [cited 2008 Aug 22]; May. Available from: http://appliedclinicaltrialsonline.findpharma.com/appliedclinicaltrials/Global+T rials/Clinical-Trialsin-Latin-America/ArticleStandard/Article/detail/80235.

${ }^{70}$ Luz PL. InCor: além da assistência. Rev Assoc Med Bras. 2006; 52(6):387.

${ }^{71}$ Instituto do Coração. O que é o Incor. [citado 19 out 2007]. Disponível em: http://www.incor.usp.br/r-quemsomos.htm.

${ }^{72}$ Instituto do Coração. Unidade de informações médicas e hospitalares. 2007 [citado 19 out 2007]. Disponível em: http://uimh-server/rel_pdf.asp. 
${ }^{73}$ Marconi MA, Lakatos EM. Técnicas de pesquisa: planejamento e execução de pesquisas, amostras e técnicas de pesquisa, elaboração, análise e interpretação de dados. $2^{\mathrm{a}}$ ed. São Paulo: Atlas; 1990. Cap. 3, p.57-123: Técnicas de pesquisa.

${ }^{74}$ Rosner B. Fundamentals of biostatistics. 4th ed. New York: Duxbury Press; 1994. p. 682.

${ }^{75}$ Bardin L. Análise de conteúdo. Lisboa: Edições 70; 1977.

${ }^{76}$ Westphal MF, Bógus CM, Faria MM. Grupos focais: experiências precursoras em programas educativos em saúde no Brasil. Bol Oficina Sanit Panam. 1996;120(6):472-82.

${ }^{77}$ Kitzinger J. Qualitative research. BMJ. 1995;311:299-302.

${ }^{78}$ Patton MQ. Qualitative research and evaluation methods. 3rd ed. California: Sage Publications; 2002. p.385-90.

${ }^{79}$ Soares CB, Reale D, Brites CM. Uso do grupo focal como instrumento de avaliação de programa educacional em saúde. Rev Esc Enferm USP. 2000; 34(3):317-22. 
${ }^{80}$ Glik D, Gordon A. Focus group methods for formative research in child survival: an ivorian example. Int Q Community Health Educ. 1987;8(4);297315.

${ }^{81}$ Carlini-Cotrim B. Potencialidades da técnica qualitativa grupo focal em investigações sobre abuso de substâncias. Rev Saúde Pública. 1996;30(3): 285-93.

${ }^{82}$ Nogueira-Martins MCF, Bógus CM. Considerações sobre a metodologia qualitativa como recurso para o estudo das ações de humanização em saúde. Saúde Soc. 2004;13(3):44-57.

${ }^{83}$ Souza MK. Termo de consentimento livre e esclarecido (TCLE): fatores que interferem na sua adesão [dissertação]. São Paulo: Faculdade de Medicina, Universidade de São Paulo; 2005.

${ }^{84}$ Instituto Paulo Montenegro. $5^{\circ}$ Indicador Nacional de Alfabetismo Funcional: um diagnóstico para a inclusão social pela educação [avaliação de leitura e escrita]. 2005 [citado 10 jan 2008]. Disponível em: http://www.acaoeducativa.org.br/downloads/inaf05.pdf .

${ }^{85}$ Instituto Paulo Montenegro. Indicador Nacional de Alfabetismo Funcional. Boletim INAF, 2007 [citado 13 jun 2008] Disponível em: http://www.ipm.org.br/download/bol_inaf_2007_03.pdf. 
${ }^{86}$ UNESCO. La cooperación de la UNESCO em Educación em América Latine y El Caribe, 1993-1996 [citado 23 out 2007]. Disponível em: http://unesdoc.unesco.org/images/0012/001213/121358so.pdf.

${ }^{87}$ Instituto Brasileiro de Geografia e Estatística (IBGE). Síntese de indicadores sociais 2007 [citado 4 set 2007]. Disponível em: http:// www.ibge.gov.br/home/presidencia/noticias/noticia_impressão.php?id_notici $a=987$.

${ }^{88}$ UNESCO. Pronunciamento. $\mathrm{O}$ analfabetismo: proposta para sua erradicação [citado 6 set 2007]. Disponível em: http://unesco.org.br.

${ }^{89}$ Ribeiro VM. Alfabetismo functional: referências conceituais e metodológicas para a pesquisa. Educação \& Sociedade. 1997;60:144-58.

${ }^{90}$ US. National Center for Education Statistics. Dept of Education. Adult Literacy in America: a first look at the results of the National Adult Literacy Survey. 3rd ed.; 2002 [cited 2007 Nov 27]. Available from: http://nces.ed.gov/pubsearch/pubsinfo.asp?pubid=93275.

${ }^{91}$ Willians MV, Parker RM, Baker DW, Parikh NS, Pitkin K, Coates WC, Nurss $J R$. Inadequate functional helth literacy among participants at two public hospital. JAMA. 1995; 274:1677-82. 
${ }^{92}$ Sudore RL, Landefeld CS, Willinas BA, Barnes DE, Lindquist K, Schillinger D. Use a modified informed consent process among vulnerable patients: a descriptive study. J Gen Intern Med. 2006;21:867-73.

${ }^{93}$ Sakaguti NM. O conhecimento de usuários de serviços públicos de saúde envolvidos em pesquisas clínicas, sobre seus direitos [dissertação]. São Paulo: Faculdade de Odontologia, Universidade de São Paulo; 2005.

${ }^{94}$ Lamosa BWR. Psicologia aplicada à cardiologia. São Paulo: Fundo Editorial ByK; 1990.

${ }^{95}$ Verástegui EL. Consenting of the vulnerable: the informed consent procedure in advanced cancer patients in Mexico. BMC Med Ethics. 2006;7: $1-12$

${ }^{96}$ Osuch JR. The power of the doctor, the vulnerability of the patient, and informed consent. Surg Neurol. 2004;61:494-6.

${ }^{97}$ Fletcher RH, Fletcher SW. Epidemiologia clínica: elementos essenciais. Porto Alegre: Artmed; 2006. Cap. 8, p. 154-178: Tratamento.

${ }^{98}$ Horton R. The clinical trial: deceiful, disputable, unbelievable, unhelful, and shameful - What next. Control Clin Trials. 2001;22:593-604.

${ }^{99}$ Alves EMO, Tubino P. Conflito de interesses em pesquisa clínica. Acta Cir. Bras. 2007;22(5):412-5. 
${ }^{100}$ Thompson DF. Understanding financial conflicts of interest. N Engl J Med. 1993;329(8):573-6.

${ }^{101}$ Albrecht TL, Blanchard C, Ruckdeschel JC, Coovert M, Strongbow R. Strategic physician communication and oncology clinical trials. J Clin Oncol. 1999;17:3324-32.

${ }^{102}$ Tahka V. Relacionamento médico-paciente. Porto Alegre: Artes Médicas; 1998.

${ }^{103}$ Lloyd A, Hayes P, Bell PR, Naylor AR. The role of risk and benefit perception in informed consent for surgery. Med Decis Making. 2001;21(2): 141-9.

${ }^{104}$ Edwards A, Glyn E. How well do patients understand the concept of risk? Lessons for clinical risk communication. Qual Health Care. 2001;10(Suppl I):i9-i13.

${ }^{105}$ Goldim JR. O consentimento informado numa perspectiva além da autonomia. Rev AMRIGS. 2002;46(3,4):109-16.

${ }^{106}$ Fylkesnes K, Fylkesnes TK. Informed consent as part and parcel of the scientific injury. Lancet. 2003;361:2171-2. 
${ }^{107}$ Cassileth BR, Zupkis RV, Sutton-Smith K, March V. Informed consent Why are its goals imperfectly realized? N Engl J Med.1980;302:896-900.

${ }^{108}$ Clotet J, Goldim JR, organizadores, Francisconi CF . Consentimento informado e a sua prática na assistência e pesquisa clínica no Brasil. Porto Alegre: EDIPUCRS; 2000. Cap. 4, p.73-84: Componente da informação.

${ }^{109}$ Lidz CW, Meisel A, Osterweis M, Holden JL, Marx JH. Munetz MR. Barries to informed consent. Ann Intern Med. 1993;99:539-43.

${ }^{110}$ Suborne A, Lowestein J. Exploring asymmetry in the relationsship between patients and physicians. J Clin Ethics. 2003;14:183-188.

${ }^{111}$ Lings P, Seamark D, SEAMARK C, Sweeney K, Dixon M, Gray DP. The doctor-patient relationship in US primary care. J R Soc Med. 2003;96:180-84.

${ }^{112}$ Fitzgerald DW, Marotte C, Verdier RI, Johnson WDJr, Pape JW. Comprehension during informed consent in a less-developed country. Lancet. 2002;360(26):1301-2.

${ }^{113}$ Paasche-Orlow MK, Taylor HÁ, Brancati FL. Readability standards for informed-consent forms as compared with actual readability. $N$ Engl $J$ Med. 2003; 348(8):721-6. 
${ }^{114}$ Zoboli ELCP. Vulnerability in biomedical research: a framework for analysis. In: Häyry M, Takala T, Herissone-Kelly P. Ethics in biomedical research. Netherlands: Rodopi B V; 2007. p.167-79.

${ }^{115}$ Brody BA, McCullough LB, Sharp RR. Consensus and controversy in clinical research ethics. JAMA. 2005;294(11):1411-4.

${ }^{116}$ Grisso T, Appelbaun PS. Assessing competence to consent to treatment: a guide for physicians and other health professionals. New York: Oxford University Press; 1998.

${ }^{117}$ Tunzi M. Can the patient decide? Evaluating patient capacity in pratice. Am Fam Psysician. 2001;64(2):299-306.

${ }^{118}$ Towle A, Godolphin W. Framework for teaching and learning informed sharing decision making. BMJ. 1999;319:766-9.

${ }^{119}$ Slawka S. O termo de consentimento livre e esclarecido e a pesquisa em seres humanos na área de saúde: uma revisão crítica [dissertação]. São Paulo: Faculdade de Medicina, Universidade de São Paulo; 2005.

${ }^{120}$ Appelbaum PS. Assessment of patients' competente to consent to treatment. N Engl J Med. 2007;357:1834-40. 
${ }^{121}$ Lorda PS, Salvador JJR, Maroto AM, Pisa RML, Júdez J. La capacidad de los pacientes para tomar decisiones. Med Clin (Barcelona). 2001; 117:41926.

${ }^{122}$ Simon P, Salvador JJR, Maroto AM, Pisa RML, Júdez J. La capacidad de los pacientes para tomar decisiones. In: Gracia D, Júdez J, editores. Ética en la práctica clínica. Madrid: Triacastela; 2004. p. 55-74.

${ }^{123}$ Bowling A, Ebrahim S. Measuring patient' preferences for treatment and perceptions of risk. Qual Health Care. 2001;10(Suppl I):i2-i8.

${ }^{124}$ Laporte JR. Principios básicos de investigación clínica. Barcelona: Astrazeneca; 2001. Cap. 3, p.43-7: El ensayo clínico controlado.

${ }^{125}$ Taub HA, Baker MT, Sturr JF. Informed consent for research: effects of readability, patient age, and education. Am Geriatr Soc. 1986;34:601-6.

${ }^{126}$ Appelbaum PS, Grisso T. Capacities of hospitalized medically ill patients to consent to treatment. Psychosomatics. 1997;38:119-25.

${ }^{127}$ Palmer BW, Dunn LB, Appelbaum PS, Mudaliar S, Thal L, Henry R, Golshan S, Jeste DV. Assesment to capacity to consent to research among older persons with schizophrenia, Alzheimer disease or diabetes mellitus: comparison of a 3-item questionaire with a comprehensive standardized capacity instrument. Arch Gen Psychiatry. 2005;62:726-33. 
${ }^{128}$ Ferguson PR. Patients' perceptions of information provided in clinical trials.J Med Ethics. 2002;28:45-8.

${ }^{129}$ Andrus MR, Roth MT. Health literacy: a review. Pharmacoterapy. 2002; 22(3):282-302.

${ }^{130}$ Fitzmaurice DA, Adams JL. A systematic review of patient information leaflets for hypertension. J Hum Hypertens. 2000;14(4):259-62.

${ }^{131}$ Bulla MC, Benincasa CC, Goldim JR, Francisconi CFM. O uso de termos de consentimento informado nas áreas assistenciais do hospital de clínicas de Porto Alegre. Rev AMRIGS. 2003;47(2):101-3.

${ }^{132}$ Davis TC, Holcombe RF, Berkel HJ, Pramanik S, Divers SG. Informed consent for clinical trials: a comparative study of standard versus simplified forms. J Natl Cancer Inst. 1998;90:668-74.

${ }^{133}$ Hardy E, Bento SF, Osis MJD. Consentimento livre e esclarecido: experiência de pesquisadores brasileiros na área de regulação da fecundidade. Cad Saúde Pública. 2004;20(1):216-23.

${ }^{134}$ Moodley K, Pather M, Myer L. Informed consent and participant perceptions of influenza vaccine trials in South África. J Med Ethics. 2005; $31: 727-32$. 
${ }^{135}$ Santos SCC, Luis MAV. A relação da enfermagem com o paciente cirúrgico. Goiânia: AB; 1999.

${ }^{136}$ Jofee S, Cook EF, Cleary PD, Clark JW, Weeks JC. Quality of informed consent in cancer clinical trials a cross-sectional survey. Lancet. 2001; 358:1772-7.

${ }^{137}$ Lidz CW, Appelbaum OS, Grisso T, Renaud M. Therapeutic misconception and the appreciation of risk in clinical trials. Soc Sci Med. 2004;58:1689-97.

${ }^{138}$ Sreenivasan G. Does informed consent to research require comprehension. Lancet. 2003;362:2016-8.

${ }^{139}$ Henderson GE, Easter MM, Zimmer C, King NMP, Davis AM, Rothschild BB, Churchill LR, Wilfond BS, Nelson DK. Therapeutic misconception in early phase gene transfer trials. Soc Sci Med. 2006;62:239-53.

${ }^{140}$ Fuente-Fernández R. Placebo, efecto placebo y ensayos clínicos. Neurologia. 2007;22(2):69-71.

${ }^{141}$ Bienenfeld L, Frishman W, Glasser SP. The placebo effect in cardiovascular disease. Am Heart J. 1996;132:1207-21. 